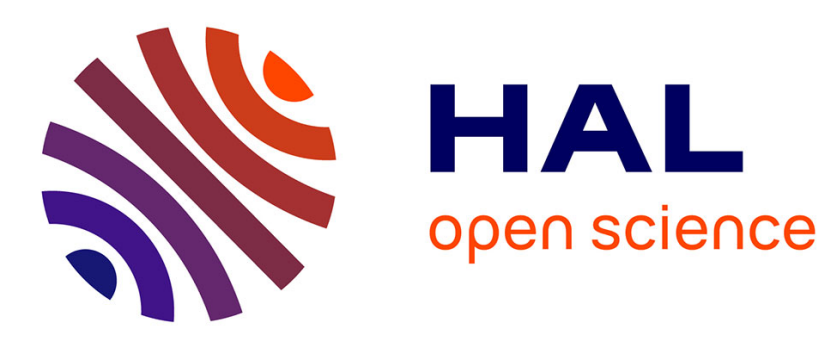

\title{
Un réseau défensif de l'âge du Bronze moyen dans les Marges arides de Syrie du Nord
}

\author{
M.-O. Rousset, Bernard Geyer, Nazir Awad, Shadi Shabo
}

\section{To cite this version:}

M.-O. Rousset, Bernard Geyer, Nazir Awad, Shadi Shabo. Un réseau défensif de l'âge du Bronze moyen dans les Marges arides de Syrie du Nord. Paléorient, 2017, 43 (2), pp.115-163. halshs-01667502

\section{HAL Id: halshs-01667502 \\ https://shs.hal.science/halshs-01667502}

Submitted on 5 Jan 2021

HAL is a multi-disciplinary open access archive for the deposit and dissemination of scientific research documents, whether they are published or not. The documents may come from teaching and research institutions in France or abroad, or from public or private research centers.
L'archive ouverte pluridisciplinaire HAL, est destinée au dépôt et à la diffusion de documents scientifiques de niveau recherche, publiés ou non, émanant des établissements d'enseignement et de recherche français ou étrangers, des laboratoires publics ou privés. 


\title{
UN RÉSEAU DÉFENSIF DE L'ÂGE DU BRONZE MOYEN DANS LES MARGES ARIDES DE SYRIE DU NORD
}

\author{
M.-O. ROUSSET, B. GEYER, N. AWAD et S. SHABO
}

\begin{abstract}
Résumé: La mission de prospection géoarchéologique des «Marges arides de Syrie du Nord» a découvert plus d'un millier de sites qui apportent un éclairage nouveau à la connaissance des régions steppiques pour toutes les périodes de l'histoire de la Syrie et du Proche-Orient. Cet article évoque la période de l'âge du Bronze moyen, qui voit une accentuation du caractère défensif des sites et, surtout, de la protection du territoire. De Salamya à Qinnasrīn, des forteresses, des fortins et des tours, pour la plupart inconnus, s'organisent en un réseau de fortifications hiérarchisées qui longent le relief dominant la steppe. Cet article décrit ce réseau, présente les relevés de chaque type de construction et avance une hypothèse quant à sa fonction première: la protection des terres les plus attractives en terme de mise en valeur agricole.
\end{abstract}

\begin{abstract}
In a region of ca $7000 \mathrm{~km}^{2}$, the geoarchaeological survey, carried out by the "Arid Margins of Northern Syria" mission, discovered more than one thousand sites. They were in a rather good condition, and for some of them in an exceptional state of preservation. All placed within their environmental context, they shed new light on the knowledge of the steppe regions for all periods in the history of Syria and the Middle East. This article discusses the period of the Middle Bronze Age, which saw an accentuation of the defensive character of the sites and, above all, the protection of the useful territory.

The question of borders and, more broadly, of territorial boundaries in the ancient Orient is one of the subjects often debated and the discoveries made in the Arid Margins area have several times contributed significantly to this debate. Thus, one of the oldest boundaries marked on the ground is the "Very Long Wall" that we connect with the Early Bronze Age IV. The kind of fortification of the "Arid Margins" zone in the Middle Bronze Age has a different system of logic. At that time was set up what appears to be a genuine network, relying on a hierarchized system (in terms of distribution and dimensions) of fortresses, forts, towers and small towers. This article describes this system which has only been briefly mentioned in our previous publications. It presents the plans of each type of fortified site, specifies their mode of construction and installation, and places them in their environmental context. Since this system was mainly located within the area we were surveying, it has been possible to define on the ground its implantation modalities and morphological characteristics. The constructions are built on naturally fortified locations or more rarely on artificial embankments and are built mostly with large polygonal basalt blocks. One of the decisive criteria for their location is the visibility between establishments, which are spaced at a maximum of $20.8 \mathrm{~km}$, to allow signals-based communications. According to this logic, we were able to reconstruct the extension of this network well beyond the limits of the zone we have been surveying, on a distance north-south of ca $150 \mathrm{~km}$ for an average depth of $30 \mathrm{~km}$ (but which can reach more than $70 \mathrm{~km}$ ). This research, using satellite imagery, has allowed to discover unknown and unpublished sites, some of them reaching up to 50 ha. Finally, the geometrical characteristics of their geographical distribution, too regular to be due to chance, show that there is a unity between this network and the large contemporary cities known around the steppe: Yamhad (Aleppo), Qatna (Tall Mišrifa), Ebla (Tall Mardih), Tall al-Nāșirīya, Tall al-Ṭūkān and Tall al-Șūr.

These largely unpublished data, connected with the context of the settlement of the margins of the steppe during the Middle Bronze Age, allow us to propose a first interpretation of the primary functions of this network. It was established for the most part at the eastern edge of fertile basaltic plateaus, making the most of the relief, decidedly turned towards the east, and its role would consist in the defense of the territory, the surveillance and protection of the axes of circulation (some of which have been stated by our study), communication (by signals), but also and above all the protection of the most attractive lands in terms of potential for settlement and agricultural development. It is at least towards these conclusions that the analysis of the geographical and material data provided by the survey of the arid margins area of Northern Syria leads.

Our research, based on the analysis of a corpus of nearly a hundred sites, shows that, from the end of the Middle Bronze Age I, a defense organization would have been set up on a regional scale and as well, most likely, the coordination of the defensive systems of
\end{abstract}


several kingdoms involving an overall design, a concerted project. This structuring would have been based on the creation of new sites, fortifications at the edge of the basaltic plateaus dominating the steppe and their network of secondary installations: forts and towers, which protected the lowlands agglomerations during the Middle Bronze Age II. The findings of the "Arid Margins of Northern Syria" mission thus make it possible to reinterpret the results of the study of the neighboring regions and sites and to consider the whole from a broader and systemic point of view, thanks to a diachronic and multidisciplinary method of survey and global analysis, developed, tested and validated by our team.

The purpose of this article is to present to the specialists of this period the primary data collected during the survey of the arid margins and by the study of aerial imagery in an analysis detached from the historical considerations, but which we wanted rigorous. The description of this network is only a first step. While waiting to be able to return to the field, we leave it to the historians and archaeologists specialists of the period to deepen these lines of reflection.

Mots-clés: Géo-archéologie ; Croissant fertile; Peuplement; Réseau fortifié; Yamhad; Ebla; Qatna; Tunip; Bronze moyen. Keywords: Geo-archaeology; Fertile Crescent; Settling; Fortified network; Yamhad; Ebla; Qatna; Tunip; Middle Bronze Age.

\section{INTRODUCTION}

On ne compte plus les découvertes faites dans le cadre de la mission de prospection des «Marges arides de la Syrie du Nord», dirigée par N. Awad (DGAMS), B. Geyer (Archéorient) et R. Jaubert (IHEID, Genève) ${ }^{1}$. Ce programme de recherches, qui étudie les relations Homme-milieu en domaine semi-aride et aride durant l'Holocène, a conduit à l'analyse géo-archéologique de plus d'un millier de sites inédits, prospectés lors d'une ou deux missions d'un mois, chaque année entre 1995 et 2002 , puis, lors d'une ultime campagne, en 2010, dans une région qui couvre $c a 7000 \mathrm{~km}^{2}$. Cette région, à cheval entre le monde des sédentaires et celui des nomades, s'est révélée, à plusieurs reprises au cours de son histoire, être aussi une zone frontière entre différentes entités géopolitiques. C'est cet aspect du peuplement qui avait été privilégié par R. Mouterde et A. Poidebard (1945) dans leur ouvrage intitulé Le limes de Chalcis. Nos travaux ont montré que, si l'usage du terme «limes» pouvait être considéré comme abusif pour l'époque romaine ${ }^{2}$, en revanche, il pouvait très bien s'appliquer à d'autres périodes et que la frontière entre les mondes pouvait revêtir différentes formes, de la marche militaire très large, comme au début de l'époque islamique (Rousset 2013a et b), à la ligne d'un mur. Ainsi, l'une des limites les plus anciennes matérialisée sur le terrain est le «Très

1. Voir la bibliographie complète de la mission dans l'introduction de Rousset et al. 2016: 11-17.

2. II n'y a pas de «mur» à proprement parler à l'époque romaine. De plus, les lieux que Mouterde et Poidebard interprétaient comme romains ne le sont pas tous: leur datation s'étale entre l'époque romaine et le début de la période islamique: Geyer 2000. Il y a cependant, depuis la fin de l'époque hellénistique jusqu'à l'Antiquité tardive, plusieurs lignes de fortifications successives: Rousset 2011.
Long Mur» découvert par la mission et relevé par elle sur près de $230 \mathrm{~km}$, que nous rattachons à l'âge du Bronze ancien IV (Geyer 2009; Geyer et al. 2010). Le mode de fortification de cette zone à l'âge du Bronze moyen relève d'une logique différente. À cette époque a été mis en place ce qui semble être un véritable réseau, s'appuyant sur un système hiérarchisé de forteresses, de fortins et de tours, à la lisière orientale des plateaux basaltiques. Ce système n'ayant été que brièvement évoqué dans nos précédentes publications ${ }^{3}$, nous le décrivons ici plus en détail. Le contexte du peuplement des marges de la steppe à l'âge du Bronze moyen permet d'en proposer une première interprétation. Notre but n'est cependant pas d'établir une synthèse sur les modes d'occupation du sol à l'âge du Bronze moyen mais de présenter aux spécialistes de cette période les données inédites collectées lors de la prospection des Marges arides et grâce à l'analyse de l'imagerie aérienne.

\section{LE PEUPLEMENT DE L'ÂGE DU BRONZE MOYEN DANS LA RÉGION DES «MARGES ARIDES »}

D'après les datations fournies par la céramique collectée lors de la prospection des Marges arides, 87 sites présentent une occupation assurée à l'âge du Bronze moyen et 16 n'ont pas livré suffisamment de matériel diagnostique pour l'affirmer (fig. 1 et tabl. 1) ${ }^{4}$. Dans un certain nombre de cas, le

3. Voir Calvet 2002: 105; Geyer et al. 2004-2005: 27-28 et fig. 8; $2007: 277$ $280 ; 2010: 65-66$.

4. La quantité et la qualité des céramiques collectées ne permettent pas toujours de préciser la datation au-delà de la période et de la sous-période, 


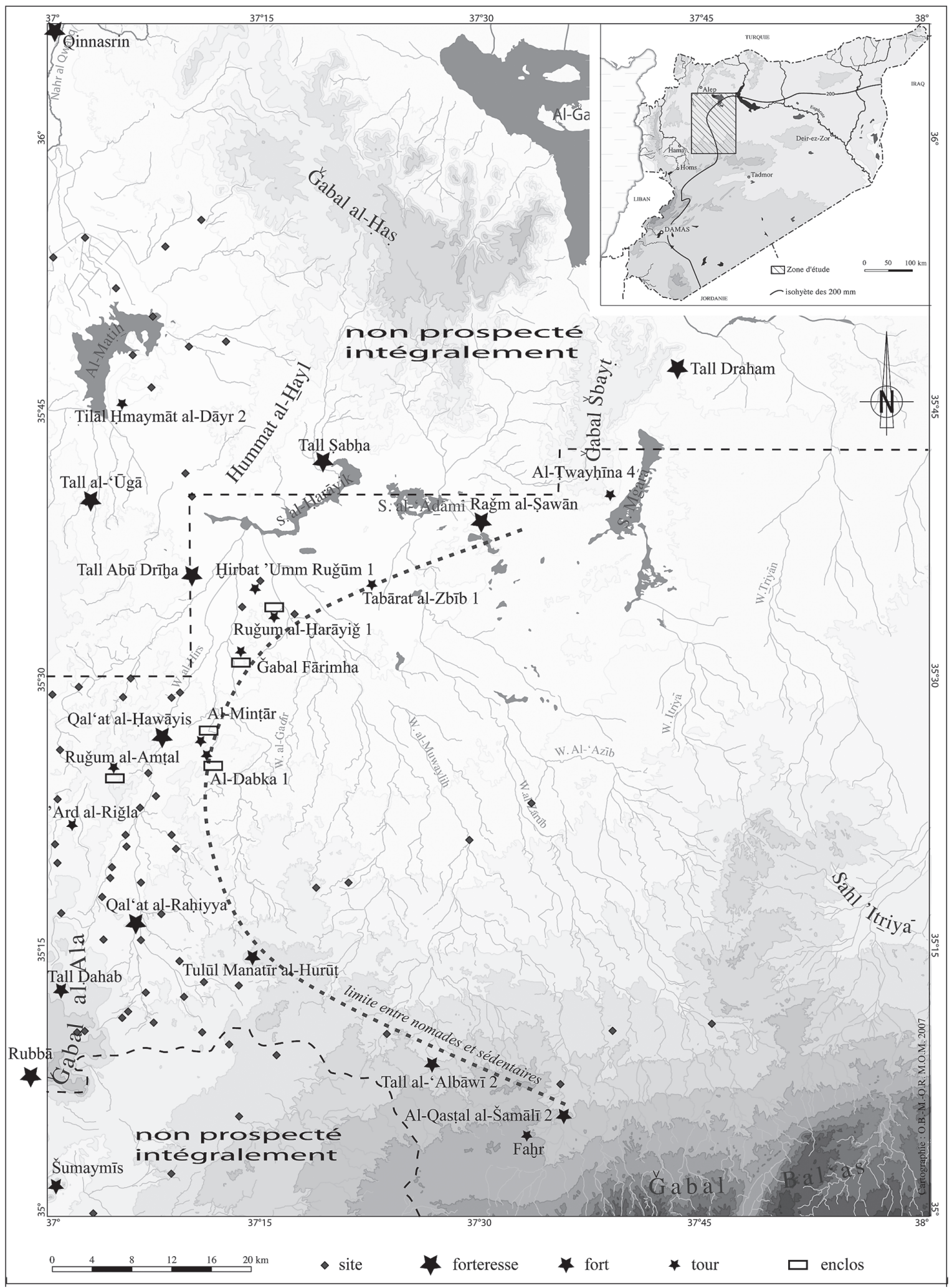

Fig. 1 - Carte générale des Marges arides avec les sites et fortifications de hauteur de l'âge du Bronze moyen (cartographie MOM, O. Barge, M.-O. Rousset). 
Tableau 1 - Classification des sites avec de la céramique de l'âge du Bronze moyen.

\begin{tabular}{|c|c|c|c|c|c|c|c|}
\hline Sites & $\begin{array}{c}\text { Bronze } \\
\text { ancien }\end{array}$ & $\begin{array}{l}\text { Bronze } \\
\text { moyen }\end{array}$ & $\begin{array}{l}\text { Bronze } \\
\text { moyen I }\end{array}$ & $\begin{array}{c}\text { Bronze } \\
\text { moyen II }\end{array}$ & $\begin{array}{c}\text { Bronze } \\
\text { récent }\end{array}$ & Fer & Total \\
\hline Sites du Bronze moyen (dont 16 possibles) & & & & & & & 103 \\
\hline Nombre de sites par période & 61 & 87 & 12 & 31 & 2 & 41 & \\
\hline \multicolumn{8}{|l|}{ Types de sites du Bronze moyen } \\
\hline Tells & 43 & 55 & 8 & 18 & 2 & 35 & 55 \\
\hline Grands tells (plus de 130 m de diamètre) & 23 & 30 & 4 & 10 & 2 & 19 & 30 \\
\hline Tells avec ville basse & 19 & 21 & 1 & 7 & 1 & 14 & 21 \\
\hline Tells avec fossé & 15 & 27 & 3 & 9 & & 18 & 27 \\
\hline Tells de $\pm 120 \mathrm{~m}$ de diamètre & 9 & 13 & 3 & 5 & & 9 & 13 \\
\hline Petits tells de moins de $90 \mathrm{~m}$ de diamètre & 11 & 12 & 1 & 3 & & 7 & 12 \\
\hline Sites de faible élévation de $\pm 60 \mathrm{~m}$ de diamètre & & 1 & & 1 & & & 1 \\
\hline Petits sites & 4 & 8 & & 1 & & & 8 \\
\hline Sites du réseau fortifié & 14 & 20 & 8 & 15 & & 5 & 24 \\
\hline Forteresses & 6 & 7 & 5 & 6 & & 4 & 7 \\
\hline Forts & 3 & 4 & 1 & 3 & & 1 & 4 \\
\hline Tours & 3 & 6 & 1 & 4 & & & 7 \\
\hline Petites tours & 2 & 3 & 1 & 2 & & & 4 \\
\hline
\end{tabular}

type d'occupation ne peut que difficilement être caractérisé avec les seules données de la prospection, notamment pour les tells occupés sur une longue durée, dont les vestiges observés peuvent appartenir à plusieurs périodes. En effet, 61 des sites de l'âge du Bronze moyen sont déjà occupés à l'âge du Bronze ancien (dont 50 au Bronze ancien IV). Dans d'autres cas, une ébauche de chronologie relative semble possible, lorsque les vestiges sont suffisamment bien conservés et les plans, les matériaux et les techniques de construction clairement différentiables. Une datation des différentes phases ou unités archéologiques peut alors être proposée, par comparaison avec des installations similaires datées. Cette datation est renforcée lorsque les grandes périodes chronologiques déterminées par l'analyse de la céramique sont en nombre réduit. Enfin, le cas idéal est celui des sites avec une structure bien visible, associée à une seule période d'occupation. La nature du terrain, très peu remanié jusqu'en 2010, la prise en compte systématique de la composante géographique dans la compréhension des modes d'implantation et de mise en valeur et le type de prospection que nous avons conduit, concernant la totalité du peuplement

dans ce cas l'âge du Bronze moyen. C'est pourquoi, dans le Tableau 1, l'ensemble des sites avec de la céramique datée de cette période apparaissent dans la colonne 'MBA' et également, lorsqu'une datation plus fine a été établie, dans les colonnes 'MBAI' ou 'MBAII'. Les comptages relatifs aux sites de l'âge du Bronze ancien IV ne sont pas définitifs, la céramique de cette période n'ayant pas été totalement revue. de la fin du Pléistocène ${ }^{5}$ à nos jours, facilitent ce type d'analyse ${ }^{6}$.

Depuis 2004, la mise en ligne des images satellitaires sur Google Earth, puis des images Microsoft et, enfin, des images Corona (de 1968, 1969 et 1970), nous a permis d'aller bien audelà des observations de terrain. Elles permettent de les compléter, le terrain restant bien entendu indispensable à la compréhension des images. La confrontation de l'ensemble de cette documentation a rendu possible une analyse spatiale fine.

Dans leur majorité, les sites de l'âge du Bronze moyen sont des tells (55 sites), localisés dans les plaines et vallées, souvent à la confluence de deux oueds. Parmi ceux-ci, 43 sont déjà occupés à l'âge du Bronze ancien (tabl. 1). Les plus gros tells offrent la chronologie la plus complète; c'est là qu'a été découvert le matériel de l'âge du Bronze récent (2 sites). Deux tiers des tells occupés à l'âge du Bronze moyen ont également une occupation de l'âge du Fer (19 tells). Cette proportion est encore plus importante dans le cas des gros tells à acropole et ville basse, qui sont presque tous déjà occupés à l'âge du Bronze ancien (19 tells sur 21), tandis que quasiment les deux-

5. Si des bifaces acheuléens et des artefacts levallois ont été récoltés (identification S. Muhesen), leur nombre restreint ne permet pas de tirer de conclusions quant au peuplement de la région pour ces hautes époques. Ce n'est qu'à partir du Kébarien que les vestiges se révèlent assez nombreux pour se faire une idée de l'occupation (Coqueugniot 2011; Geyer et Coqueugniot 2013; Geyer et al. 2014).

6. Pour plus de détails sur la méthodologie mise en œuvre, voir Geyer et al. 2004-2005. 
tiers d'entre eux le sont aussi à l'âge du Fer (14 tells sur 21). Pour les tells de taille moyenne et les petits tells, l'âge du Bronze récent est absent mais l'âge du Bronze ancien et l'âge du Fer sont représentés dans les mêmes proportions quelle que soit la taille des tells.

La moitié des tells ont des fossés bien visibles (27 sur 55), dont la largeur varie entre $10 \mathrm{~m}$ et $25 \mathrm{~m}$. Ils ceinturent la ville basse (à moins qu'il ne s'agisse d'une extension antérieure plus importante de la ville) et/ou l'acropole. La proportion des tells déjà occupés à l'âge du Bronze ancien sur lesquels des fossés ont été clairement identifiés est moindre (15 sur 27 tells) tandis qu'elle reste stable pour les tells occupés à l'âge du Fer (18 sur 27). À noter que sur l'ensemble des tells datés de l'âge du Bronze ancien, des fossés ont été repérés sur seulement un quart d'entre eux (20 sur 80 tells). Il est évident que nombre de fossés, aujourd'hui comblés ou recouverts par des constructions modernes, nous ont échappé. Cependant, ces chiffres pourraient indiquer qu'il y a, à l'âge du Bronze moyen, des fossés plus importants ou des fossés antérieurs recreusés (mais peut-être aussi à l'âge du Fer) qui sont par conséquent restés mieux visibles. Si les remparts ont été observés de manière récurrente tout au long de l'âge du Bronze, les fossés en revanche paraissent plus fréquents au Bronze moyen. De fait, une constante du peuplement de l'âge du Bronze moyen serait le renforcement des constructions défensives.

Un fait frappant est l'absence, dans la région, de sites clairement identifiés comme étant des sites de nomades. En effet, quelle que soit la période considérée, la prospection des Marges arides a mis en évidence la variabilité de la limite entre nomades et sédentaires d'une période à l'autre mais aussi la complémentarité des deux espaces. Dans le cas du peuplement de l'âge du Bronze moyen, l'apparente absence de nomades pourrait s'expliquer par leur présence beaucoup plus à l'est, audelà d'une sorte de no-man's land, ou alors par l'utilisation d'une vaisselle qui n'aurait pas laissé de trace ou par une tradition matérielle complètement étrangère à celle des sédentaires. Dans tous les cas, cela dénote une coupure nette entre les deux mondes.

Un certain nombre de sites, non occupés à l'âge du Bronze ancien, du Bronze récent ou du Fer (16 sites) nous permet d'évaluer quels ont pu être les types d'installations propres à l'âge du Bronze moyen. Les plus nombreuses sont des positions défensives (une forteresse, un fortin et quatre tours). Cinq sites sont de petite taille, avec quelques murs épars qui peuvent également appartenir à des périodes récentes (postérieures à l'époque hellénistique). Un site se trouve sous un village actuel et nous n'en avons vu qu'un mur. Les quatre derniers sites sont des tells, tous datés de l'âge du Bronze moyen II. Le plus petit de ces tells a un diamètre de ca 65 m (Al-Mağāṣ 2, à l'est du Mațh); il a également livré de la céramique de l'époque hellénistique. Il se présente sous la forme d'une masse de brique crue en voie de disparition, avec de nombreux trous qui laissent voir des niveaux de sol et des couches cendreuses. Les trois suivants sont des exemples qui pourraient être plus représentatifs de la morphologie des établissements sédentaires de l'âge du Bronze moyen II. Dans la vallée entre Qal'at al-Rahiyya et Qal'at al-Hawāyis, Wādī al-Salīla 2 est installé sur une colline naturelle dominant le fond d'oued. Il s'agit d'un tell labouré de $120 \mathrm{~m}$ de diamètre, entouré d'un fossé d'une dizaine de mètres de largeur (fig. 2). Des meules de basalte y ont été vues, ainsi qu'une céramique abondante, qui date de la fin de l'âge du Bronze moyen I et du Bronze moyen II. Tall Hadīb se trouve dans le même secteur, à $3,5 \mathrm{~km}$ de Wādī al-Salīla 2 . Ce tell à peu près circulaire (100 $\mathrm{m}$ de diamètre à la base) est implanté en lisière d'un petit oued évasé. Entouré d'un fossé de ca $10 \mathrm{~m}$ de largeur creusé à travers la dalle calcaire, il a des flancs raides et semble construit avec un glacis sur le côté nord. Des murs sont conservés, à mi-pente et à la base, au-dessus de la dalle, en blocs de roche. Il est daté, par la céramique et une figurine féminine, de l'âge du Bronze moyen II. Ğadū'iyyat al-Šamāliyya 1 n'est pas à proprement parler un tell car il ne conserve qu'une faible élévation et n'est pas entouré d'un fossé. Cependant, il est très bien conservé et date uniquement de l'âge du Bronze moyen II. Il est implanté en lisière de la fayda $a^{7}$ d'al-Hirš, au sud-ouest de Hirbat 'Umm Ruğūm. Il est un des rares établissements de plaine pour lequel on puisse proposer une description. Un mur d'enceinte, de 1,50 m d'épaisseur, réalisé en blocs métriques de basalte bruts, à segments rectilignes et décrochements, dessine un plan circulaire de $63 \mathrm{~m}$ de diamètre. Il est doublé d'un autre mur circulaire, à l'intérieur, qui aménage des pièces de $3 \mathrm{~m} \times 2 \mathrm{~m}$. La porte, côté sud-ouest, est encadrée de contreforts de 3,20 m de largeur. Un bâtiment de deux pièces s'appuie contre la muraille à l'extérieur, au sud-est (13 m x 8 m) (figs. 3-4).

L'analyse du peuplement de l'âge du Bronze moyen dans les Marges arides fait ressortir un groupe de sites particuliers: des fortifications établies sur des hauteurs, qui se distinguent des autres établissements. Les deux tiers des sites occupés à la fin de l'âge du Bronze moyen I et la moitié des sites datés de l'âge

7. Les faydas (terminologie locale) sont des évasements des fonds de vallées profitant de sols d'apport, profonds et bien irrigués par les eaux de ruissellement, localisés soit à la confluence des oueds, soit sur des replats structuraux ou autour des dépressions endoréiques. 


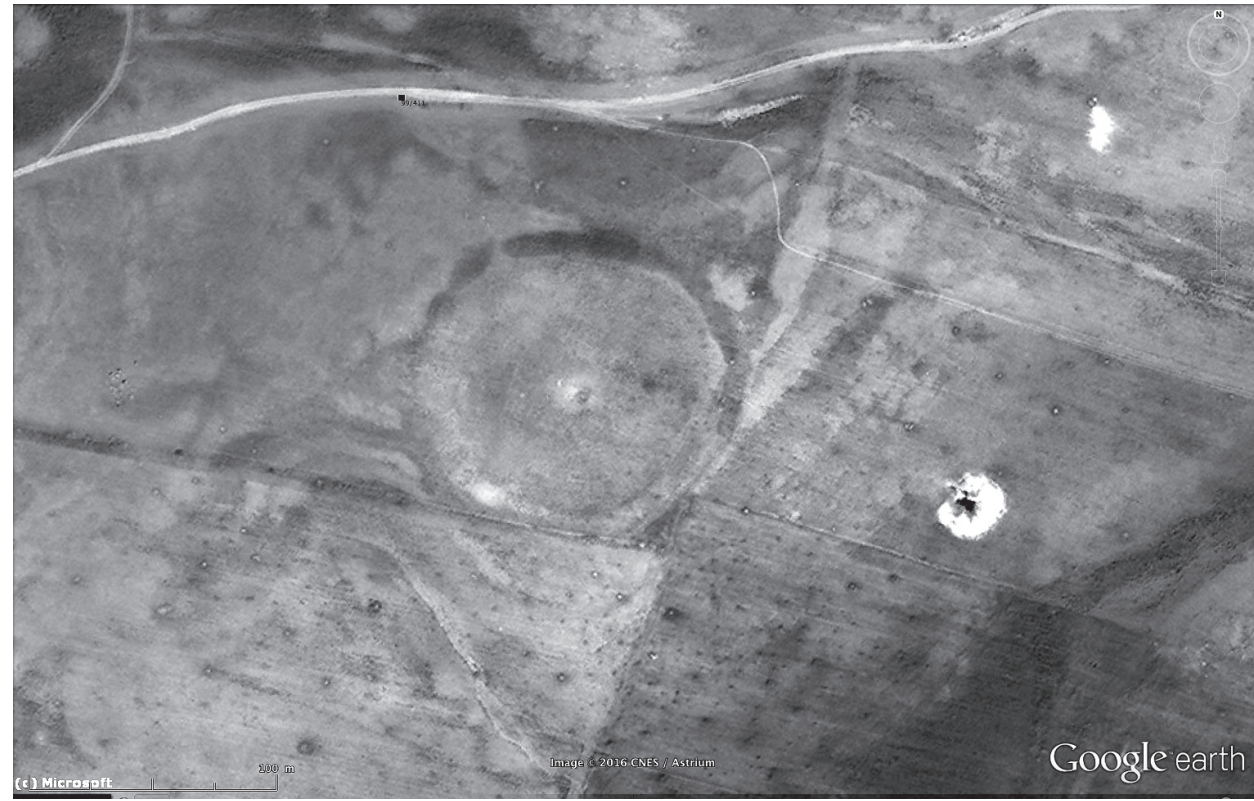

Fig. 2 - Image satellite du site de Wādī al-Salīla 2 (Google Earth; pour toutes les images satellitales, le nord est en haut).

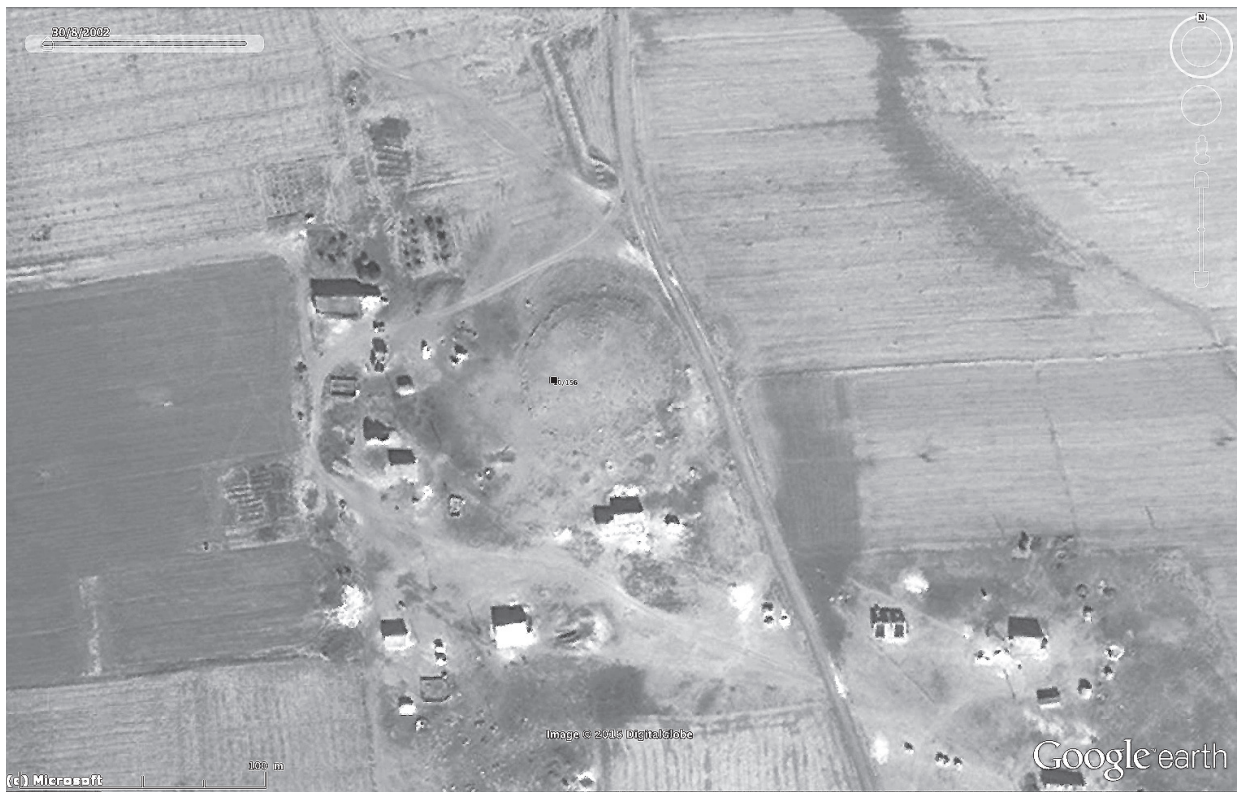

Fig. 3 - Image satellite du site de Ğad̄̄ 'iyyat al-Šamāliyya 1 (Google Earth).

du Bronze moyen II correspondent à ce type d'édifices (tabl. 1). En complément des sites de plaine, ces 24 installations pourraient appartenir à un réseau de défense, qui s'étale en arc de cercle, du piémont des Palmyrénides à la lisière orientale du Ğabal al-'Alā et au nord de la zone des grandes sebkhas et qui semble se poursuivre vers le nord-est en longeant la façade orientale du Ğabal Šbayṭ (fig. 1). Elles sont régulièrement espacées et, situées sur des points hauts avec vue panoramique, sont toujours en vue d'une ou de plusieurs des autres fortifications. Elles dominent la zone de steppe à proprement parler. Ces forteresses, par leur localisation, bénéficient peu ou prou de la ressource en eau constituée par les nappes perchées infra- 


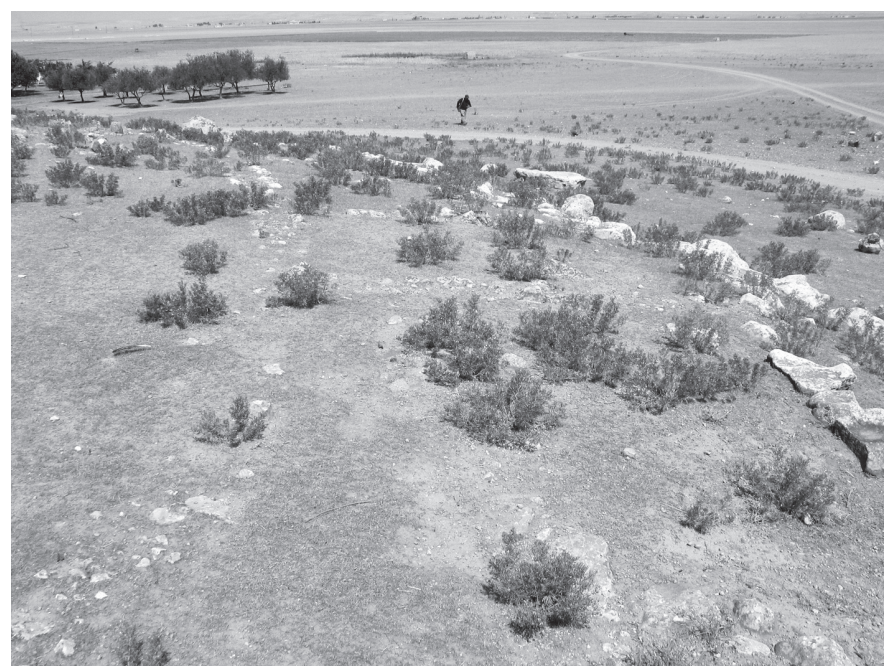

Fig. 4 - Le mur d'enceinte de Ğad̄̄ 'iyyat al-Šamāliyya 1 vu vers le nord (photo M.-O. Rousset).

basaltiques (Besançon et Geyer 2006: 40) lorsqu'elles sont implantées sur les mesas basaltiques ou sur leurs pentes. Elles sont situées dans ou en lisière d'une aire écogéographique qui correspond à des terroirs relativement favorisés, ne connaissant qu'une aridité climatique modérée ${ }^{8}$, mais sont le plus souvent implantées sur des corniches de roche à nu, répulsives et peu adaptées à la mise en valeur agricole. Cette disposition est donc avant tout stratégique et semble répondre à des impératifs militaires de surveillance des territoires de l'est et de protection des terres fertiles de l'ouest ${ }^{9}$.

La région étudiée compte, parmi ces installations, huit constructions similaires, des forteresses de 0,9 à 3,1 ha: sept ont été prospectées par la mission «Marges arides» (Rubbā, Qal'at al-Rahiiyya, Qal'at al-Hawāyis, Tall Abū Drīha, Tall al-'Ūgā, Tall Șabḥa et Rağm al-Șawān), auxquelles s'ajoute Tall Draham. Ce dispositif est complété par des fortins de $c a$ 60 m de diamètre (Qal'at Šumaymīs, Al-Qasțal al-Šamālī, Tall al-'Albāwī et Tulūl Manatīr al-Hurūṭ), par des tours de ca 30 m de diamètre (Fahrr, 'Arḍ al-Riğla, Ruğum al-Amțal, Ğabal Fārimha, Huirbat 'Umm Ruğūm, Tabārat al-Zbīb 1 et Tilāl Ḣmaymāt al-Dāyr) et par des petites tours de plan carré, de 12 à 15 m de côté (Al-Dabka 1, Al-Mințār, Ruğum al-Hुarāyĭğ, Al-Ṭwayhīna 4). Certaines de ces constructions avaient été remarquées par H.C. Butler, J. Lassus, R. Mouterde et A. Poidebard (Butler 1920: 3 et 16; Lassus 1935: 15-16, 79-82

8. Aire écogéographique 1a de J. Besançon et B. Geyer (2006: 43-46), avec des précipitations moyennes de plus de $300 \mathrm{~mm} / \mathrm{an}$.

9. Elle explique aussi pourquoi très peu de ces sites ont été prospectés, n'étant pas localisés dans les zones traditionnelles des tells: les plaines. et pl. III et XI.1 et 2; Mouterde et Poidebard 1945: 73-74), qui évoquaient des «forteresses primitives »-donc antérieures à l'époque romaine -, mais l'ensemble n'avait pas été perçu comme pouvant appartenir à un même système de défense et n'avait donc pas été envisagé dans sa globalité. Nous pensons qu'il s'agit d'un système cohérent et précisément structuré. Nous décrirons d'abord le réseau de sites prospectés dans le cadre de la mission des «Marges arides», puis nous montrerons comment d'autres établissements paraissent liés à ce réseau de surveillance fortifié.

\section{LES FORTERESSES}

Les grandes forteresses qui constituent selon nous le cœur d'une ligne des fortifications de l'âge du Bronze moyen (fig. 5) sont régulièrement espacées, tous les 13 à $20 \mathrm{~km}$, et occupent des positions stratégiques. Elles sont construites avec les matériaux disponibles sur place - basalte, terre crue ou pierre calcaire -, mais selon des techniques comparables.

Elles sont présentées ci-dessous du sud vers le nord.

La forteresse de Rubbā, au nord-ouest de Salamya, était déjà connue avant notre visite, en 2000 (Butler 1920: 6-7). Construite en lisière sud-est de la coulée basaltique (mesa) du Ğabal al-'Alā, elle s'élève sur près de 10-15 m de hauteur. La muraille, réalisée avec des blocs pouvant atteindre plus d'1,5 m de longueur, cyclopéens bruts, uniquement de basalte, enclot un espace de 230 x 175 m (fig. 6). La porte principale se situe sur un décrochement dans la muraille, au nord-ouest, et un bâtiment devait lui être associé, à l'intérieur. Une autre porte a été observée dans l'angle sud-est, ainsi que, par endroits, des redans. Au moins deux tours subsistent du côté est. Très vaste, l'intérieur est relativement plan, avec de nombreuses arases de murs en blocs d'un module plus petit que ceux de l'enceinte: elles marquent l'emplacement de bâtiments édifiés contre la muraille mais aussi d'épierrements récents. Un cimetière non daté largement pillé et des arases de murs s'étalent hors-lesmurs, à l'est. D'après la céramique, cet établissement a été en activité à l'âge du Bronze ancien IV, à ceux du Bronze moyen IB et II et du Fer II.

Qal'at al-Rahiyya est l'un des plus beaux exemples de fortification de l'âge du Bronze moyen ${ }^{10}$, installé à l'extrémité orientale de la mesa du Ğabal al-'Alā. Cette position lui permettait de surveiller la steppe à l'est et la vallée du Nahr al-Hawāyis / Wādī al-Hirš, et de voir la citadelle de Qal'at

10. Le site a été mentionné la première fois dans Butler 1920: 24, puis par Lassus 1935 : 204. Voir aussi Rousset et Duvette 2015 ; Rousset et al., sous presse. 


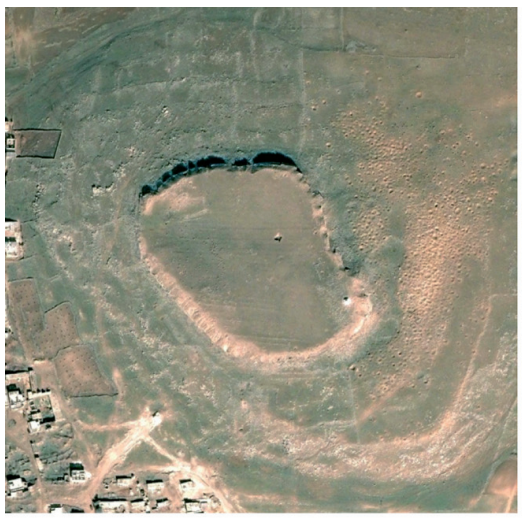

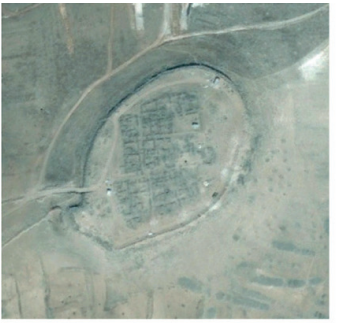

Qal'at al-Rahiyya

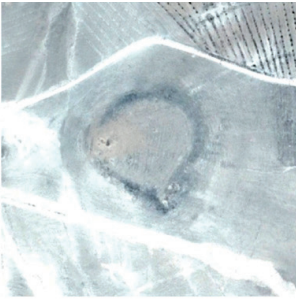

Qal'at al-Ḥawāyis

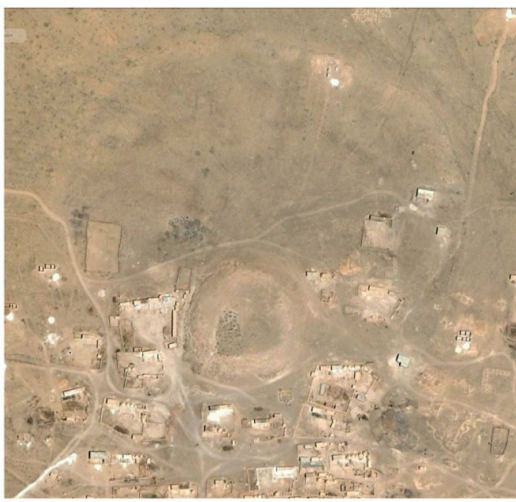

Tall Șabha

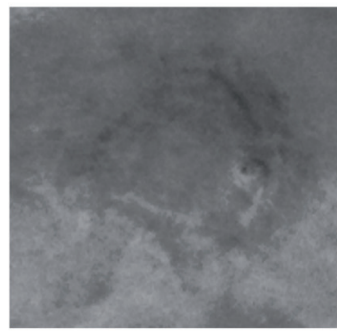

Ğabal al-Šahīd
Tall Draḥam

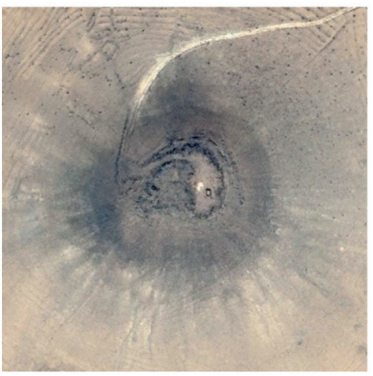

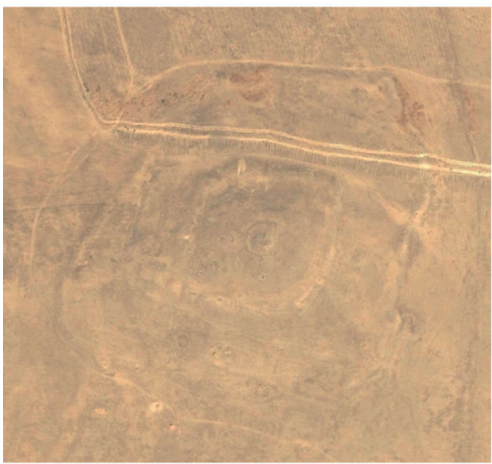

Rağm al-Șawān

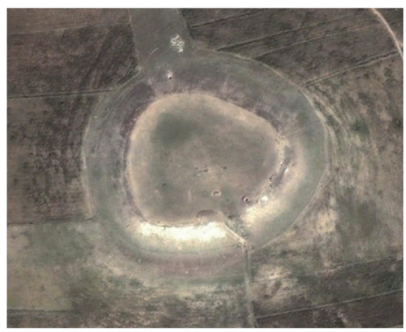

Tall al-'Ūgā

Fig. 5 - Images satellites (Google Earth et Corona) des forteresses avérées et supposée ( $\breve{G} a b a l$ al-Šahīd).

al-Hawāyis, le fortin de Tall Ḍahab et les tours de 'Arḍ al-Riğla et Ruğum al-Amțal. Elle a été étudiée par notre équipe en 1998 et en 2000. Les constructions recouvrent la totalité d'un piton à couronnement basaltique, retaillé à l'ouest, dont les pentes sont entièrement recouvertes de blocs issus du démantèlement de la coulée. La plateforme sommitale mesure 230 x 160 m, avec une protubérance au sud à l'emplacement de l'entrée (fig. 7). La muraille, qui suit les courbes de niveau, est épaisse d'au moins 4,50 m (fig. 8). Elle est construite avec un fruit prononcé en appareil polygonal de gros module métrique (fig. 9). Les blocs ont été prélevés de la coulée basaltique et à peine retaillés, la plus grande face plane disposée en parement. Le mur extérieur est doublé du côté interne d'une, voire de plusieurs rangées de caissons rectangulaires (fig. 7: k). Au sud, l'aspect défensif a été renforcé par le creusement d'un fossé, d'où a probablement été extraite une partie des blocs de construction. C'est de ce côté que se situe l'entrée. Il s'agit d'un système complexe, composé d'une rampe qui longe la muraille à l'extérieur (fig. 7: c et 


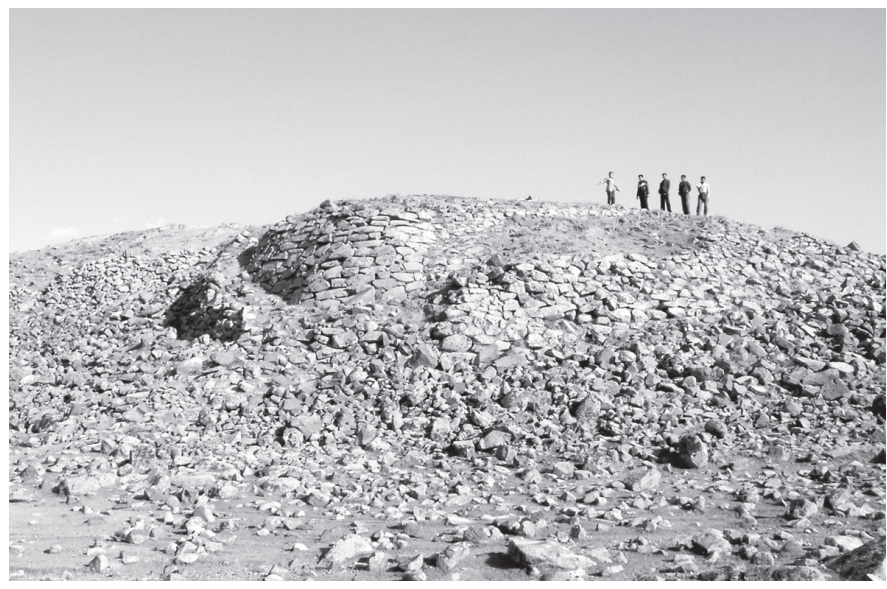

Fig. 6 - L'angle sud-est de la forteresse de Rubbā (photo M.-O. Rousset).

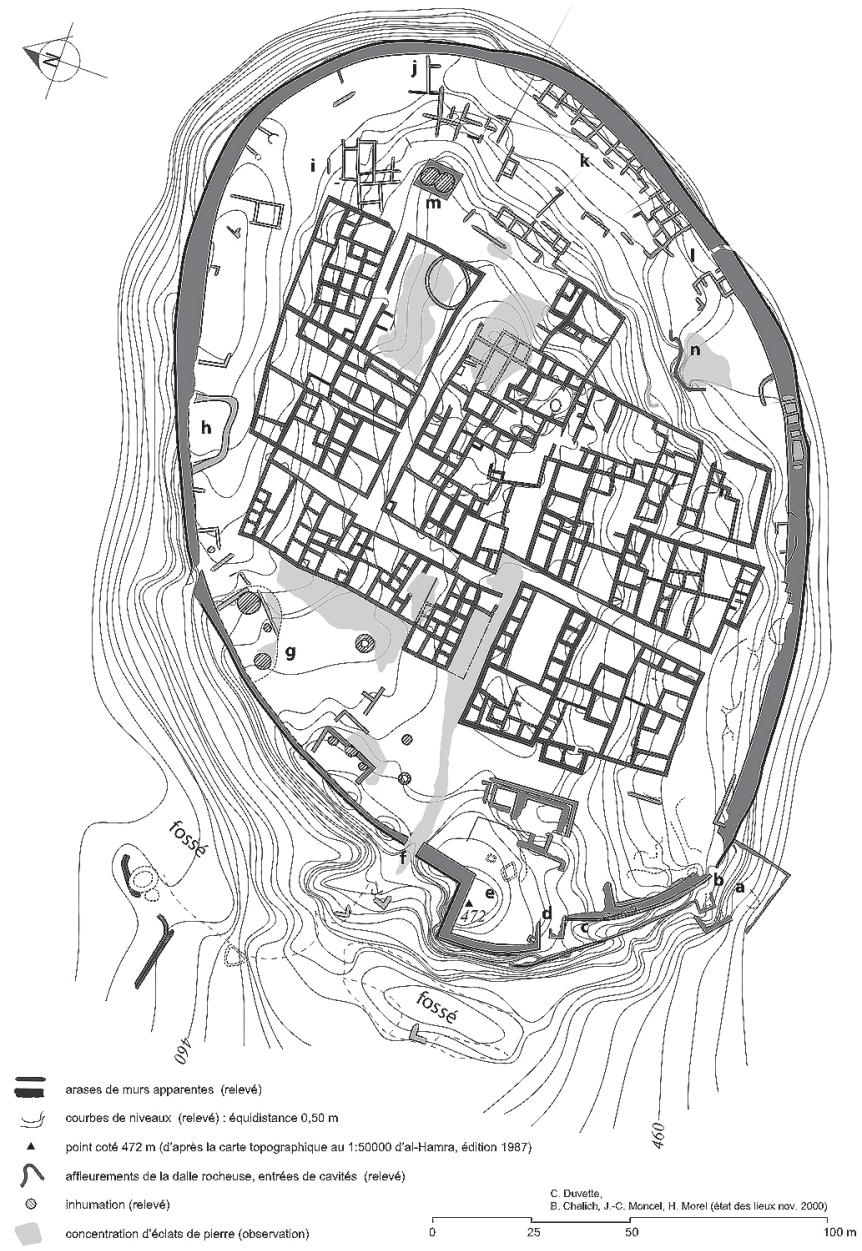

Fig. 7 - Plan de la citadelle de Qal'at al-Rahiyya. État des lieux novembre 2000 (relevé B. Chalich, C. Duvette, J.-C. Moncel et H. Morel).

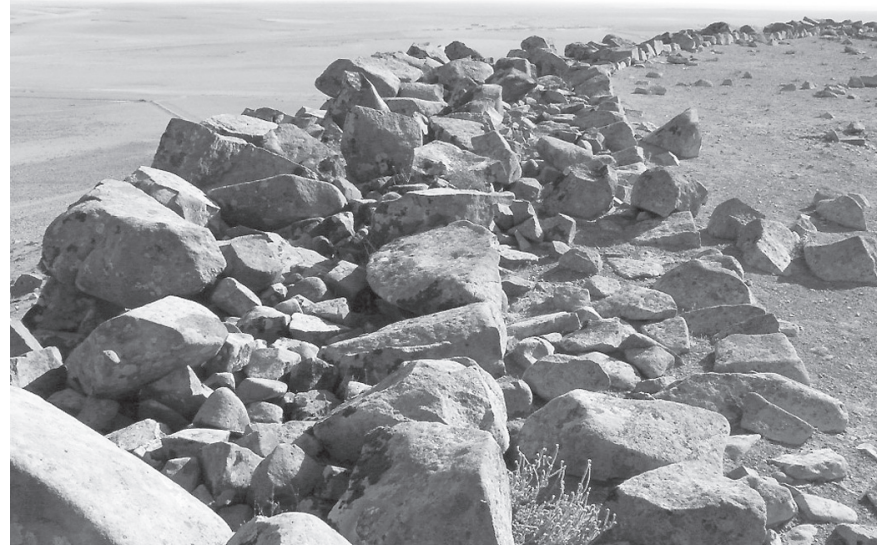

Fig. 8 - Vue, vers l'est, de l'épaisseur de la muraille nord de Qal'at al-Rahiyya (photo M.-O. Rousset).

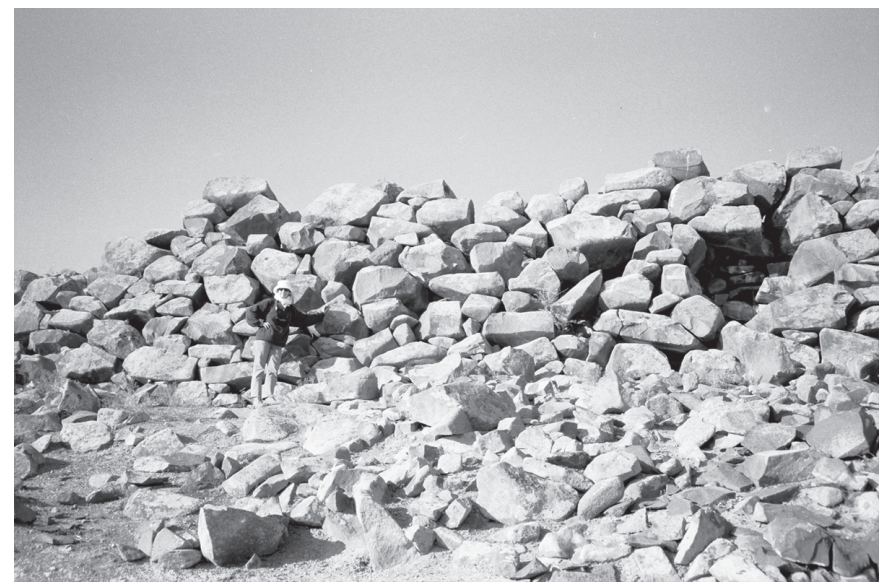

Fig. 9 - Détail de l'appareil du rempart, face est, de Qal'at al-Rahiyya (photo B. Geyer).

fig. 10). L'ascension de la colline permettait d'atteindre une construction rectangulaire de 18 x $15 \mathrm{~m}$, à la base de la rampe (fig. 7: a). Il y avait là probablement une première porte, protégée par une tour de $c a 8 \mathrm{~m}$ de côté, faisant face à la muraille (fig. 7: b). La rampe montait ensuite vers une autre tour ou contrefort, de ca 3,50 m d'épaisseur (fig. 7: d), placée cette fois-ci contre la muraille. Au-delà d'une seconde porte, on accédait à une seconde plateforme sub-rectangulaire (fig. $7:$ e), d'environ $22 \mathrm{~m}$ de longueur, se terminant par un décrochement d'une douzaine de mètres par rapport à l'alignement de la muraille. Cet espace, le plus élevé de la fortification, était défendu à l'extérieur, par le fossé. Il est occupé, au moins 


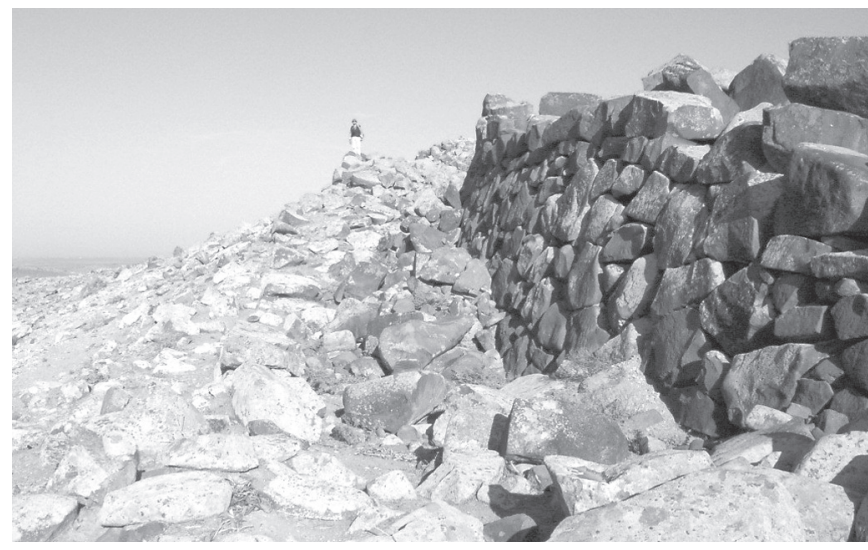

Fig. 10 - Rampe d'accès à Qal'at al-Rahiyya, vue vers le nord-ouest (photo M.-O. Rousset).

partiellement, par un bâtiment rectangulaire, de 40 x $25 \mathrm{~m}$. En dehors de l'entrée monumentale, il existait un passage dans la muraille, à l'est, qui pourrait être une poterne ou un accès à une tour (fig. 7: 1). À l'intérieur, des arases de murs correspondant à la même phase architecturale forment un plan rayonnant le long de la muraille; certaines, très larges, atteignent 1,20 m d'épaisseur. Elles sont visibles dans les parties non recouvertes par les constructions postérieures (fig. 7: i-k). L'analyse du matériel archéologique montre que la fortification en appareil polygonal, construction la plus ancienne du site, devrait être rattachée à la période de l'âge du Bronze ancien (faiblement attesté) ou du Bronze moyen, tandis que le bâtiment rectangulaire, au débouché de la rampe d'accès (fig. 7: e), pourrait être un peu plus tardif, peut-être de l'âge du Fer. Le village, dont les murs masquent une grande partie des constructions antérieures, peut être daté de l'époque ayyoubide.

Qal'at al-Ḥawāyis avait été visitée par l'expédition de Princeton qui y avait relevé des inscriptions rupestres en grec, d'époque romaine, sur des grands blocs de basalte in situ au milieu de l'établissement ${ }^{11}$. Nous avons effectué nos propres observations en 1999, 2000 et 2001. La forteresse, située elleaussi en lisière orientale du Ğabal al-'Alā, repose sur une buttetémoin légèrement décollée de la mesa, au tiers supérieur du versant, sur une coulée basaltique presque totalement démantelée (fig. 11). Elle domine, vers le nord, une très belle fayda de confluence et, vers le sud, cette même vallée, plus resserrée. De là, la vue s'étend jusqu'à Qal'at al-Rahiyya et Tall Abū Drīha, toutes les deux dans le même alignement (voir ci-

11. Elles sont datées de 252-253 ap. J.-C.: Lassus 1935: 132-136 et pl. XXIVXXVII.

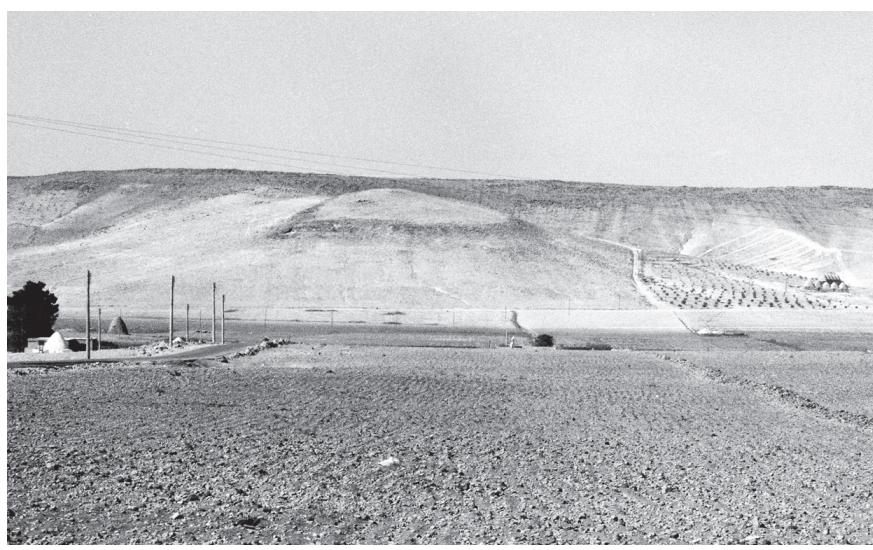

Fig. 11 - Qal'at al-Hawāyis vue de l'est (photo B. Geyer).

dessous), jusqu'aux tours de Hirbat 'Umm Ruğūm, Ğabal Fārimha, Al-Mințār et Al-Dabka 1. Le site épouse la forme de la colline: une surface en pente régulière vers l'est, de 115 x $110 \mathrm{~m}$. Les murailles, de 4 à $5 \mathrm{~m}$ d'épaisseur, sont construites en blocs de basalte qui mesurent jusqu'à $1 \mathrm{~m}$ de longueur. Ces murs en très gros appareil sont montés sans mortier ni liant, sans assises, par endroits de type cyclopéen. Au sud-est, un angle est renforcé par une tour massive en forte saillie sur l'extérieur. Un fossé a été creusé, à l'amont de la muraille, à l'ouest, pour accentuer la défense. La porte s'ouvre vers le sud, sur un décrochement de la muraille de $c a 1 \mathrm{~m}$, protégée par une tour. Elle est édifiée avec des blocs bruts de basalte de $2 \mathrm{~m}$ de longueur, avec probablement un petit ouvrage de défense à l'avant. À l'intérieur, des murs subsistent; certains s'appuient contre la muraille. Il y aurait eu un puits dans la forteresse. La période chronologique indiquée par la céramique est l'âge du Bronze moyen IB et $\mathrm{II}^{12}$.

Tall Abū Drīha est implantée, elle aussi sur la mesa du Ğabal al-'Alā, sur le point culminant de l'extrémité d'une coulée démantelée qui domine la reculée d'al-Hirš. La forteresse a été édifiée sur un remblai qui lui permet d'atteindre une hauteur suffisante pour voir les forteresses de Tall al-'Ūgā, Tall Șabhạ et Qal'at al-Hawāyis et d'être sur le même alignement que cette dernière et Qal'at al-Rahiyya. Elle peut communiquer visuellement avec les tours de Tilāl Ḥmaymāt al-Dāyr, Tabārat al-Zbīb 1, Hirbat 'Umm Ruğūm, Ruğum al-Ḩarāyiğ, Ğabal Fārimha, Al-Mințār et Ruğum al-Amțal. Visitée en 2000, elle apparaît sous la forme d'un tell tabulaire, à peu près circulaire, de $10 \mathrm{~m}$ à $15 \mathrm{~m}$ de hauteur et de $135 \mathrm{~m}$ de diamètre

12. L'assemblage a été publié dans Calvet 2002 (tessons numéros 99.415). 
sommital ${ }^{13}$. Le mur d'enceinte, de $c a 7 \mathrm{~m}$ de largeur, est construit en terre crue entre deux parements de petits moellons, sur un soubassement de blocs de basalte de module moyen et de calcaire. Le mur n'est pas circulaire mais constitué de segments rectilignes. L'accès se situait probablement vers l'ouest et la surface basaltique. Dans la dépression centrale ont été observées des arases de murs en petits moellons de basalte et de calcaire. La céramique date très majoritairement de l'âge du Bronze moyen IB et II, avec quelques tessons de l'âge du Bronze ancien (voir plus loin).

Tall al-'̄̄gā est installée sur une colline bien individualisée en avant de la mesa basaltique d'où on voit parfaitement les forteresses de Tall Abū Drīhna et Tall Șabḥa, ainsi que la tour de Tilāl Ḥmaymāt al-Dāyr. Nos observations sur ce site ont été effectuées en 2000 et 2001. Il s'agit d'un haut tell, grossièrement triangulaire, de $c a 170 \mathrm{~m} \times 150 \mathrm{~m}$ au sommet. La base du mur d'enceinte, à caissons, de $7 \mathrm{~m}$ de largeur, est construite en blocs de calcaire éocène. Au tiers inférieur de la pente, de gros blocs de basalte métriques forment un alignement plus ou moins régulier, visible à l'ouest de la porte (renfort? mur bas?), de 1,30 m de largeur. Celle-ci est située côté sud; elle était édifiée avec des blocs métriques de basalte non taillés, maintenant éboulés en contrebas, dans la pente. Ces derniers portent plusieurs marques gravées ou piquetées qui semblent être les traces de lettres qui font penser à une inscription similaire à celle de Qal'at al-Hawāyis. L'abondante céramique récoltée fournit une datation de l'âge du Bronze moyen IB et II pour la surface du tell à l'intérieur de la muraille, complétée par une faible attestation de l'âge du Bronze ancien sur le tracé de la muraille (cette céramique plus ancienne pourrait provenir de terres rapportées pour la confection des briques crues).

Tall Șabḥa est localisée au nord-est de Tall Abū Drīhna et de Tall al-'ڤ'̄gā. Elle a été prospectée par A. De Maigret en 1964 (De Maigret 1978) et n’a été vue que rapidement en 1999. Elle est installée en lisière sud du plateau de Hummat al-Hayl, sur une avancée de basalte qui domine la Sabhat al-Harāyik. Elle se compose clairement de plusieurs parties: un établissement entouré d'une grande enceinte circulaire en pierre de $480 \mathrm{~m}$ de diamètre et d'une dizaine de mètres de largeur, un tell tabulaire de $115 \mathrm{~m}$ de diamètre, à l'intérieur mais désaxé vers le sud par rapport à la première enceinte et les vestiges d'un village aux constructions de briques crues qui recouvrent une partie du site ancien et s'étalent vers l'est - la céramique dans ce secteur date de la fin de l'époque hellénistique et de l'époque romaine. Un village récent recouvre en partie le site.

13. Elle est mentionnée par Lassus 1935 : 214.
Le tell est de forme pentagonale arrondie et une dépression qui pourrait marquer l'emplacement de l'entrée se trouve au nordest. La datation fournie par la céramique pour les parties les plus anciennes correspond aux âges du Bronze ancien IV, du Bronze moyen I et II et du Fer $\mathrm{II}^{14}$. Par sa position topographique, sa forme générale et sa datation, le tell tabulaire offre des parallèles convaincants avec les autres forteresses de l'âge du Bronze moyen. Il est en vue des forteresses de Rağm al-Ṣawān, Tall Abū Drīhna et Tall al-'Ūgā et des tours de Ruğum al-Harāyiğ et Hirbat 'Umm Ruğūm.

Rağm al-Ṣawān, localisée à l'est de la précédente, à l'extrémité nord du «Très Long Mur $»^{15}$ est implantée sur un lambeau de coulée basaltique prolongeant le Ğabal 'Ubaysān, en pleine zone aride. Elle a été visitée en 1997, 2000 et 2002 (Geyer 2009 et Geyer et al. 2010). Il s'agit d'un grand site composé de trois enceintes concentriques, dont la plus puissante semble être la médiane. Ces remparts délimitent des terrasses superposées. Dans la plus basse, de $370 \mathrm{~m}$ x $330 \mathrm{~m}$ (soit 10,5 ha), les appareils des murs témoignent de plusieurs périodes de construction: des murs en blocs de basalte surmontent des murs construits en gros blocs de calcaire et de basalte. Un grand enclos y a été observé, incluant un bâtiment et un grand espace vide. La forteresse médiane, de $170 \mathrm{~m}$ x $170 \mathrm{~m}$, construite en terre sur une base de pierres, peut-être à caissons, épaisse d'une quinzaine de mètres, montre de nombreuses arases de murs internes. La céramique de ce secteur permet de l'attribuer aux âges du Bronze ancien IV et du Bronze moyen II. Une occupation de l'âge du Fer II est également attestée sur le site. Le dernier niveau de défense est constitué par une tour centrale de $20 \mathrm{~m}$ de diamètre, entourée d'un mur de $35 \mathrm{~m}$ de diamètre, qui domine l'ensemble. Son emplacement légèrement surélevé lui permet d'être en vue de Tall Șabhạ, Ruğum al-Harāyiğg, Tabārat al-Zbīb 1 et Al-Ṭwayhīna 4.

Enfin, l'aboutissement de la ligne de surveillance à l'est des massifs basaltiques semble être la forteresse de Tall Draḥam, sur un piton rocheux, une butte-témoin de $90 \mathrm{~m}$ de hauteur, s'élevant $1,2 \mathrm{~km}$ en avant de la mesa du Šbayṭ. Située dans un camp militaire moderne, elle n'a pu être visitée mais la description et le plan que nous en a laissé J. Lauffray ${ }^{16}$ mentionnent plusieurs éléments qui rappellent les citadelles déjà évoquées. L'auteur la qualifie de «solide forteresse à quadruple défense ${ }^{{ }^{17}}$.

14. La datation proposée par De Maigret (1978: 90) est le Bronze ancien IVB. 15. Ce dernier délimite les domaines des nomades à l'est et des sédentaires à l'ouest, à l'âge du Bronze ancien IV (Geyer et al. 2010).

16. Voir Mouterde et Poidebard 1945: 170-171 et pl. XCII.2 et XCIV; voir aussi Haase 1983: 71.

17. Mouterde et Poidebard 1945: 168; J. Lauffray mentionne également la similitude des appareils avec ceux d'al-Bāb. 
Elle repose sur une colline cônique, calcaire, couverte d'une nappe basaltique ovale, de 120 x $91 \mathrm{~m}$. L'accès, par une rampe de $4 \mathrm{~m}$ de largeur, est visible du côté nord-ouest. Le rempart extérieur, de 2,30 $\mathrm{m}$ de largeur, est implanté à $4,50 \mathrm{~m}$ en contrebas du rebord du plateau. Il est construit en blocs de basalte irréguliers polygonaux, posés sans mortier, et comporte 15 saillants, espacés mur à mur de 5 à $13 \mathrm{~m}$. L'entrée pouvait s'effectuer par une chicane au sud tandis qu'une poterne est notée à l'est. Un second rempart, large de 2,50 m, est construit sur le bord du plateau avec les mêmes matériaux et technique que le premier. Il est pourvu d'une douzaine de tours dont une, au sud-ouest, de forme pentagonale, qui double une tour rectangulaire plus ancienne. À l'intérieur, une enceinte rectangulaire avec un mur en pierres non taillées de $1,75 \mathrm{~m}$ de largeur enclôt plusieurs constructions dont deux en pierres taillées. Il ne fait aucun doute que ce plan reflète plusieurs périodes de construction; les deux remparts extérieurs pourraient dater de l'âge du Bronze. La forteresse de Tall Draham permettait de surveiller les régions orientales potentiellement jusqu'à l'Euphrate. Elle est en contact avec la tour d'al-Ṭwayhīna 4.

\section{LES FORTINS}

Cet alignement de grandes forteresses semble complété par des fortins, dans la partie sud du réseau. Certains dessinent une deuxième ligne de défense, vers l'est, composée de fortins espacés de 20,5 km, de 20,5 km et de 15,5 km (figs. 1 et 12). Ces derniers sont eux aussi placés sur des points élevés, en limite du relief des Palmyrénides. Ils comportent une muraille de plan polygonal de $60 \mathrm{~m}$ de diamètre, couronnant un tell pentu, souvent pourvu d'un glacis et entouré d'un fossé.

Qal'at Šumaymīs, situé à $4,5 \mathrm{~km}$ au nord-ouest de Salamya, est surtout connu pour son château de l'époque ayyoubide et a été visité par un grand nombre de voyageurs ${ }^{18}$. Cette citadelle est installée sur une butte témoin avec couverture basaltique bien préservée coiffant le calcaire sous-jacent. Un plan en a été dressé par J. Bylinski et l'étude de ses vestiges, couplée à celle des références historiques, a révélé plusieurs périodes de construction, matérialisées par l'utilisation de quatre types d'appareils différents, dont une maçonnerie de gros blocs grossiers de basalte. L'analyse de la céramique récoltée lors de notre passage en 2000, outre une grande majorité de fragments médiévaux, a montré qu'il y avait également eu là une occupation durant l'âge du Bronze moyen (Rousset et Calvet 2016). Actuellement, la plateforme sommitale, entourée

18. On en trouvera le détail dans Bylinski 2006. d'un fossé profond, mesure ca $82 \mathrm{~m}$ x $53 \mathrm{~m}$. Sa partie centrale est occupée par un bâtiment rectangulaire, de $c a 30$ m x $35 \mathrm{~m}$ de côté, non daté. Il est difficile également de déterminer à quelle époque a été creusé le fossé. Cependant, la disposition de cette citadelle rappelle celle des autres fortifications présentées dans cet article.

Al-Qasțal al-Šamāīi 2, sur la partie haute d'une colline conique à $1 \mathrm{~km}$ à l'ouest d'al-Qasțal, domine le bourg et les environs. De là, la vue porte jusqu'à la tour de Fahr (infra, p. 129). L'observation de ce site, en 1997, 1998, 2000 et 2002, a permis de distinguer une forteresse de $c a 60 \mathrm{~m}$ de diamètre. Au nord, à l'ouest et au sud, trois tours rectangulaires, de $c a$ $15 \mathrm{~m}$ de largeur, saillent de la muraille. Des redans ou contreforts s'intercalent entre les tours. Le dispositif d'entrée, côté oriental, est encadré par deux tours de $c a 20 \mathrm{~m}$ de large chacune. La construction est faite en très gros appareil métrique, des blocs de dalle calcaire à silex bruts, isolant toute la partie haute de la colline. Quelques murs encore conservés montrent qu'il y avait des bâtiments intérieurs. Quelques tombes ont été pillées sur le sommet. Le matériel est abondant: mortier trépied en basalte, base de moulin biconique, deux meules dormantes en basalte, deux mortiers en calcaire, et la céramique comprend de nombreuses jarres de stockage. Les périodes représentées sont les âges du Bronze ancien IV, du Bronze moyen II et du Fer II. Les périodes byzantine et abbasside sont également attestées.

Tall al-'Albāwī 2, à $12 \mathrm{~km}$ au nord-ouest de 'Aqīrbāt, est installé sur le sommet d'une colline, butte résiduelle d'une ancienne surface de glacis démantelé, dans une zone d'openfield. Le site a été visité à deux reprises, en 1997 et 2000, et a fait l'objet de ramassages de céramique et d'un relevé (fig. 13).

Il s'agit d'une fortification grossièrement circulaire de $66 \mathrm{~m}$ de diamètre, voire polygonale car son mur extérieur se compose en fait de 16 segments rectilignes formant des redans. Elle est construite en gros blocs de dalle calcaire souvent métriques, non cimentés, non jointoyés. L'accès semble s'être effectué par une poterne ouvrant vers l'est, protégée par une construction de deux pièces, à l'intérieur. De nombreux murs, espacés de 4 à $5 \mathrm{~m}$, rayonnent à partir du mur d'enceinte vers l'espace central, occupé par une structure rectangulaire, de 27,50 m x 33,50 m, qui englobe une pièce de $21 \mathrm{~m}$ de côté. La céramique recueillie date cette installation des âges du Bronze ancien IV et du Bronze moyen II. De ce point, la vue porte jusqu'à la tour de Fahr (infra, p. 129) et le contact visuel est possible également avec le fortin de Tulūl Manatīr al-Hurūṭ.

Tall Ḍahab, implanté sur la mesa du Ğabal al-'Alā, installé dans un vallon très évasé, à proximité d'une tête de réseau, avait 


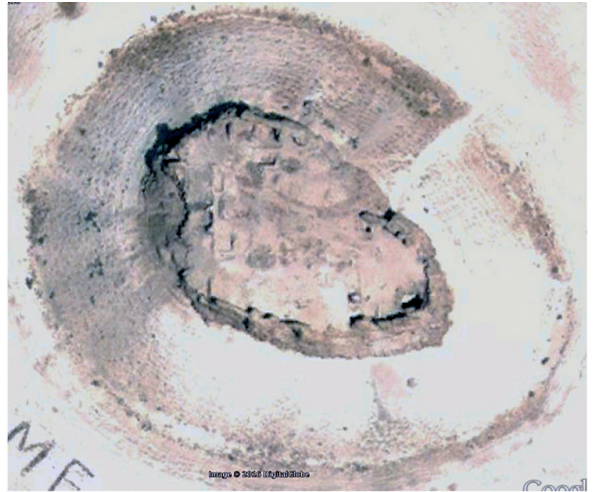

Qal'at Šumaymīs

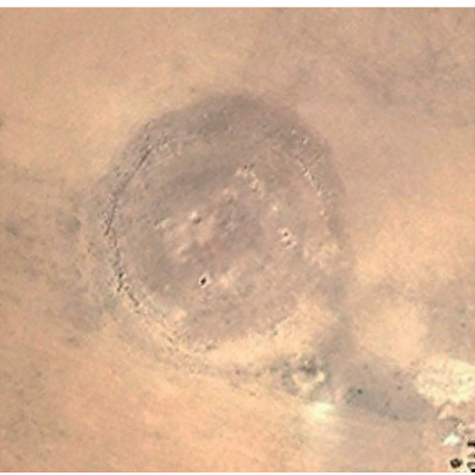

Tall al-‘Albāwī

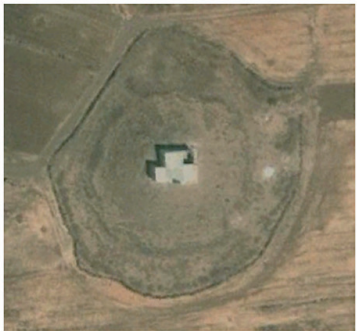

Tall Farzān

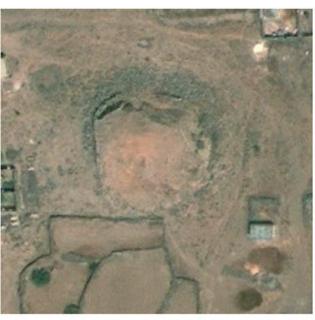

Tall Ḍahab $100 \mathrm{~m}$

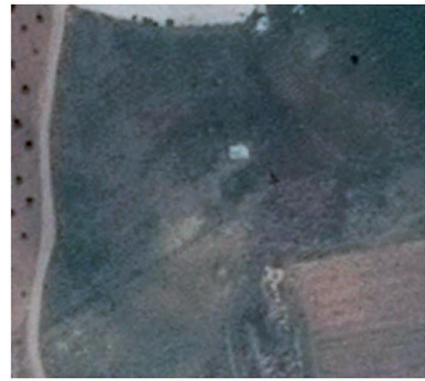

Tall Harī‘

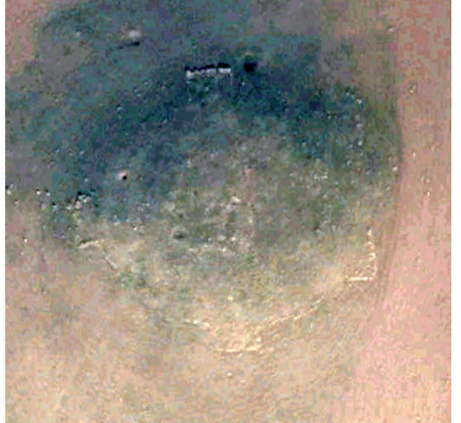

Al-Qasțal al-Šamālī

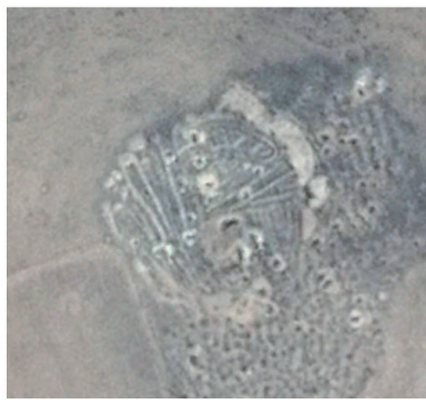

Tulūl Manatīr al-Hurūt

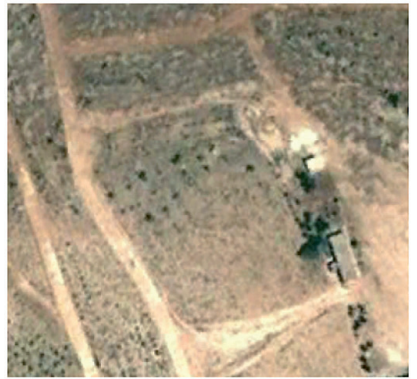

Dahrat Abū Maqām

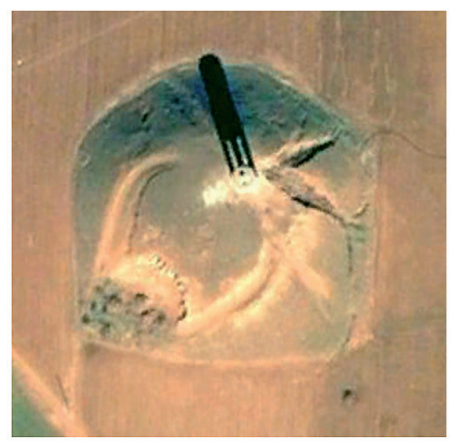

Tall Nabārīz

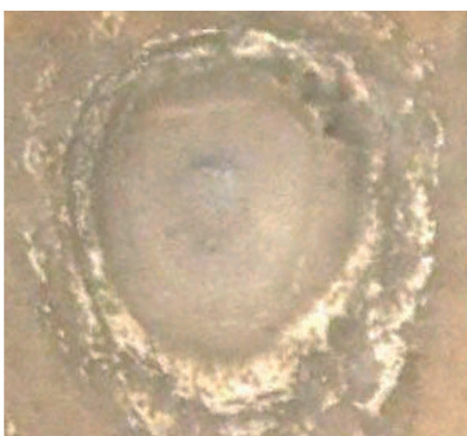

Ğabal al-Mahdiyya

Fig. 12 - Images satellites (Google Earth et Corona) des fortins avérés (les 5 en haut) et supposés (les 5 en bas). 


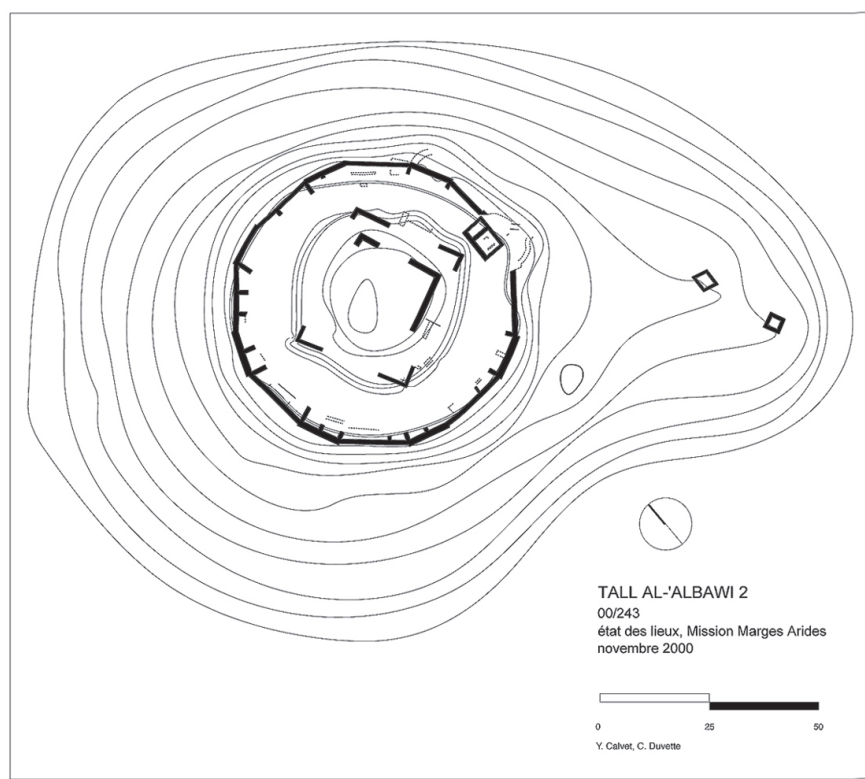

Fig. 13 - Plan du fortin de Tall al-'Albāwī 2 (relevé Y. Calvet, C. Duvette). État des lieux novembre 2000.

été vu par la mission de Princeton ${ }^{19}$. Nous l'avons étudié en 2001. Le fortin domine un village, datant de la fin de l'Antiquité et des époques médiévale et moderne, qui s'étend à ses pieds. Il repose sur un tell plus ancien, à l'ouest. De plan arrondi, de $\mathrm{ca} 40 \mathrm{~m}$ de diamètre, il est très bien conservé (sauf l'angle sud-est) et ses murs sont construits en appareil polygonal métrique de basalte, avec un fruit marqué (fig. 14). Les blocs de parement de la muraille mesurent de 1,40 m à 1,75 m de long. Le mur s'élève sur $\mathrm{ca} 4 \mathrm{~m}$ de haut à l'ouest, au-dessus du tell et sur $c a 8 \mathrm{~m}$ à l'est, au-dessus de la plaine. L'accès s'effectuait par le côté nord, où se distingue ce qui semble être une rampe d'accès. Cet élément pourrait également correspondre à un chemisage extérieur d'une muraille plus ancienne. La plateforme sommitale, de 30-32 $\mathrm{m}$ de diamètre, porte des restes de murs. La céramique recueillie date des périodes de l'âge du Bronze ancien IV, du Bronze moyen IB-II et peut-être de l'âge du Fer. De là, il est possible de voir la tour de Ruğum al-Amțal, la forteresse de Qal'at al-Rahiyya et le fortin de Tulūl Manatīr al-Hurūṭ. En revanche, toutes les positions à l'ouest et au sud échappent à sa vue.

Tulūl Manatīr al-Hurūṭ doit également être pris en considération, bien qu'il n'ait pas été reconnu en tant que fortin lors de notre passage en 1999. Le site, localisé à une altitude de $565 \mathrm{~m}$, sur une colline conique, est le point culminant du sec-

19. Butler 1920: 16-17; voir aussi Callot 2010: 278 n 43 .

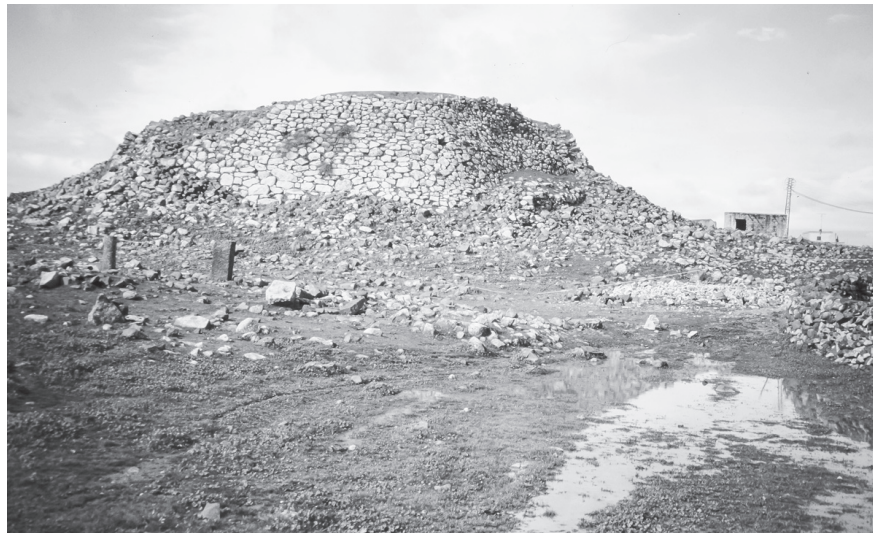

Fig. 14 - Vue du fortin de Tall Dahab depuis le nord-est (photo B. Geyer).

teur. Nous l'avions alors interprété comme étant un cimetière (celui du site romain implanté à proximité), pillé et détruit au bulldozer. Nous avions identifié au moins un gros bloc de basalte brut et de beaux blocs de calcaire taillés, parallélépipédiques, dont nous pensions alors qu'ils étaient les vestiges d'un monument funéraire. Cependant, nous avions été gênés par les perturbations modernes. Or, sur la photographie aérienne de 1958, on distingue une plateforme grossièrement circulaire de $c a 60 \mathrm{~m}$ de côté. Pourrait-on avoir là un fortin de l'âge du Bronze moyen? Assez peu de céramique a été vue mais elle n'a pas été ramassée car a priori non caractéristique. Cependant, la localisation sur le point le plus haut du secteur, la morphologie de la colline, la vue directe sur les forteresses de Qal'at al-Rahiyya et Qal'at al-Hawāyis, sur les fortins de Tall Dahab et Tall al-'Albāwī 2 et la tour d'al-Dabka 1 plaident pour intégrer ce site dans le réseau défensif du Bronze moyen. En outre, il n'y a pas d'autre site possible pour une fortification dans les environs proches. Il serait un point essentiel à l'articulation de la branche nord-sud et de celle qui va jusqu'à al-Qasțal al-Šamālī.

\section{LES TOURS}

De grandes tours, de $c a 20$ à $30 \mathrm{~m}$ de diamètre, et quelques tours plus petites s'insèrent entre les grandes forteresses et les fortins, lorsqu'ils ne sont pas visibles les uns des autres. Indispensables pour la surveillance du territoire et pour relayer un signal visuel, elles sont situées de part et d'autre de la ligne des forteresses et leurs positions répondent parfaitement aux nécessités de communication directe. Les points élevés permettant une vue dégagée, régulièrement espacés, ont donc été 


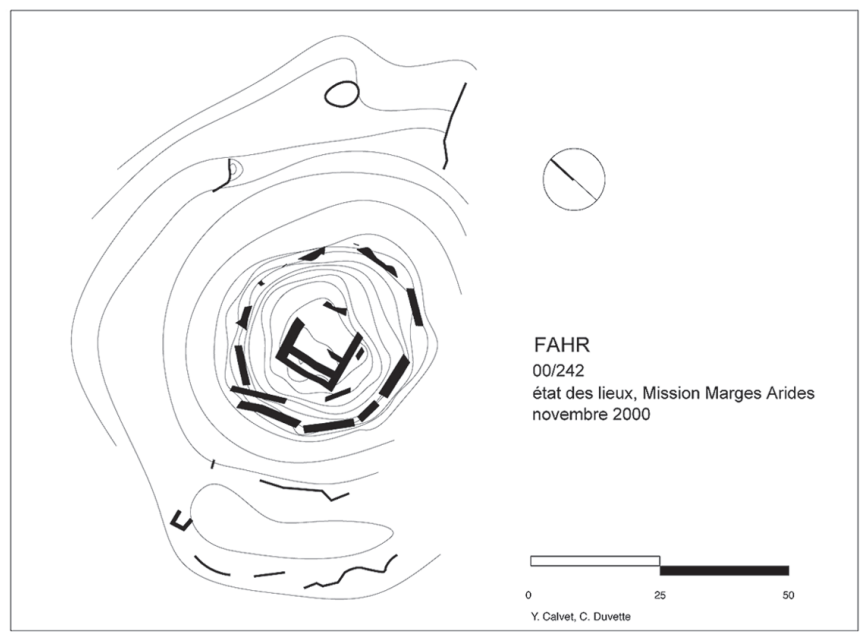

Fig. 15 - Plan de la tour de Fahr (relevé Y. Calvet, C. Duvette). État des lieux novembre 2000.

privilégiés. Ce sont les mêmes qui ont été récemment équipés d'antennes de téléphonie mobile.

La tour de Fahr est installée en lisière de la haute surface de glacis à dalle, dominant toute la dépression de Qasțal, sur une butte artificielle conique du haut de laquelle il est possible de voir les fortins de Qasțal al-Šamālī 2 et Tall al-'Albāwī 2. Le site a été visité en 2000 et 2002 et a été relevé (figs. 15 et 16). La butte est entourée d'un fossé. Elle a été édifiée avec des blocs informes, disposés sur plusieurs assises (ce remplissage était visible dans un trou de clandestins), qui ont pu être extraits des carrières que l'on devine dans les jardins à l'est et à l'ouest. Au tiers inférieur de la pente, un mur, composé d'une dizaine de segments rectilignes, forme une enceinte ovale de $34 \mathrm{~m} \mathrm{x}$ $37,50 \mathrm{~m}$, en gros blocs de dalle calcaire, mesurant jusqu'à $2 \mathrm{~m}$ de long. L'accès, tangent au mur, se trouve du côté occidental. Le sommet est couronné par un bâtiment rectangulaire, de $12,50 \mathrm{~m} \mathrm{x} 15 \mathrm{~m}$, comprenant plusieurs pièces et peut-être un escalier. La céramique ramassée date de l'âge du Bronze moyen.

'Arḍ al-Riğla, sur une crête résiduelle de coulée, dominant une alvéole fertile, est en vue de Qal'at al-Rahịyya et de Ruğum al-Amțal. Vue en 2002, elle a depuis été intégrée à un camp militaire. Cette tour, de forme circulaire, de 21 à $22 \mathrm{~m}$ de diamètre, comporte un mur polygonal (à redans ?) dont la base était encore en place. Les murs, conservés sur quelques assises dans la partie sud-ouest, sont en blocs bruts de basalte. Quelques traces de murs intérieurs subsistent au sud-est. Le peu de céramique découvert pourrait dater de l'âge du Bronze moyen. Cette tour était plutôt destinée à surveiller la riche

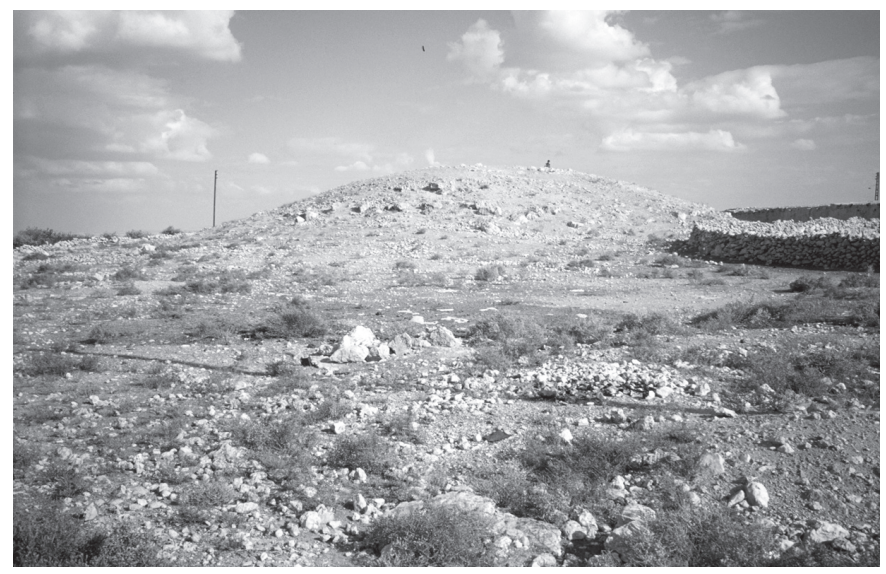

Fig. 16 - La tour de Fahr vue depuis le nord (photo B. Geyer).

vallée intérieure et pouvait doubler la communication entre la forteresse de Qal'at al-Rahiyya et la tour de Ruğum al-Amțal.

Ruğum al-Amțal, sur le sommet d'une avancée du Ğabal al-'Alā, sur la mesa bien plane, se trouve à mi-distance de 'Arḍ al-Riğla et de Qal'at al-Hawāyis, qu'elle ne voit pas cependant. Le site a été prospecté en 2002. La tour se présente sous la forme d'une construction quadrangulaire de $20 \mathrm{~m}$ de côté, aux murs de $1,10 \mathrm{~m}$ de largeur, en gros blocs quasi métriques bruts. Des cercles de pierres postérieurs lui sont accolés et des tombes se sont installées dans les ruines. La céramique, assez abondante, est datée de l'âge du Bronze moyen II, avec quelques tessons des époques byzantine et ayyoubide. La tour met en relation les forteresses de Qal'at al-Rahiyya et Tall Abū Drīha et était en contact avec celle proche de Qal'at al-Hawāyis par l'intermédiaire de la tour d'al-Mințār. La tour de 'Arḍ al-Riğla est également visible. Un enclos à murs épais, à $500 \mathrm{~m}$ au sud, pourrait être lié à cette tour (fig. 17).

Ğabal Fārimha a été visitée en 2010. Il pourrait s'agir d'une tour, implantée sur une coulée basaltique, en lisière sommitale ouest de celle-ci. Cet amoncellement de blocs métriques de basalte, recouverts de blocs issus d'épierrements postérieurs, forme un amas de $c a 25 \mathrm{~m}$ de diamètre. Dans le chaos de blocs apparaissent, sur quelques mètres, des alignements de blocs cyclopéens. Aucune céramique n’a été découverte. On peut voir, de là, les forteresses de Qal'at al-Hawāyis et Tall Abū Drīhna et la tour d'al-Mințār. Le relief à l'est de la tour ne permet pas de surveiller la steppe à partir de là. Par conséquent, elle est plutôt tournée vers l'intérieur des terres des sédentaires et sa fonction aurait été plutôt de transmettre l'information aux populations en cas de danger. À $350 \mathrm{~m}$ au sud se trouve un enclos limité par des murs en appareil de basalte polygonal, larges de 1,30 m et conservé parfois sur 


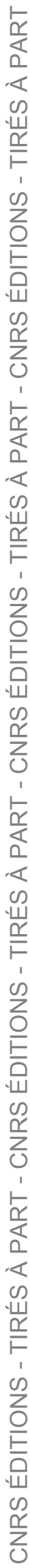
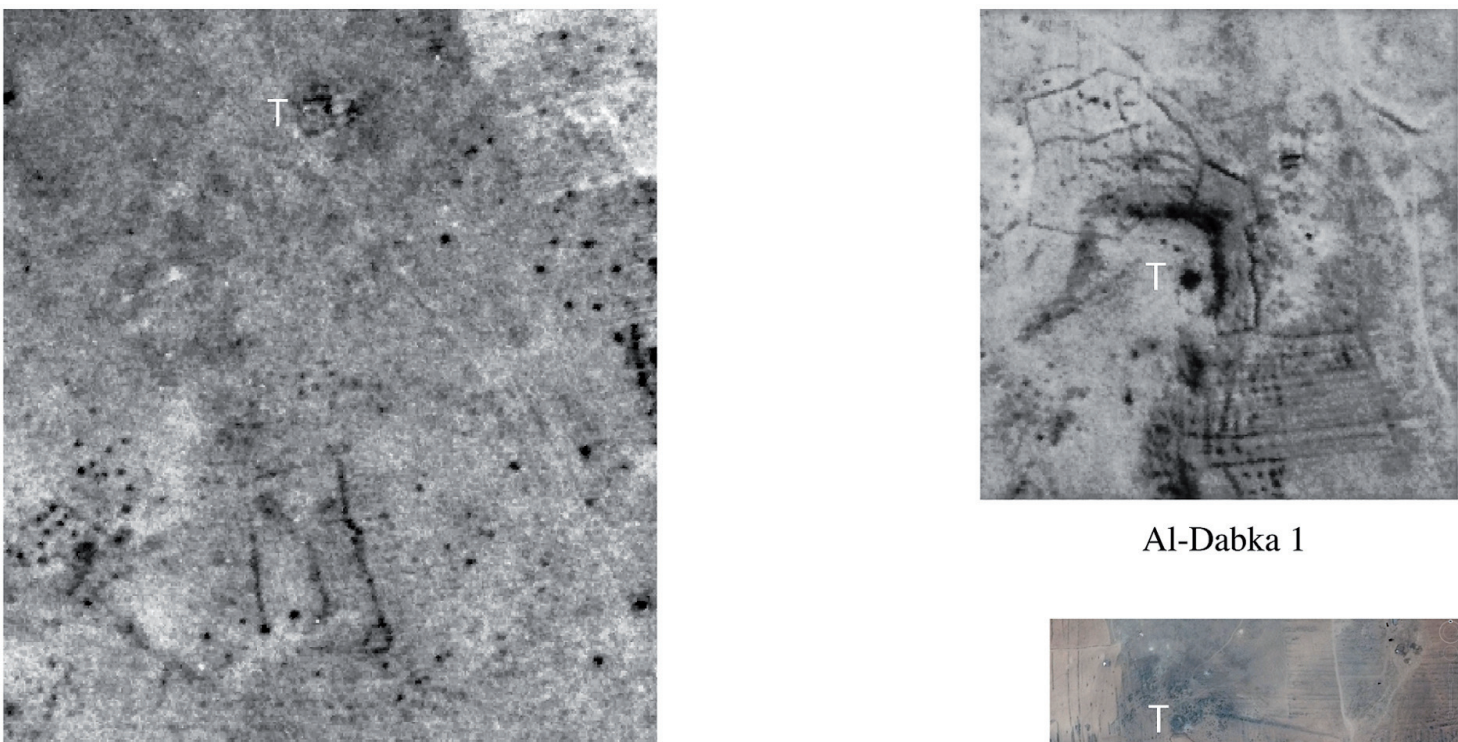

Al-Dabka 1
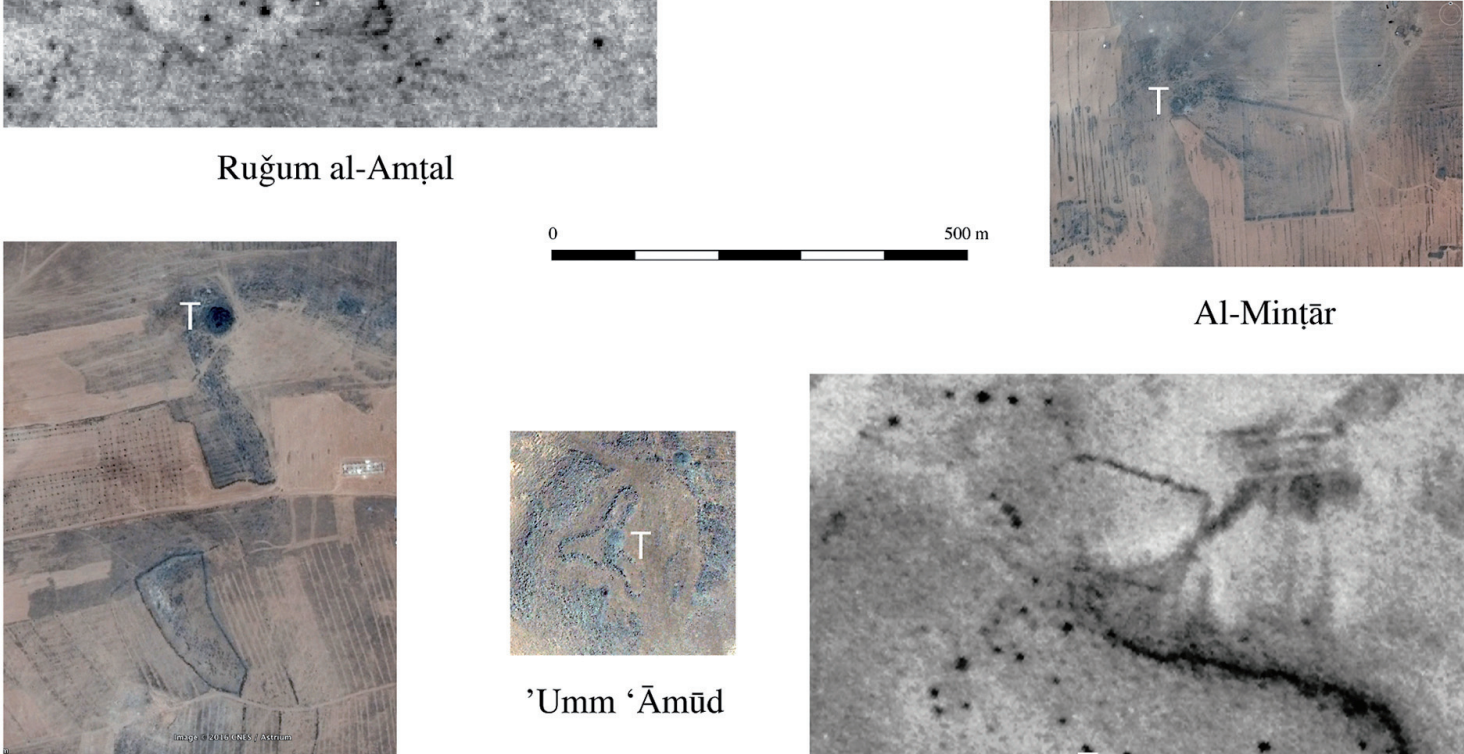

Al-Mințār

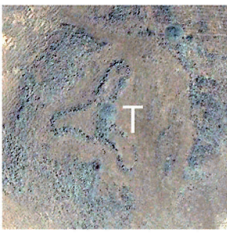

'Umm ‘'̄̄mūd

Ğabal Fārimha
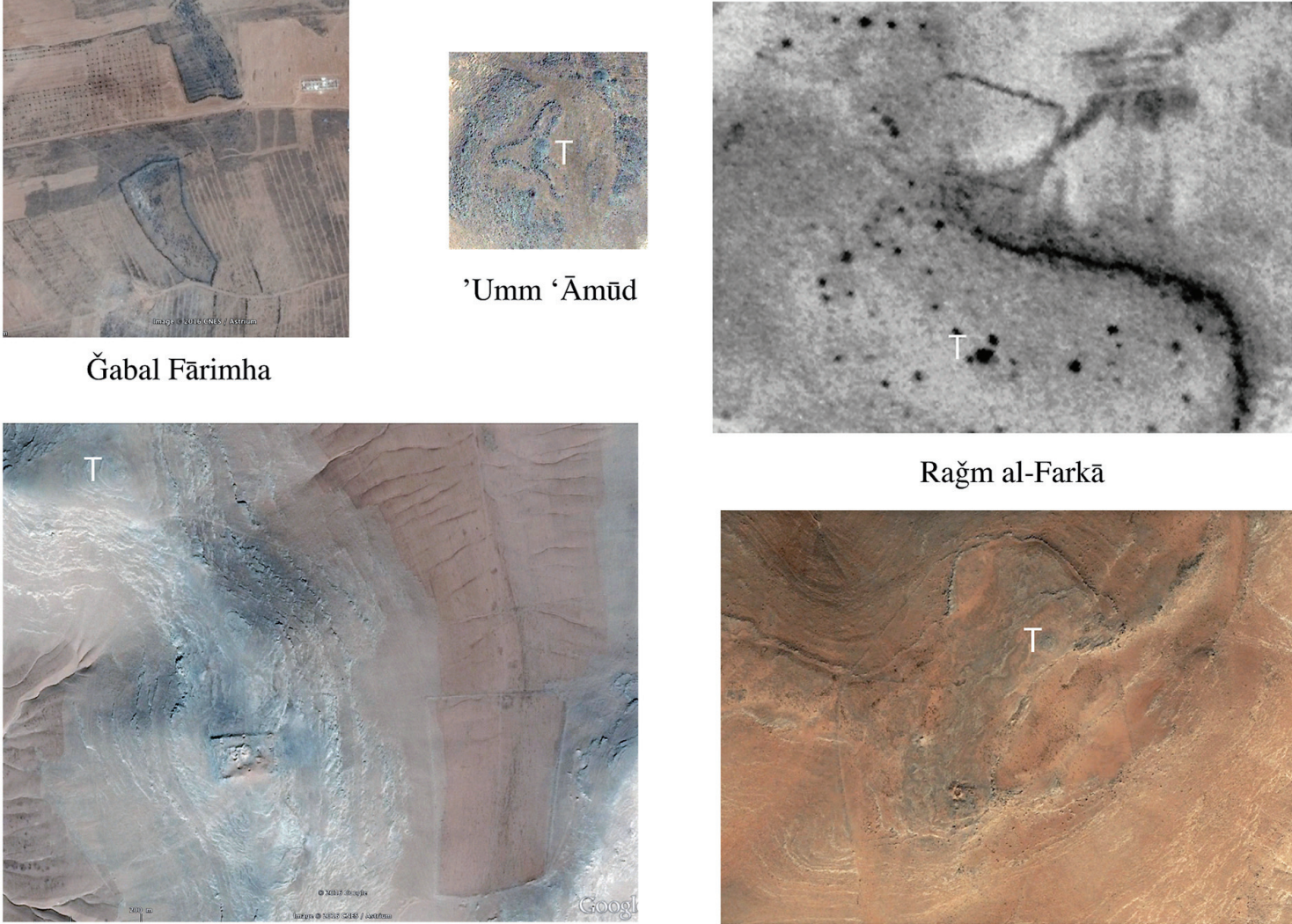

Rağm al-Farkā

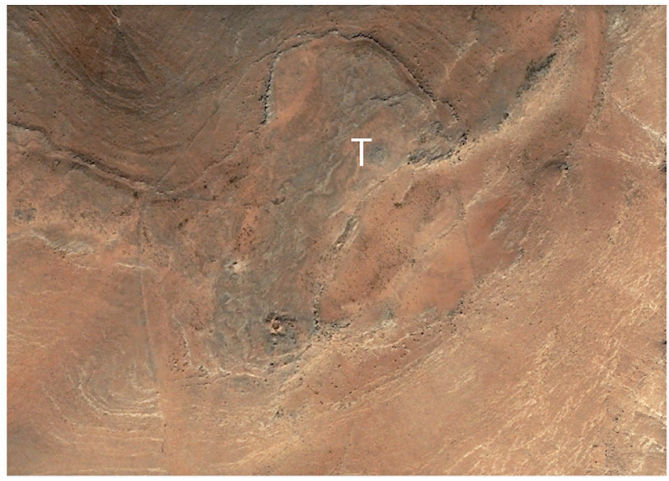

Al-Luğğ

Qaşr al-Mukarram

Fig. 17 - Images satellites (Google Earth, Corona et Microsoft) des tours (T) associées à des enclos. 
deux assises (fig. 17 et 18). Il est implanté en lisière sommitale ouest de la coulée. Aucune céramique n'a été collectée.

Hirbat 'Umm Ruğūm a été vue en 2010. Elle est implantée sur l'extrémité d'une langue de basalte, sur une croupe en position dominante avec vue sur les forteresses de Tall Abū Drīhna, Tall Șabḥa, Qal'at al-Hawāyis et la petite tour de Ruğum al-Harāyi ̌̆. Il s'agit d'un petit tell, de $35 \mathrm{~m}$ de diamètre (60 m à la base), avec une enceinte polygonale à retraits et redans, en blocs bruts de basalte pouvant dépasser le mètre. Sur le sommet, des buttes de terre crue, des arases de murs en petits moellons et peut-être des tombes sont probablement postérieures et correspondraient à la céramique de la fin de l'époque hellénistique et de l'époque romaine prélevée sur le site. Le reste du matériel est daté des âges du Bronze ancien IV (quelques tessons) et surtout du Bronze moyen IB et II.

Tabārat al-Zbīb 1 est un petit tell de $c a 75 \mathrm{~m}$ de diamètre mais qui se voit de loin. Il est implanté sur la terrasse alluviale d'al-Andarīn (Besançon et Geyer 2006: 26), dans la grande fayda centrale. Il domine une «ville basse» de $c a 200 \mathrm{~m}$ de long qui s'étend au nord-ouest, couverte par des buttes de terre crue représentant environ une vingtaine de bâtiments. Le matériel céramique est daté des âges du Bronze ancien IV, du Bronze moyen II et de l'époque romaine (cette dernière sur la ville basse uniquement). D'après les images aériennes, le sommet du petit tell est de plan carré, de ca $25 \mathrm{~m}$ de côté. Il pourrait s'agir d'une tour servant de relais entre les forteresses de Rağm al-Ṣawān et de Tall Abū Drīhna. De là, il est possible de voir la petite tour de Ruğum al-Harāyiğ et, théoriquement, le fortin de Tulūl Manatīr al-Hurūt, à 39 kilomètres au sud ${ }^{20}$.

Le site de Tilāl Ḥmaymāt al-Dāyr 2 a été vu en 1996. Il est implanté sur la dernière butte sud de la lunette ${ }^{21}$ qui borde le Mațh au sud-est et se présente sous la forme d'un petit tell rond de 20 à $25 \mathrm{~m}$ de diamètre. Une structure à sept gros blocs calcaires bien équarris $(1,10 \mathrm{~m}$ x $0,50 \mathrm{~m})$ forme une sorte de couloir en partie dégagé à l'intérieur, d'au moins $2,50 \mathrm{~m} \mathrm{x}$ $0,65 \mathrm{~m}$, formé par deux angles de murs conservés sur deux assises. La céramique récoltée date de l'âge du Bronze ancien IV et surtout du Bronze moyen II. Nous interprétons cet édifice comme ayant été une tour, relais entre les forteresses de Tall Abū Drīha et Tall al-'Ūgā et les positions plus au nord.

20. La limite de vision par tous les temps se situant aux environs de $20 \mathrm{~km}$, la vue entre les deux ne serait possible que par temps clair et plutôt de nuit pour percevoir des signaux lumineux.

21. Dune faite d'un matériau fin, de tracé concave face au vent (George 1993: 275), qui s'est constituée sur la lisière sud-est de la dépression du Mațh.

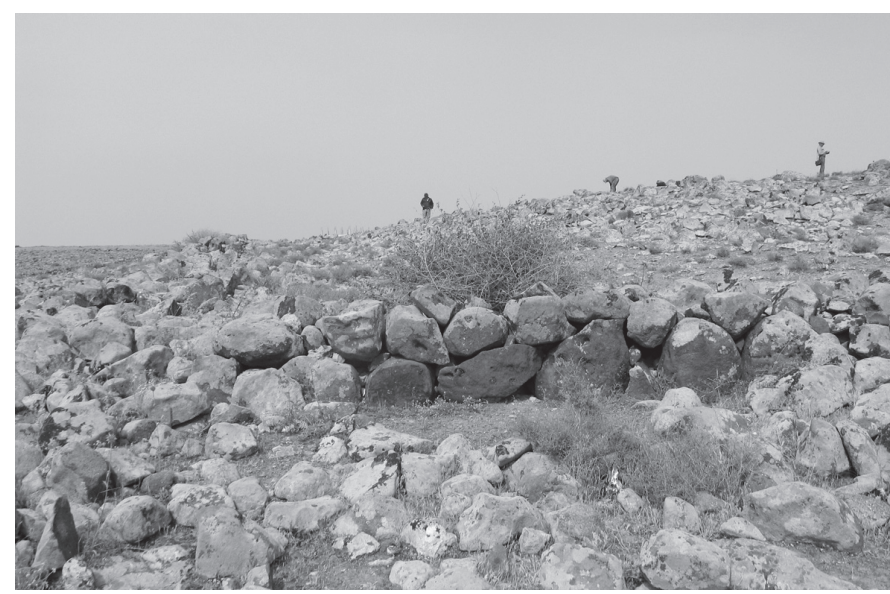

Fig. 18 - Mur de l'enclos de Ğabal Fārimha 2, vu vers l'est (photo M.-O. Rousset).

\section{LES PETITES TOURS}

Quelques tours rectangulaires, de 9 à $15 \mathrm{~m}$ de côté, s'insèreraient également dans le dispositif. Disposées sur des hauteurs, elles sont de construction plus simple et ne comportent généralement pas de glacis à leur base. Certaines ont pu servir d'intermédiaires entre des établissements qui ne peuvent être en contact visuel direct (comme celles de Ruğum al-Amțal et d'al-Ṭwayhīna 4), d'autres (Al-Mințār, Al-Dabka 1) sont localisées en lisière des établissements sédentaires, et complètent la surveillance des secteurs non visibles depuis les forteresses et les fortins. Dans la plupart des cas, elles ne sont pas très éloignées d'un fortin ou d'une forteresse. On peut donc supposer que ces tours étaient avant tout destinées à la communication ou à la surveillance plutôt qu'à un quelconque rôle défensif, dans la mesure où elles sont de petite taille et ne pouvaient héberger que quelques personnes. Ces tours ne semblent pas avoir été occupées longtemps ou de manière permanente car très peu de céramique a été observée. Enfin, certaines d'entre elles semblent associées à des enclos vides limités par des murs beaucoup plus larges et massifs que les murs d'enclos ordinaires, qui pourraient être des enceintes-refuges temporaires (supra, p. 130, fig. 17).

Al-Mințār a été vue en 2000, sur un point culminant d'une coulée basaltique démantelée d'où émergent des chicots. Le site, à peu près au centre d'un ancien corral de kyte détruit par des épierrements, est constitué d'un ensemble de structures en basalte. De grands cercles montés sur plusieurs assises, de $c a 10$ à $12 \mathrm{~m}$ de diamètre, sont construits en blocs de divers modules. Quatre groupes de tombes de $c a 4 \mathrm{~m}$ de diamètre, agglutinées 


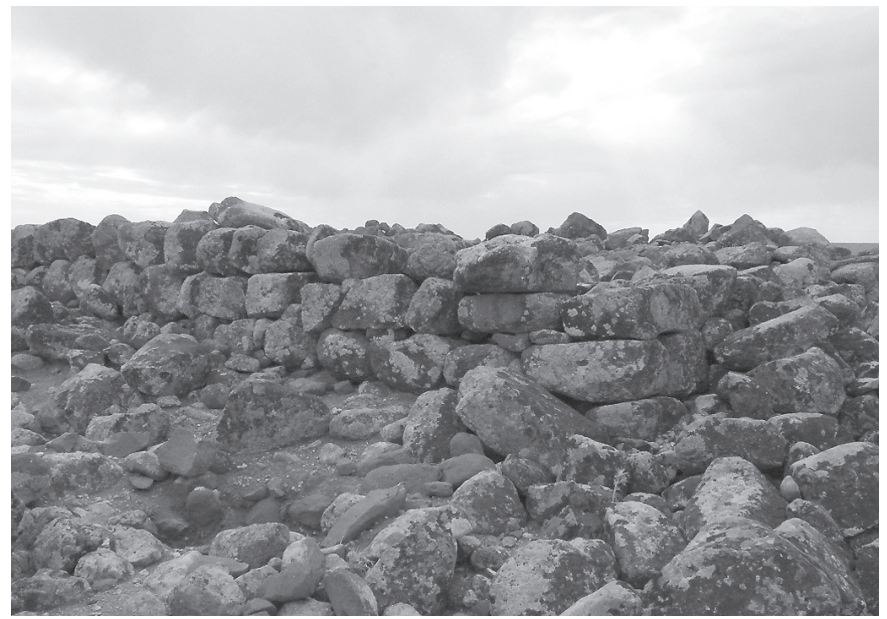

Fig. 19 - La tour d'Al-Dabka 1, vue depuis le sud-ouest (photo B. Geyer).

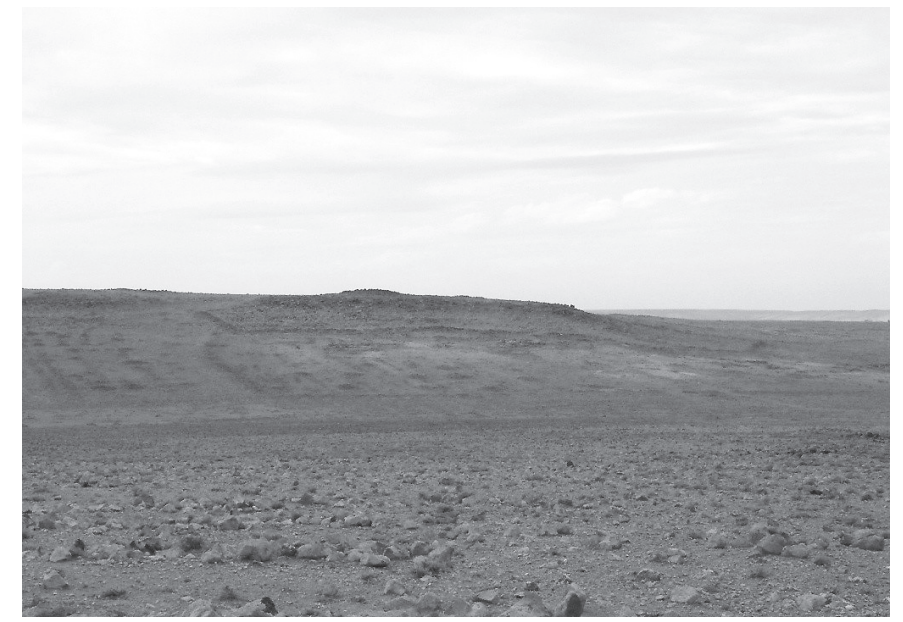

Fig. 20 - La tour d'Al-Dabka 1 avec son enclos, vus de l'est (photo M.-O. Rousset). et édifiées avec des blocs plus petits, recouvrent ces cercles. Toutes ont été pillées de longue date. En contrebas, un enclos quadrangulaire, de $130 \mathrm{~m}$ x $140 \mathrm{~m}$, avec des murs larges, limite des épierrements perpendiculaires à la pente. L'un de ses côtés s'étire en pointe jusqu'au sommet, où une masse de basalte de ca $16 \mathrm{~m}$ de côté marque la pointe de l'enclos. Son association avec un enclos montre qu'il s'agirait plutôt d'une tour que d'une construction funéraire. La céramique date surtout de l'âge du Bronze moyen I et II avec de rares tessons de l'âge du Bronze ancien et de l'époque hellénistique. Elle est en contact visuel direct avec les forteresses de Tall Abū Drīha et Qal'at al-Hawāyis ainsi qu'avec les tours de Ğabal Fārimha, Ruğum al-Amțal et Al-Dabka 1. Elle surveille la steppe au nord-est; en revanche, le Ğabal 'Ayza l'empêche de voir les secteurs au sud-est.

Al-Dabka 1, installée sur une surface un peu rabaissée de la coulée basaltique démantelée, permet de voir à la fois Qal'at al-Ḥawāyis, Al-Mințār et Tulūl Manatīr al-Hurūṭ. Elle complète la surveillance de la steppe au sud du Ğabal 'Ayza. En 2000, nous y avons vu une tour carrée, en gros appareil de blocs bruts de basalte métriques (de 0,50 à $1 \mathrm{~m}$ de longueur, fig. 19). La construction, de $c a 12 \mathrm{~m}$ de côté, est conservée par endroits sur quatre assises. L'intérieur est un chaos de blocs. Des tombes pillées se trouvent à proximité. La céramique de l'âge du Bronze moyen (dont un tesson avec des signes cunéiformes imprimés) est accompagnée de quelques fragments attribuables aux époques romaine et byzantine. Trois enclos accolés longent la corniche en contrebas de la tour, à l'est (1,2 ha et 5 ha; fig. 20 ) et au nord ( 3 ha).

Ruğum al-Harāyiğ est l'un des premiers sites des Marges arides à avoir été visité, dès 1993. Nous y sommes retournés en
1999 et en 2010. La tour est installée sur le sommet et en lisière d'une langue de coulée basaltique, sur la pente d'un promontoire qui domine toute la région, avec vue directe sur Tall Abū Drīhna, Tall Ṣabḥa et Rağm al-Ṣawān et les tours de Tabārat al-Zbīb 1 et Huirbat 'Umm Ruğūm. Elle est rectangulaire, de $10 \mathrm{~m}$ x 9 m, construite avec des murs de 2,30 m d'épaisseur et une entrée au sud. Elle est enchâssée dans un glacis circulaire, de $25 \mathrm{~m}$ de diamètre à sa base, en gros blocs de basalte polygonaux (fig. 21). La partie nord-ouest est la mieux conservée; ailleurs, les pierres du glacis ont été débitées, ne laissant subsister que des éclats de taille. Elle a été incluse dans un fortin plus tardif dont elle a constitué l'angle nord-ouest. La céramique trouvée sur la tour date des âges du Bronze ancien IV, du Bronze moyen II et des époques hellénistique et romaine. Il est par conséquent difficile, sans étude plus poussée, d'attribuer une période spécifique à chaque aménagement. Cependant, la position topographique et la présence de céramique du Bronze moyen plaident pour la présence d'une tour à cet emplacement dès cette période. La tour aurait alors servi d'intermédiaire entre Tabārat al-Zbīb 1 et Tall Abū Drīha. Un enclos à murs larges, dont seul le côté occidental est conservé, prolonge les constructions vers le sud.

Al-Ṭwayḥīna 4, implantée à l'extrémité sud-est du Ğabal Šbayț, sur le sommet d'une butte témoin en vue de Tall Draḥam, était déjà connu avant notre passage, en 1999 et en 2002, pour son monastère byzantin (Mouterde et Poidebard 1945: 172; Haase 1983: 71; Musil 1928: 202). Ce dernier s'est révélé être construit autour d'un noyau central composé d'une tour carrée de $9 \mathrm{~m}$ de côté, avec des murs de 1,20 m d'épaisseur, en gros blocs de basalte non taillés à appareil polygonal, qui servent de base à une tour plus étroite, avec des murs de $1 \mathrm{~m}$ d'épaisseur, en 


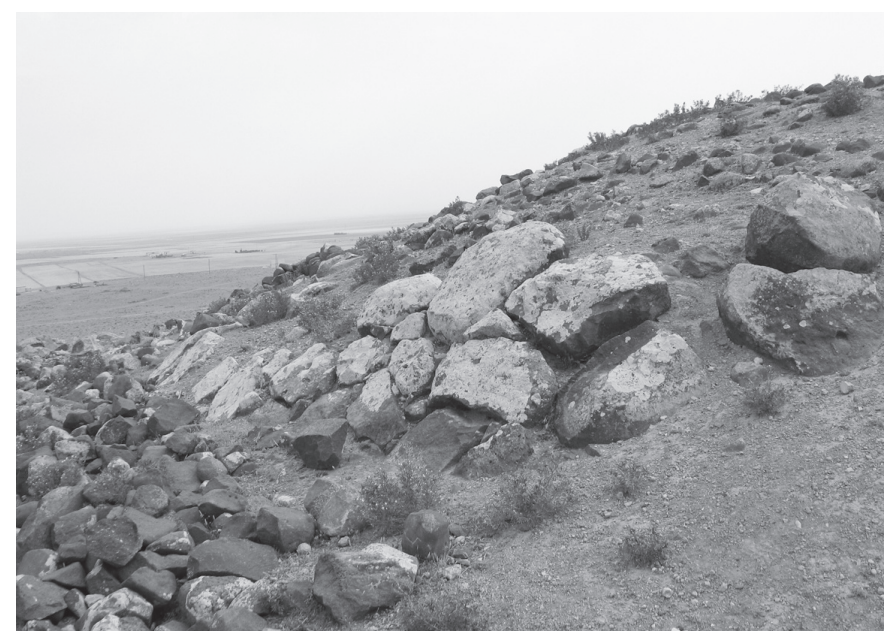

Fig. 21 - Le glacis de la tour de Ruğum al-Harāyi $\breve{g}$, côté ouest vu vers le nord (photo M.-O. Rousset).

petit appareil (fig. 22). Même si aucune céramique du Bronze moyen n'a été notée, le matériau employé et la disposition rappellent fort les constructions de l'âge du Bronze. Il pourrait y avoir là les restes d'une tour, située à égale distance de Tall Draḥam et de Rağm al-Ṣawān et servant de relais entre les deux.

\section{UN RÉSEAU DÉFENSIF ORGANISÉ?}

L'analyse des sites prospectés a permis de définir leur nature à l'âge du Bronze moyen mais aussi de distinguer des vestiges de très petites installations, implantées dans des secteurs aux ressources faibles, de ceux caractérisant les établissements sédentaires de l'ouest. Il n'y a en effet aucun établissement que l'on pourrait qualifier de sédentaire à l'est de la zone fortifiée (fig. 1). Sa limite correspond également peu ou prou à l'isohyète des $200 \mathrm{~mm}$ de précipitations annuelles, traditionnellement considérée comme la limite des cultures pluviales. Les forteresses sont dans le domaine des sédentaires; les tours et fortins plus proches de la zone «vide», où circulaient probablement des nomades, sans que nous puissions pour l'instant les identifier par des traces matérielles. L'élaboration et la construction de ce réseau défensif semblent par conséquent liées à cette distinction sociale et environnementale.

La taille des différents types d'implantations semble répondre à un rapport simple (la moitié) : plus de $120 \mathrm{~m}$ de diamètre pour les forteresses, en moyenne $60 \mathrm{~m}$ de diamètre pour les fortins, $30 \mathrm{~m}$ pour les grandes tours et de 15 à $9 \mathrm{~m}$ pour les petites tours. La taille des sites, mais aussi leur disposition les

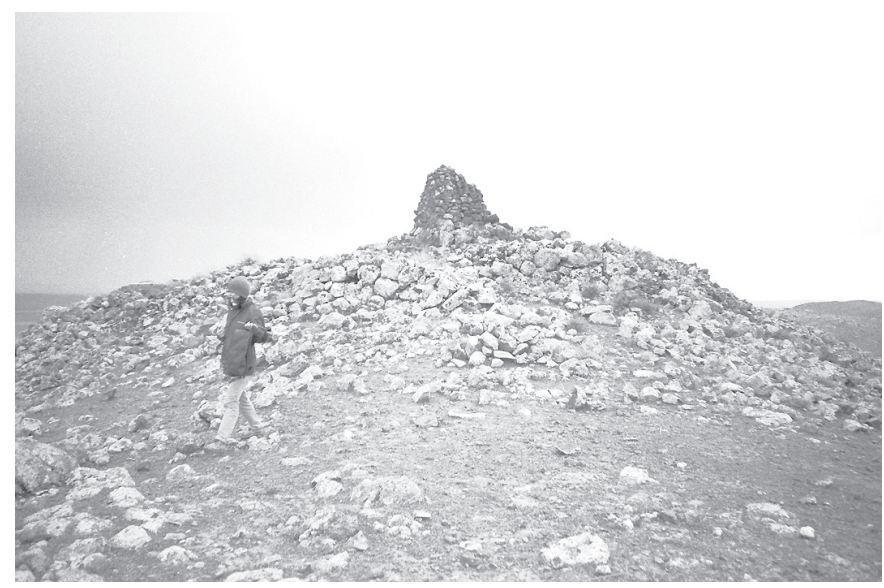

Fig. 22 - La tour du monastère d'al-Twayhīna 4, vue de l'ouest (photo B. Geyer).

uns par rapport aux autres, reflètent une hiérarchisation des installations défensives. Les forteresses les plus vastes sont installées dans les secteurs à plus forte densité de sites et au potentiel agricole le plus élevé (fig. 23). Pouvaient-elles servir de refuge pour les populations en cas d'attaque, en complément des fortifications des agglomérations? Il est à noter que, du côté des Palmyrénides, la taille des tours et des fortins, ainsi que leur nombre sont plus réduits: il ne s'agit pas de la principale ligne de défense. Par ailleurs, il n'y a que peu d'installations humaines, même de nomades, au-dessus de $650 \mathrm{~m}$ d'altitude.

Létude de la répartition des différentes installations montre qu'une logique précise semble avoir prévalu lors du choix de leur implantation, en favorisant les meilleurs emplacements en termes de défense, de surveillance et de communication (par signaux lumineux ou fumée, voir infra, p. 152). La localisation topographique des différentes positions est une constante pour tous les sites du réseau: le critère de choix dominant est celui d'un lieu permettant une vue large, même lorsqu'un point plus élevé se situe à proximité. La position en hauteur, sur le pourtour de la dépression centrale, entérine l'idée d'une surveillance tournée vers l'est et vers la steppe aride.

Les forteresses sont disposées selon une ligne nord-sud et espacées de 20 à 13 km, de Rubbā à Tall al-'Ūgā. Une autre ligne de fortification part de Tall Abū Drīha vers l'est. De ce point, elles sont espacées de 18,5 à 13,5 km. La plupart disposent d'un angle de vision très ouvert sur la steppe. Bien qu'optimal, il n'est parfois pas complet car, dans plusieurs cas, des reliefs s'interposent entre la forteresse et la steppe. Des tours avancées ont par conséquent été érigées pour pouvoir surveiller la totalité du paysage. Ce serait le cas de Tabārat al-Zbīb 1, qui permet de com- 


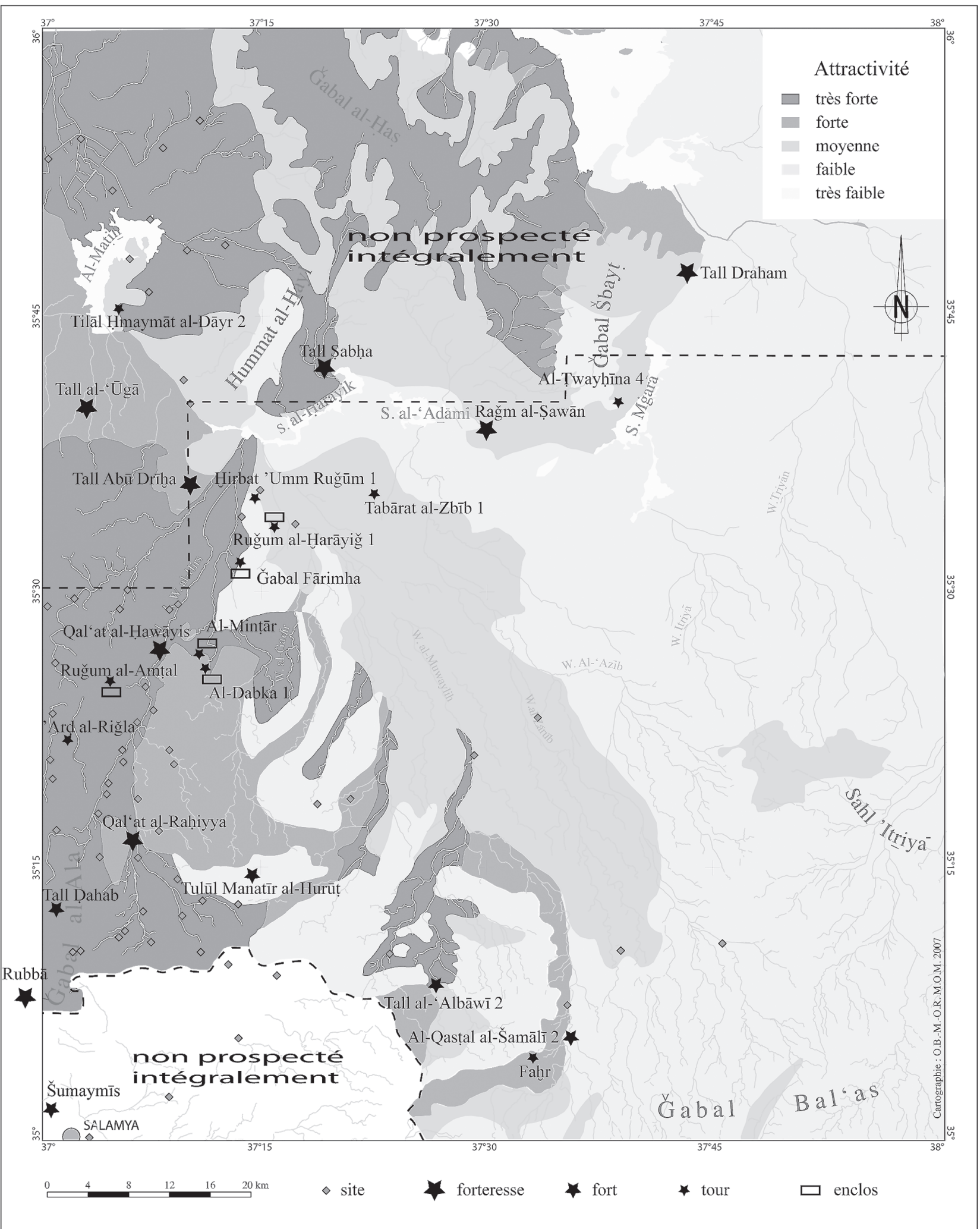

Fig. 23 - Carte d'attractivité de la zone des Marges arides avec les sites et fortifications de hauteur de l'âge du Bronze moyen (cartographie MOM, O. Barge, M.-O. Rousset). 
pléter la vision de Tall Șabhạ, par delà l'élévation du terrain au sud de la sebkha et de Ruğum al-Harāyiğ qui complète la vue de Tall Abū Drīha et surveille les zones les plus orientales. Les trois tours au sud-est de Tall Abū Drīhna mettent cette forteresse en relation avec les parties nord (Hirbat 'Umm Ruğūm), est (Ruğum al-Harāyiğg) et ouest (Ğabal Fārimha) du réseau. Celles à l'est de Qal'at al-Hawāyis regardent l'une vers le nord-ouest (Al-Mințār) et l'autre vers l'est (Al-Dabka 1).

Enfin, certains amoncellements de pierres, visibles de loin sur des emplacements particuliers (bordure de plateau, ligne de partage des eaux...), dans le même alignement que des forteresses et parfois à mi-chemin, ont pu avoir plusieurs fonctions. Ils pourraient avoir été destinés à servir d'intermédiaires pour «répéter» les signaux (répéteurs) en cas de visibilité réduite mais ceci est peu probable car sans réelle nécessité (infra, p. 152); ils peuvent aussi avoir servi de jalons topographiques pour l'implantation des édifices de surveillance et de défense ${ }^{22}$. Ceci expliquerait pourquoi très peu, voire aucune céramique n'a été trouvée sur ce type de construction, malgré nos recherches. Il pourrait également s'agir de tombes d'une toute autre époque, le matériel étant généralement abondant dans les tombes de l'âge du Bronze, dont la majeure partie a été pillée depuis longtemps. Une fonction funéraire pour ce genre de lieux est attestée à des époques plus anciennes ou plus tardives (à partir de la fin de l'époque hellénistique).

Le système mis en évidence par la prospection s'étale sur toute la zone prospectée, soit au minimum une centaine de kilomètres. On peut supposer qu'il y a là la majeure partie du réseau défensif avancé.

\section{LES AUTRES ÉTABLISSEMENTS POTENTIELLEMENT LIÉS AU RÉSEAU}

Se pose la question de l'articulation de ce réseau avec les grandes villes contemporaines du pourtour de la steppe, notamment Qatna et Ebla. On notera déjà que leurs emplacements, du strict point de vue de la répartition des implantations, correspondent bien au maillage régulier observé pour les forteresses (fig. 24). Nous y reviendrons.

Selon la logique définie ci-dessus, plusieurs établissements qui n'ont pas été vus sur le terrain par l'équipe des «Marges arides» pourraient s'intégrer au réseau de défense ou de surveillance et de communication. Ils répondent aux mêmes critères géographiques, morphologiques et topographiques que

22. Nous remercions Damien Laisney pour cette suggestion. les sites décrits ci-dessus. Certains se trouvent à l'intérieur de la zone: ce sont les sites qui n'ont pas été vus du fait de leur localisation à l'intérieur de camps militaires contemporains ou qui ont été détruits récemment par l'installation du réseau de téléphonie mobile. Pour ces cas-là, la pérennité de l'occupation militaire et le potentiel en terme de télécommunication sont, en eux-mêmes, une confirmation de leur valeur dans un réseau défensif et de surveillance.

D'autres positions défensives potentielles jouxtent la région des Marges arides. Certaines parmi ces dernières ont été prospectées par des collègues ou ont fait l'objet de fouilles. Il est néanmoins difficile de suivre ce réseau de fortifications en dehors de la zone des Marges arides car la plupart des prospections qui ont eu lieu dans les régions limitrophes se sont avant tout attachées, pour les époques anciennes, à l'exploration des tells $^{23}$. Les tours notamment n'ont pas été répertoriées. Il est parfois difficile de les distinguer sur les images aériennes lorsqu'elles n'ont pas été prospectées au sol. Certains de ces sites attestent une occupation plus tardive mais presque toujours de nature funéraire: fréquemment des tombes à cercle qui s'agglutinent autour d'une tombe plus importante. Le nombre élevé de cairns et de tombes disposés sur des crêtes ou des points marquants du paysage n'a pas permis leur étude systématique par la mission Marges arides, celle-ci s'étant d'abord concentrée sur les autres formes d'anthropisation du paysage. Néanmoins, l'utilisation de certaines de ces constructions à plusieurs époques pourrait s'expliquer par leur position topographique adaptée à la surveillance du territoire: il pourrait alors s'agir de tours ${ }^{24}$.

Lanalyse attentive des photographies aériennes (1958) et des images satellitaires Corona (1968, 1969 et 1970), Google Earth et Microsoft, ainsi que des cartes topographiques au 1:50 000 a permis d'identifier des sites qui pourraient faire partie intégrante de ce réseau, notre intense pratique du terrain nous fournissant des clés pour leur interprétation. Chaque emplacement probable selon les critères définis ci-dessus a été vérifié. Ces résultats, bien qu'hypothétiques, sont confortés par l'absence, autour des sites retenus, d'établissements similaires. Les sites présentés dans cette partie découlent de cette analyse raisonnée de la documentation.

23. Mantellini 2013. Cependant, dans la région de Homs, un projet a été conduit sur les cairns: Philip and Bradbury 2010: 146-148; Bradbury and Philip 2011.

24. Une étude spécifique des cairns de la région basaltique de Homs a montré qu'ils ne correspondaient pas forcément toujours à des tombes: "Analysis has shown that at $60 \%$ of clusters where square and rectangular cairns are visible there is some evidence for multi-period activity and possible re-use of monuments." (Bradbury and Philip 2011: 175). 


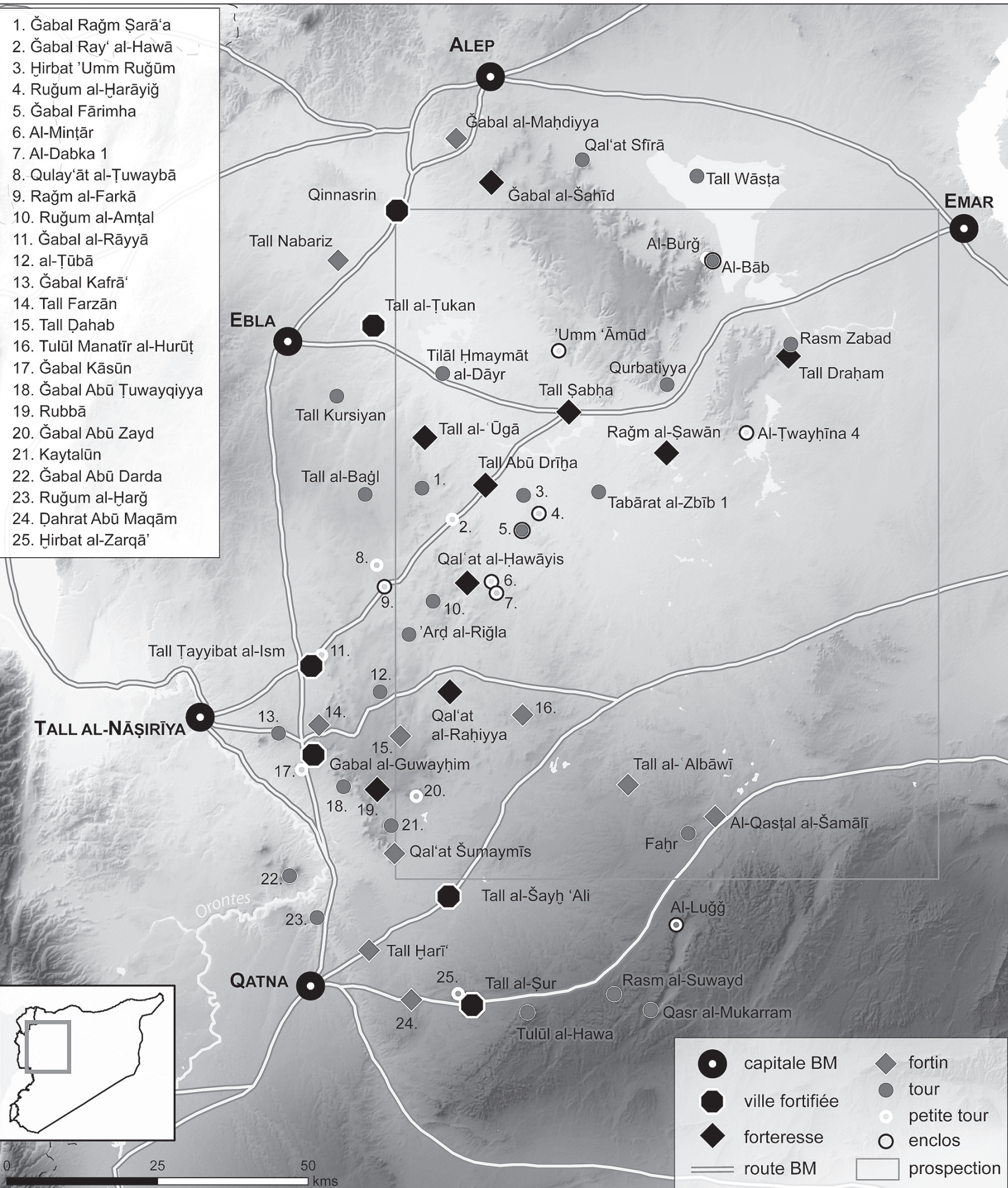

Fig. 24 - Le système défensif et sa relation avec les villes majeures et les routes connues ou supposées à l'âge du Bronze moyen (d'après Joannès 1996). Le cadre représente la zone prospectée par la mission des Marges arides (E. Régagnon, M.-O. Rousset). 


\section{LES GRANDES VILLES FORTIFIÉES À LA LISIÈRE DE LA STEPPE}

Plusieurs grands sites de la lisière de la steppe, connus pour avoir été occupés à l'âge du Bronze moyen, sont donc contemporains du réseau décrit ci-dessus. Il s'agit à la fois de grosses villes fortifiées et de forteresses de hauteur, qui semblent bien s'imbriquer, du point de vue de leur répartition dans l'espace, dans ce réseau défensif. En dehors des très grands sites connus pour la période (Ebla, Tall al-Nāṣirīya, Qatna), ce sont les plus vastes installations repérées sur le pourtour de la steppe. Certaines ont été étudiées, d'autres sont inédites et n'ont pas même fait l'objet de prospection. Elles présentent des traits communs par leurs proportions (surface de plus de $40 \mathrm{ha}$ ), leur disposition par rapport aux forteresses et aux très grandes villes (les capitales de royaumes connus pour la période) et leur emplacement le long des grands axes de circulation. Elles pourraient compléter la ligne des grandes forteresses dans laquelle elles s'insèrent en respectant l'espacement régulier. Il s'agit (fig. 25), dans la partie sud, des sites de Tall al-Šayh 'Alī (à 21,4 km de Rubbā) et de Tall al-Ṣūr (à 18,3 km de Tall al-Šayh 'Alī) et, dans la partie nord, de Qinnasrīn (à 26 km d'Alep) et de Tall al-Ṭūkān (à 20,6 km de Tall al-'Ūgā et à $20 \mathrm{~km}$ de Qinnasrīn). Entre ces deux secteurs, deux grands sites inédits présentent des similitudes, pour l'un, avec les places fortes de plaine (Tall Țayyibat al-Ism) et, pour l'autre, avec Qinnasrīn (Ğabal al-Guwayḥim).

Tall al-Šayh 'Alī, au sud-est de Salamya, est un très grand site avec une ville basse et une acropole, toutes deux fortifiées. De là, le regard atteint directement Rubbā et Qal'at Šumaymīs, visible au centre de l'espace libre entre les collines qui l'entourent à l'est et au sud. Nous ne l'avons que rapidement visité en 1997 car il était en dehors de la zone d'étude. Il se situe au bord du Wādī al-Hafiyya, sur le glacis descendant du Ğabal al-Bal'as. La ville haute, de plan pentagonal, s'étale sur $270 \mathrm{~m} \mathrm{x}$ $300 \mathrm{~m}$ et domine la plaine environnante de $c a 7 \mathrm{~m}$ et la ville basse de $c a 4 \mathrm{~m}$. Les vestiges d'un bâtiment rectangulaire, de $45 \mathrm{~m}$ x $30 \mathrm{~m}$ subsistent dans sa partie sud. La ville basse est de plan grossièrement rectangulaire (dimensions maximales: $580 \mathrm{~m}$ par $460 \mathrm{~m}$ ). Elle est entourée d'un rempart de $c a 5 \mathrm{~m}$ de largeur et d'un très grand fossé (large de $30 \mathrm{~m}$ au nord et de $40 \mathrm{~m}$ à l'est et au sud). Plusieurs petites buttes à l'intérieur correspondent à des bâtiments en gros blocs de pierre. De nombreux objets en basalte ont été vus. La céramique observée datait de l'âge du Bronze et de l'époque romaine. Une datation plus précise en a été faite par la mission syrienne de Qatna en 2008. Les périodes anciennes représentées sont l'âge du Bronze ancien IVA et B, l'âge du Bronze moyen et l'âge du Fer.
Depuis Tall al-Šayb 'Alī, il n'est pas possible de voir directement Qatna, mais un site qui s'apparente à un fortin, disposé sur l'axe qui relie ces deux villes (Tall Harī') pourrait avoir servi d'intermédiaire (voir infra, p. 143).

Tall al-Ṣūr, à $27 \mathrm{~km}$ à l'est de Qatna et à $18 \mathrm{~km}$ au sud de Tall al-Šayh 'Alī, est implantée dans la vallée du Wādī al-Hyāya, limitée au nord par l'abrupt du Ğabal al-Habla et au sud par les contreforts du Ğabal al-Šawmariyyā. Cette configuration topographique offre un axe de circulation naturel estouest. Le site a été prospecté dans les années 1950 par M. Tallon, fouillé en 1984 par M. Al-Moussli, puis en 20092010 sous la responsabilité de G. Mouamar (Tallon 1956 et 1957; Al-Moussli 1985; Mouamar 2014). D'une surface totale de 720 m x 580 m (662 m x 420 m sans les fossés, soit 24 ha intra muros), il se compose de deux grandes parties. Au nord, une partie ovale de $352 \mathrm{~m}$ de largeur est entourée d'un mur massif protégé par un fossé (de 30 à $35 \mathrm{~m}$ de largeur conservée au nord). Au moins une porte donnait accès à l'intérieur, côté nord, par un passage aménagé au-dessus du fossé, et une autre porte communiquait avec la partie sud. Presque au centre se trouve une éminence de $c a 80 \mathrm{~m}$ de diamètre avec les vestiges de trois enceintes rectangulaires concentriques dont la plus interne est constituée d'un double mur en gros blocs non équarris.

Une partie rectangulaire, de même largeur que l'enceinte septentrionale, s'étend sur $420 \mathrm{~m}$ par $\mathrm{ca} 250 \mathrm{~m}$ au sud. Elle est également entourée de forts remparts et d'un large double fossé, formé de deux creux de 8 à $30 \mathrm{~m}$ de largeur séparés par un talus de 4 à $12 \mathrm{~m}$ de largeur. Deux portes percent cette défense méridionale et des passages sont aménagés sur les fossés pour y accéder. Un tell trapézoïdal $(90 \mathrm{~m}$ x $70 \mathrm{~m}$; surface sommitale de $40 \mathrm{~m}$ de côté) s'élève dans l'angle sud-est de la fortification. Deux murs parallèles espacés de $6 \mathrm{~m}$, à mipente, sont construits en gros moellons non équarris. Pour Maurice Tallon (1956:56), ce tell et celui au centre de la partie nord ont dû servir d'observatoires. Les travaux récents montrent que la première occupation, à l'âge du Bronze ancien IV, correspond à une ville pratiquement circulaire qui occupait la partie nord. Elle a été refondée à l'âge du Bronze moyen I avec un plan rectangulaire qui a englobé la première ville. C'est à cette époque que les fossés ont été creusés ou agrandis et la terre qui en a été extraite a été utilisée pour renforcer les remparts en pierre du $3^{\mathrm{e}}$ millénaire ${ }^{25}$. Le site est occupé aux âges du Bronze ancien IV, du Bronze moyen I et II, avec une occupation plus réduite au Bronze récent, au Fer II et enfin à

25. G. Mouamar (2014: 99) souligne qu'un fait similaire a été observé à Ebla. 


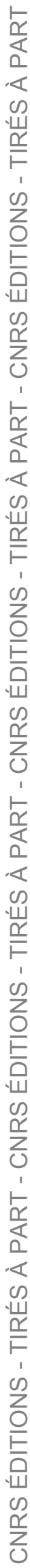
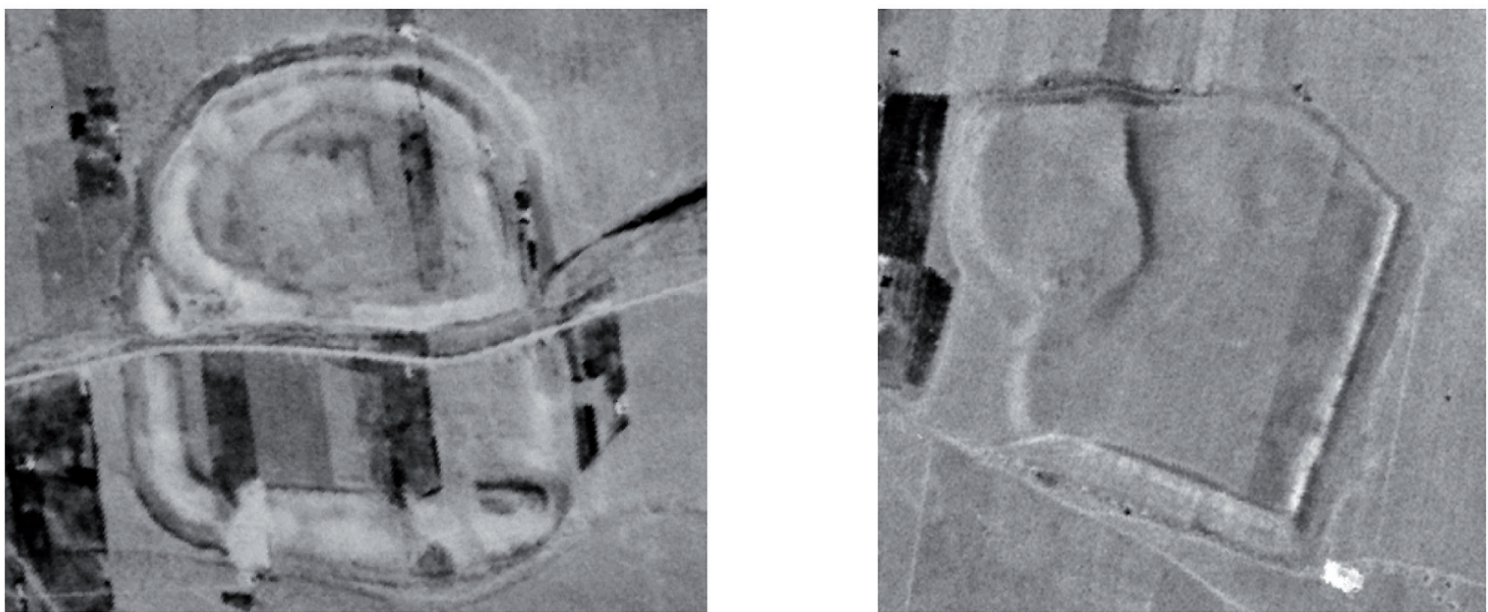

Tall al-Ṣūr

$500 \mathrm{~m}$

Tall al-Šayh 'Alī

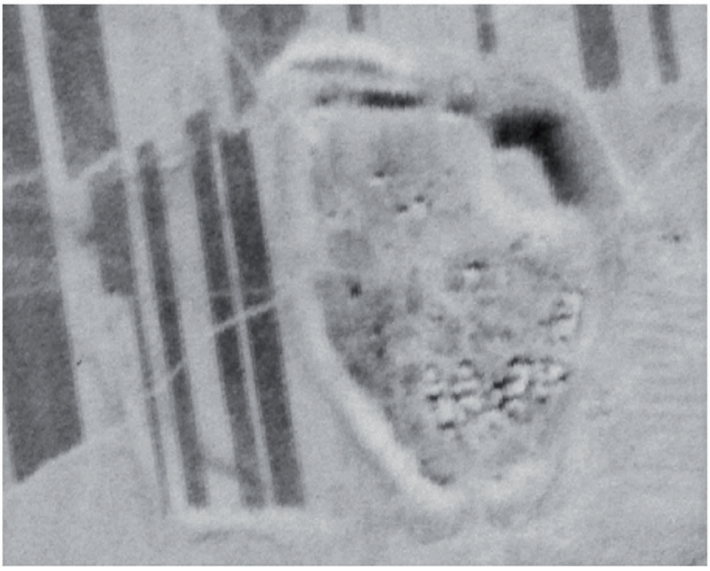

Tall Țayyibat al-Ism

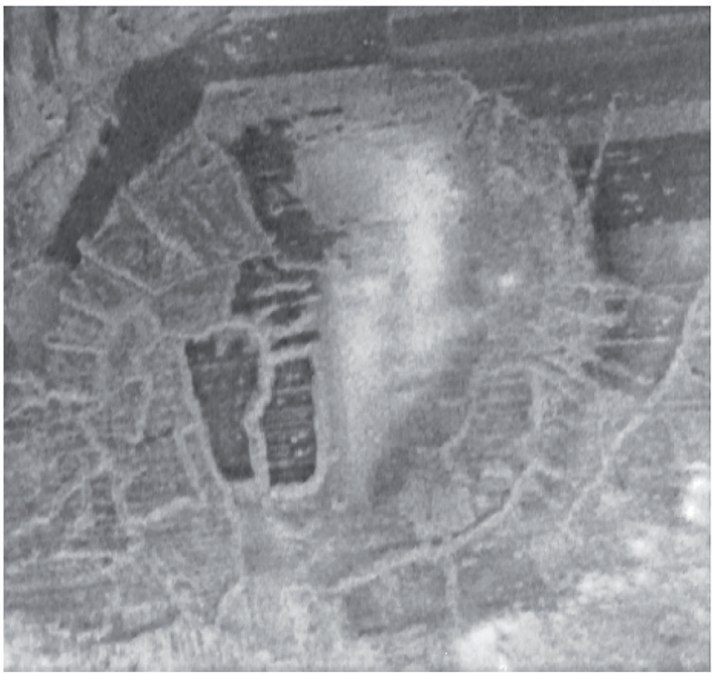

Ğabal al-Ġuwayḥim

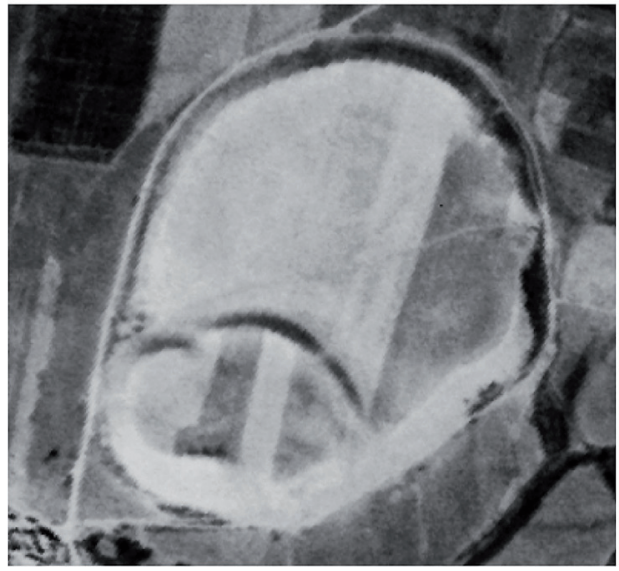

Tall al-Ț̄kān

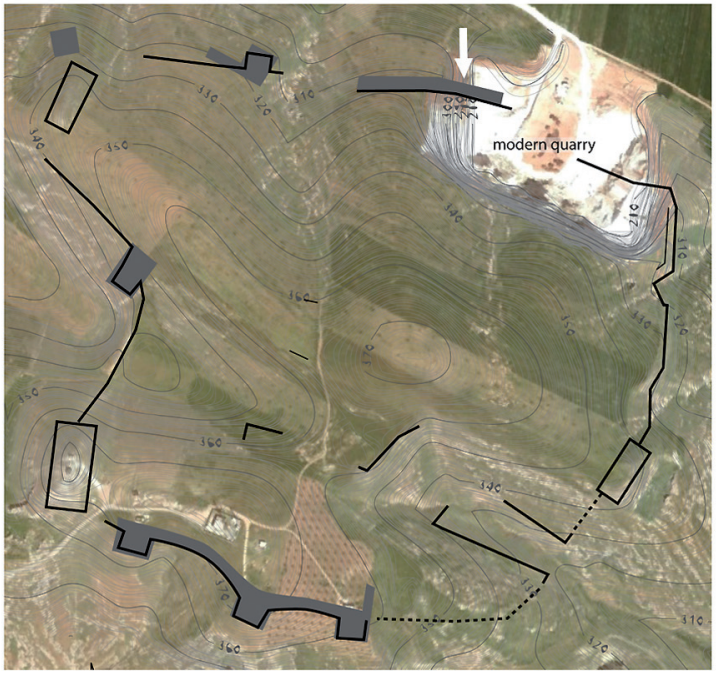

Qinnasrīn

Fig. 25 - Images satellites (Corona et Google Earth) des grandes villes fortifiées. 
l'époque byzantine ${ }^{26}$. Pour les fouilleurs, cette ville, à la lisière de la steppe aride, contrôlait l'accès aux zones agricoles de la Syrie occidentale.

La forteresse ne voit pas Qatna, ni Tall al-Šayh 'Alī, mais pourrait communiquer avec elles par fortin et tour interposés (infra, p. 143).

Qinnasrīn, où a récemment été mise en évidence une fortification ancienne, sur le sommet de la montagne qui domine la ville antique, est situé à un emplacement stratégique majeur ${ }^{27}$. En effet, depuis cette extrémité la plus orientale du Ğabal al-'Iss, la vue s'étend dans toutes les directions, notamment sur tout le bassin du Mațh. Sur cette hauteur, une forteresse, édifiée au début de l'époque islamique (Rousset 2013a et b), s'appuie sur des vestiges antérieurs, dont un mur de brique crue, construit directement sur la roche et large de plus d'une dizaine de mètres. Ce mur a été observé, pour son côté nord, dans la coupe réalisée par l'excavation d'une carrière récente (fig. 26) et il est visible au sud où subsistent trois grandes tours reliées par des courtines courbes $^{28}$. D'après la céramique, cette forteresse ancienne peut être attribuée à l'âge du Bronze moyen I et II ${ }^{29}$. La forteresse de Qinnasrīn répond aux mêmes critères géographiques et stratégiques que les forteresses de hauteur. En revanche, elle est beaucoup plus grande puisqu'elle mesure $c a 700 \mathrm{~m}$ de côté, soit une surface minimum estimée à ca 35 ha. Elle est située à mi-chemin de deux capitales de royaumes contemporains de l'âge du Bronze: Yamhad (Alep) et Ebla (Tell Mardikh).

Tall al-Ṭūkān est à mi-chemin entre Qinnasrīn et Tall al-'Ūgā, protégée à l'est par les marais du Mațh. Elle a été prospectée à plusieurs reprises depuis 1925, par W.F. Albright ${ }^{30}$ puis par M. Liverani (1965) et par A. De Maigret (1978). Quatre campagnes de fouilles, sous la direction de P. Matthiae ont eu lieu entre 1978 et 1993. De nouveaux travaux archéologiques ont repris, depuis 2003, sous la direction de F. Baffi (en dernier lieu, Baffi and Peyronel 2014). Ce grand tell ovale, de $650 \mathrm{~m}$ x $500 \mathrm{~m}$, s'élève jusqu'à $30 \mathrm{~m}$ de hauteur. Il été occupé en continu de l'âge du Bronze ancien jusqu'à l'époque byzantine, avec une extension maximale à l'âge du Bronze moyen II.

26. Voir le plan dans Mouamar 2014: 108.

27. Qinnasrīn est étudié par une mission syro-française sous la direction de Youssef Kanjou et Marie-Odile Rousset, sous l'égide du Ministère français des Affaires Étrangères, de la Fondation Max van Berchem et de la DGAMS.

28. Lors de la construction d'une maison à l'emplacement de cette tour, des assises de briques crues ont été observées. Le mur nord, vu et photographié à la fin de la dernière mission de terrain, n'a pu être étudié.

29. L'étude de C. Kepinski portant sur «La céramique de l'âge du Bronze» paraîtra dans Rousset M.-O. (dir.), Qinnasrin II, Chalcis / Qinnasrin. Évolution du site d'après les prospections (âge du Bronze moyen, II ${ }^{e}$ s. av. - XIV e. ap. J.-C.).

30. Cité dans Liverani 1965.

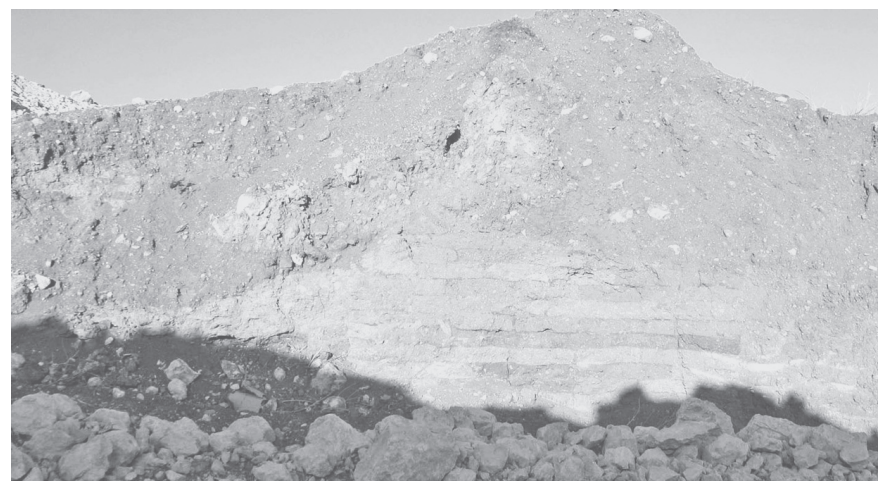

Fig. 26 - Qinnasrīn. Le rempart en brique crue coupé par le côté ouest de la carrière moderne, vu vers l'ouest (photo M.-O. Rousset).

Une ville basse est entourée d'un rempart de $1,5 \mathrm{~km}$ de longueur et une acropole de $330 \mathrm{~m}$ x $250 \mathrm{~m}$, au sud-ouest, est également ceinte de murs défensifs. Les murailles de la ville basse sont construites sur une levée de terre de $30 \mathrm{~m}$ de largeur. Elles sont en brique crue, avec des tours circulaires, et percées de trois portes monumentales en pierre. Les murailles de la ville haute, en brique crue, de 4,50 m de largeur, ont un glacis et des contreforts rectangulaires. Une porte donnait sur la ville basse et une autre directement sur l'extérieur. Des structures de l'âge du Fer et une grande résidence fortifiée d'époque perse occupent cette acropole.

Tall Țayyibat al-Ism se situe sur une voie de passage entre la vallée de l'Oronte et la Sabhat al-Harāyik, profitant d'une succession de vallées, probablement sur une ligne de faille, passant par Rağm al-Farkā. La zone a été prospectée par J. Lassus. Ce dernier en a livré une brève description dans laquelle il mentionne surtout son emplacement par rapport aux routes romaines et plus tardives (Lassus 1935 : 185-186). Nous avons pu l'identifier grâce aux images satellites (fig. 25). Il s'agit d'un grand site pentagonal, de $700 \times 600 \mathrm{~m}$ avec un large fossé ( $c a 30 \mathrm{~m}$ ) visible au nord, soit une surface totale de 36 ha. La moitié orientale est occupée par une ville haute, de 375 x $500 \mathrm{~m}$ (13,5 ha à l'intérieur), avec une acropole de $150 \times 120 \mathrm{~m}(0,6 \mathrm{ha})$ dans son angle nord-est. Les deux sont entourées d'un fossé. Un petit observatoire, de $50 \mathrm{~m}$ x $30 \mathrm{~m}$, se trouve dans l'angle nord-ouest de la ville haute. À l'ouest, la ville basse est légèrement plus élevée que la plaine environnante; elle aussi était peut-être entourée d'un fossé. Par sa position topographique, en contrebas d'un relief, ses dimensions et sa morphologie, ce site est proche de Tall al-S̄ur. Il se trouve à $21 \mathrm{~km}$ de Tall al-Nāṣirīya (un autre très vaste site à l'âge du Bronze moyen, voir infra, p. 155) avec lequel il n'est cependant pas en contact direct. 
Ğabal al-Guwayhim est une construction ovale, de 700 m x 665 m, que l'on repère sur les images satellites par les énormes pierriers rayonnants réalisés à ses dépens (fig. 25). Ceux-ci étaient déjà visibles sur les images Corona datées de 1968. Sa position, sur un promontoire arrondi du Ğabal al-'Alā, pourrait en faire un bon candidat pour une forteresse, sauf que ses dimensions sont très importantes. Nous ne pouvons en supposer plus car elle n'a jamais été prospectée. À $20 \mathrm{~km}$ à l'est de Tall al-Nāṣirīya, sa position est similaire à celle de Tall al-Šayh 'Alī par rapport à Qatna. Il y aurait eu, pour chacune de ces deux très grandes villes, deux villes secondaires en avancée sur la steppe. L'une, en plaine, est protégée par un relief naturel mais en contact avec le reste du réseau par l'intermédiaire d'une tour proche. L'autre est implantée sur un point qui permet de voir tout le paysage à l'ouest. Les deux sont disposées par rapport à la capitale selon un angle un peu inférieur à $45^{\circ}$. Ğabal al-Ġuwayhim pouvait communiquer sans intermédiaire avec Tall al-Nāșirīya.

\section{LES EXTENSIONS DU RÉSEAU EN DEHORS DE LA ZONE PROSPECTÉE PAR LA MISSION «MARGES ARIDES»}

Nous proposons comme hypothèse que le réseau défensif découvert dans la zone prospectée par la mission «Marges arides» soit lié aux grands établissements du pourtour de la steppe de Syrie du Nord (fig. 24). Plusieurs points de contact sont clairement identifiés: le fortin de Qal'at Šumaymīs et les forteresses de Rubbā et de Tall al-' 'Ūgā. De plus, il semblerait étonnant, du strict point de vue défensif, de concevoir qu'alQasțal al-Šamālī au sud-est et Tall Draḥam au nord-est constituent, aux deux extrémités du réseau, l'aboutissement de la ligne des points fortifiés. En effet, l'analyse de ce réseau a montré qu'une position fortifiée se doit, pour des raisons de sécurité, d'avoir un contact visuel avec au moins deux autres positions (infra, p. 152). Dans un système de communication aussi global, ces deux points fortifiés devraient être en relation avec d'autres.

\section{Le contournement des Ğabal Šbayt et Ğabal al-Ḥaṣ, au nord}

Au nord-est, la présence de la citadelle de Tall Draham s'explique tout-à-fait par la nécessité de surveiller la partie septentrionale de la steppe. En effet, il s'agit du point le plus élevé et le plus oriental du secteur. Cependant, il ne paraîtrait pas illogique, dans le système décrit ci-dessus, que cette position soit reliée visuellement à au moins un autre point de surveillance ou de communication.

La communication est possible, entre Qinnasrīn et Tall Draham, par des points-relais («répéteurs» pour les signaux optiques) qui permettent de contourner par le sud les chaînons basaltiques des Ğabal-s Šbayṭ et al-Haș. En respectant les limites de visibilité, c'est-à-dire en ne considérant que les distances inférieures ou égales à $20,8 \mathrm{~km}$, six positions intermédiaires s'avéreraient indispensables pour communiquer entre Tall Draḥam et Qinnasrīn (Al-Ṭwayḥ̄na 4, Rağm al-Ṣawān, Tabārat al-Zbīb 1, Tall Abū Drīhna, Tilāl Ḥmaymāt al-Dāyr et Tall al-Ṭūān). Cependant, un contournement des massifs basaltiques par le nord est également envisageable. Des « forteresses primitives », «très anciennes », peut-être «syro-hittites » ont été vues lors des prospections antérieures (Butler 1920: 3 et 16; Lassus 1935: 80; Mouterde et Poidebard 1945: 73-74), mais jamais étudiées en tant que telles. Certaines d'entre elles, sur le pourtour du Ğabal Šbayṭ pourraient appartenir au réseau des forteresses du Bronze moyen. Une «forteresse primitive» a été signalée par Mouterde et Poidebard (1945: 71-73 et pl. XXXVI à XXXVIII) à Al-Bāb. Sa position, à l'extrémité d'un éperon rocheux du Ğabal al-Ḥaș dominant le Ğabbūl et son mode de construction, en gros blocs de basalte polygonaux, s'accordent avec les caractéristiques des autres sites du réseau. Elle se compose d'une vaste enceinte trapézoïdale percée, à l'ouest, d'une porte de $3 \mathrm{~m}$ de largeur. Les murs - de 2,50 m de largeur au sommet - comportent un fruit externe. Un linteau mentionne l'agrandissement, en 223-224, d'un refuge plus ancien (Ibid.: 71-73). De la forteresse, il n'est pas possible de voir Tall Draham, à $20 \mathrm{~km}$ au sud-est ${ }^{31}$. En revanche, il est possible de voir Rasm Zabad à l'extrémité nord-est du Ğabal Šbayṭ et à $2 \mathrm{~km}$ au nord de Tall Draḥam. Jean Lauffray y signale les «fondations d'une construction en basalte, de destination incertaine» mais qui pourrait avoir été un «poste de guet $\aleph^{32}$. Le plan montre un petit bâtiment de $c a 20 \mathrm{~m}$ x $15 \mathrm{~m}$ accompagné d'une pièce isolée de $6 \mathrm{~m} \mathrm{x} 4 \mathrm{~m}$. Huit inscriptions en arabe, accompagnées de graffiti chrétiens, ont été retrouvées sur les rochers à proximité. La fonction principale d'une tour à Rasm Zabad aurait été la même que pour les tours qui surplombent Tall al-Șūr et Tall Țayyibat al-Ism (voir infra): faciliter la communication entre les établissements.

La distance entre Tall Draḥam et Al-Bāb est de $20 \mathrm{~km}$. De cette dernière, la vue est théoriquement dégagée jusqu'à la for-

\footnotetext{
31. La vue est possible depuis le sommet du massif qui la domine, à $1 \mathrm{~km}$ au nord-ouest, au lieu dit «Al-Burğ » (la tour).

32. Mouterde et Poidebard 1945: 268 et plan fig. 18. Sur la carte p. 64, une tour est indiquée vers le point géodésique $449 \mathrm{~m}$.
} 
teresse de Rağm al-Șawān, à $33 \mathrm{~km}$ au sud, par le couloir d'alMunbațah. Tall Munbațah est disposé exactement sur cet axe ${ }^{33}$. Qurbatiyya, une autre «forteresse primitive» sur un éperon qui domine ce tell, à $3,5 \mathrm{~km}$ au sud-ouest, pourrait avoir été une tour. Il s'agit dans ce cas d'une construction rectangulaire - de $20 \mathrm{~m} \mathrm{x} 10 \mathrm{~m}$ - en appareil polygonal, «arrondie sur le côté E., rectangulaire sur les autres côtés» (Mouterde et Poidebard 1945: 79 et pl. XLVI-XLIX). Sa position lui permet d'être en vue de Rağm al-Ṣawān et de la tour de Tabārat al-Zbīb 1. Un grand enclos rectangulaire (9 ha), mentionné par R. Mouterde et A. Poidebard à l'est de la tour de Qurbatiyya, pourrait lui être associé.

À la pointe nord du Ğabal al-Ḥaș, Qal'at Sfīrā est probablement un monastère byzantin sur lequel une église a été vue par E. Sachau (1883: 112) ainsi que des inscriptions syriaques (Mouterde et Poidebard 1945: 66 et 223-224). Malheureusement, cet endroit, inclus dans un camp militaire, n'a jamais réellement été exploré. Il s'inscrit dans un enclos rectangulaire, de $180 \mathrm{~m}$ x $120 \mathrm{~m}$. De là, la vue s'étend jusqu'à Alep (à 20,5 km), jusqu'à Ğabal al-Šahīd (à 15,6 km), une installation de $c a 190$ x $180 \mathrm{~m}$ qui pourrait être une forteresse, sur un piton détaché au sud du Ğabal al-Ṣahārı̆̆g, et qui permet la connection avec Qinnasrīn, jusqu'à Tall Wāsța, jusqu'au massif qui domine Al-Bāb (à $27 \mathrm{~km}$ au sud-est) et en théorie jusqu'à 'Umm al-Marā (à 33 km). L'image Corona du 4 novembre 1968 montre un fossé à l'est, ce qui pourrait être une rampe d'accès au nord et une plateforme rectangulaire en saillie à l'ouest (fig. 5).

Tall Wāsța, entouré par les eaux du Ğabbūl qui le protégeaient naturellement, est situé en avant des massifs basaltiques (Maxwell-Hyslop et al. 1942: 23). Par très beau temps, il pouvait peut-être servir de répéteur entre la tour de Rasm Zabad (qui dominait Tall Draḥam, à $32 \mathrm{~km}$ ) et Alep (à $38 \mathrm{~km}$ ). Néanmoins il est plus probable qu'il servait de répéteur entre Al-Bāb (à 14,8 km) et Qal'at Sfīrā (à 19 km).

Enfin, sur une colline détachée du Ğabal al-Maḥdiyya, dans la boucle du Qwayq, pourrait se trouver un fortin, qui a pu servir de relais entre Qinnasrīn et Alep à mi-chemin entre les deux (fig. 12). Le site est clairement visible sur les images aériennes. Dominant la vallée du Qwayq d'une soixantaine de mètres, il se présente sous la forme d'une construction polygonale, de ca $60 \mathrm{~m}$ de côté, bâtie sur une éminence naturelle et entourée d'un fossé ${ }^{34}$.

33. Il a été prospecté à plusieurs reprises par l'équipe italienne d'Ebla $\left(\mathrm{n}^{\circ}\right.$ EC 003) et daté de l'âge du Bronze ancien: Mantellini et al. 2013: 174175. Il s'agit d'un gros tell tabulaire, de $220 \mathrm{~m}$ x $240 \mathrm{~m}$ et de $15 \mathrm{~m}$ de hauteur.

34. L'image Google Earth du 4 février 2000 est particulièrement précise.

\section{Les sites de la région au sud-ouest de Qinnasrīn}

La grande forteresse qui marque l'angle nord-ouest du réseau défensif est celle de Qinnasrīn. Il s'agit là d'un point élevé qui domine la région environnante et permet une vision à presque $360^{\circ}$. Sa position, à mi chemin entre Ebla et Alep, deux capitales de royaumes de l'âge du Bronze moyen, donne à penser qu'elle a pu jouer un rôle déterminant dans la défense de leurs territoires. Elle était sans doute secondée en cela par des sites défensifs de moindre ampleur, fortins et tours. La prospection de la zone des Marges arides qui a concerné la région au sud-est de Qinnasrīn, n'a pas été systématique car nous avons fait le choix de nous concentrer dans la partie au sud de la zone; nous n'avons donc pas répertorié de telles installations. D'autres prospections ont été conduites dans ce secteur, mais elles se sont en général limitées à l'étude des tells ${ }^{35}$. Néanmoins, celles réalisées, par exemple, par A. De Maigret à l'ouest du Mațh, ont permis de découvrir plusieurs «tells coniques surmontés de robustes murs de défense en gros blocs de basalte» (De Maigret 1978: 90 et fig. 13), datés par la céramique de l'âge du Bronze moyen et dont certains pourraient, d'après les critères d'implantation définis ci-dessus, faire partie du réseau.

Entre Ebla et Qinnasrīn la vue est directe sur les $29 \mathrm{~km}$ qui les séparent mais un site pourrait jouer le rôle de répéteur en cas de mauvaise visibilité, Tall Nabārīz (EC 061; fig. 12) sur une butte à 15,5 km d'Ebla et à 13,5 km de Qinnasrīn. Ce tell, de $c a 95 \mathrm{~m}$ de diamètre à sa base pour $50 \mathrm{~m}$ au sommet, est occupé aux âges du Bronze ancien IVB et du Bronze moyen. D'après ces dimensions, il pourrait s'agir d'un fortin. Il n'est pas possible de voir Tall al-Ṭūkān depuis Tall Nabārīz. D'ailleurs, aucun site ne semble pouvoir mettre en relation Tall al-Ṭūkān et Ebla de ce côté.

Tall Kursiyan a été prospecté par M. Liverani en 1964, par A. De Maigret, puis en 2010 par l'équipe de l'«Ebla Chora Project» (site n $\left.{ }^{\circ} \mathrm{EC} 008\right)^{36}$. Il semble n'avoir été occupé qu'à l'âge du Bronze moyen. Un village byzantin s'étale à son pied. Il s'agit d'un tell conique, de $c a 70 \mathrm{~m}$ de diamètre à la base et de $25 \mathrm{~m}$ au sommet pour $15 \mathrm{~m}$ de hauteur, avec une grande quantité de pierres de basalte en surface. Il permet de voir les plus grands sites du Bronze moyen des alentours: Ebla, en

L'endroit devrait avoir été prospecté par la mission allemande d'Alep dirigée par K. Kohlmeyer; les résultats de la prospection sont étudiés par R. Del Fabbro dans le cadre de son doctorat et ne sont pas encore publiés. 35. Matthers 1981; Liverani 1965; De Maigret 1978; «Ebla Chora Project» depuis 2010.

36. Sous la direction de P. Matthiae et L. Peyronel. Liverani 1965: 117 et pl. LXXXV,3; Mantellini et al. 2013: 172. 
théorie Qinnasrīn (à 32,5 km de là), Tall al-Ṭūkān, la tour (? (37 $^{37}$ de Tall al-Bag̀l, au sud-est, ainsi que la tour (?) de Ğabal Rağm Șarāa. D'après notre typologie, il s'agirait d'une tour.

Tall al-Bagil (EC 066), un petit tell conique, de $80 \mathrm{~m}$ de diamètre à sa base pour $30 \mathrm{~m}$ au sommet, est daté uniquement de l'âge du Bronze moyen. Il pourrait correspondre à une tour en relation avec Tall Kursiyan et Ğabal Rağm Șarāa a, mais situé dans un «cul-de-sac visuel» il pourrait avoir eu pour fonction d'informer les populations d'un éventuel danger (voir aussi Qulay‘āt al-Ṭuwaybā).

Ğabal Rağm Ṣarā‘a sur une butte de basalte détachée du Ğabal al-'Alā pourrait être une tour d'environ $25 \mathrm{~m}$ de diamètre, mettant en contact une grande partie du réseau tourné vers la steppe, notamment les forteresses de Tall Abū Drīha et Tall al-'Ūgā, avec Ebla, par l'intermédiaire des tours (?) de Tall al-Baġl et de Tall Kursiyan.

\section{La ligne défensive en avant de Tall al-Nāṣirīya}

Nous avons dit plus haut que Tall al-Nāșirīya ainsi que les grandes villes fortifiées de Tall Tayyibat al-Ism et Ğabal al-Ġuwayhim étaient à prendre en compte dans l'organisation de la défense des terres orientales du Croissant fertile. En effet, malgré le relief très marqué entre la vallée de l'Oronte et la ligne des forteresses, il a été possible de trouver, grâce aux cartes topographiques et aux images satellites, des emplacements qui pourraient correspondre à des positions intermédiaires reliant ces deux secteurs. La communication avec Tall al-Nāṣirīya pouvait s'établir par un répéteur à l'ouest de Tall Țayyibat al-Ism ou par le fortin de Tall Farzān ou la tour du Ğabal Kafrā‘ Comme dans le cas de Tall al-Ṣūr, une petite tour placée sur une indentation du plateau qui surplombe la ville, à $1,3 \mathrm{~km}$ au nord-est (Ğabal al-Rāyyā de 15 x $12 \mathrm{~m}$ ), pouvait lui permettre d'être en relation avec les forteresses de Qal'at al-Rahiyya (par l'intermédiaire de la tour d'al-Țūbā) et de Tall Abū Drīha. Les tours de Rağm al-Farkā et de Ğabal Ray“ al-Hawā ont pu servir de répéteurs, sur une ligne de Tall Țayyibat al-Ism à Tall Abū Drīhna. Les distances entre ces différents points sont de 15,6 km, $16 \mathrm{~km}$ et $8 \mathrm{~km}$. Ces deux tours sont situées sur des hauteurs dominant une enfilade de vallées qui débouchent vers Tall Abū Drīha (voir supra, p. 139, la description de Tall Țayyibat al-Ism). Elles sont en contact avec celle de Ruğum al-Amțal qui apparaît comme un pivot entre les forteresses et le plateau.

Rağm al-Farkā est une plateforme détachée du plateau basaltique, à 2 km à l'est de Tall Huanzīr. Il s'agit d'une masse

37. Le point d'interrogation désigne des installations que nous considérons comme probablement associées au réseau défensif (voir aussi Tableau 2). de pierres, de 13 x $13 \mathrm{~m}$, visible sur les images Corona (fig. 17) et maintenant à côté d'une tour de télécommunication. De cet emplacement, la vue porte jusqu'aux tours de Ruğum al-Amțal et de 'Arḍ al-Riğla et jusqu'aux tours supposées de Ğabal al-Rāyyā (le site qui domine Tall Țayyibat al-Ism) et de Ğabal Ray' al-Hawā. Un enclos rectangulaire, de $c a$ 1,6 ha, se trouve à $250 \mathrm{~m}$ au nord de Rağm al-Farkā.

Ğabal Ray' al-Hawā est également une butte détachée du plateau. À son extrémité sud, une construction en basalte de $15 \times 15 \mathrm{~m}$ pourrait avoir été une tour. Elle domine un gros tell, à $1,8 \mathrm{~km}$ au sud-est. De ce point, il est possible de voir la forteresse de Tall Abū Drīha et les tours de Hirbat 'Umm Ruğūm, Ğabal Fārimha, Ruğum al-Amțal, ainsi que les tours (?) de Rağm al-Farkā et Ğabal Rağm Șarā'a.

Qulay'āt al-Ṭwaybā, si elle appartient au réseau, n’a pas à proprement parler un rôle clé dans les communications interrégionales car seule la tour de Ruğum al-Amțal est visible depuis cet endroit. J. Lassus la nomme Al-Qal'at et signale qu'elle se voit de loin (Lassus 1935: 79-82, pl. XI et XLVII.1). Il a photographié, relevé et décrit une tour de $15 \times 12 \mathrm{~m}$, construite en blocs bruts de basalte, qui comprend quatre pièces. Elle était conservée sur 4,50 $\mathrm{m}$ de hauteur lors de sa visite. Elle se trouve au centre d'un enclos circulaire de $65 \mathrm{~m}$ de diamètre, à l'intérieur duquel il a également pu observer une longue salle de 14,50 m par $3 \mathrm{~m}$ de largeur, couverte de dalles en encorbellement et au fond de laquelle s'ouvrait un puits. Pour J. Lassus, ce genre de construction est tout-à-fait exceptionnel et ne peut être que «syro-hittite». Il s'agirait d'un édifice plutôt tourné vers l'information et la protection des populations alentours.

Al-Ṭūbā est un village connu pour son site de l'époque byzantine (Lassus 1935: 197, n 117). À l'ouest du village, les images Corona (04/11/1968) et Google Earth (du 29/01/2007) montrent la trace d'une construction carrée en basalte, de $20 \mathrm{~m}$ de côté, qui pourrait correspondre à une tour. Celle-ci serait disposée quasiment à équidistance des relais qui la mettent en contact avec Tall Țayyibat al-Ism (par la petite tour [?] de Ğabal al-Rāyyā, à 11,2km), avec Ğabal al-Ġuwayḥim (par le fortin [?] de Tall Farzān, à 11,6 km) et avec la forteresse de Qal'at al-Rahiyya (à 11,4 km). Il s'agit de l'un des rares emplacements de la région qui permette également de voir le fortin de Tall Dahab. Elle est en vue de la tour de Ruğum al-Amțal et du fortin (?) de Tall Farzān (fig. 12). Ce dernier, sur le bord occidental du Ğabal al-'Alā, se présente sous la forme d'une butte polygonale d'environ $50 \mathrm{~m}$ de diamètre, surmontée d'un petit oratoire musulman. Il a pu servir d'intermédiaire entre Tall al-Nāṣirīya, Ğabal al-Ġuwayḥim et Tall Țayyibat al-Ism et permettre les communications visuelles 
entre les tours (?) d'al-Țūbā et de Ğabal Kafrā' d'une part et les petites tours (?) de Ğabal al-Rāyyā et de Ğabal Kāsūn d'autre part.

Au nord de la boucle de l'Oronte et au sud-ouest du plateau du Ğabal al-'Alā, plusieurs buttes isolées offrent des positions stratégiques avec vue sur la vallée de l'Oronte.

Ğabal Kafrā', à 13 km à l'est de Tall al-Nāṣirīya, est une butte conique dont le sommet a pu porter une tour. Elle pouvait servir d'intermédiaire entre Tall al-Nāșirīya, Ğabal alGuwayhim et Tall Țayyibat al-Ism, et également faire office de répéteur entre la tour (?) de Ğabal Abū Darda (à 23,6 km au sud), la petite tour (?) de Ğabal Kāsūn et le fortin (?) de Tall Farzān. Immédiatement au nord de l'enceinte de l'antenne moderne, c'est-à-dire sur le point le plus haut, l'image Corona du 20/11/1968 montre une construction de $c a 30 \mathrm{~m}$ de diamètre, non prospectée et non datée.

La surface du Ğabal Kāsūn porte des traces de constructions en blocs de basalte (un bâtiment avec un enclos quadrangulaire d'environ $120 \mathrm{~m}$ de côté, dans sa partie sud) ainsi que de nombreux pierriers, rectilignes ou en tas. L'un d'entre eux, carré, de $15 \mathrm{~m}$ de côté, pourrait correspondre à une tour en avant de la forteresse (?) de Ğabal al-Guwayḥim (à 3,5 km au nord-est). Elle permet de voir directement des positions à l'est: la tour (?) de Kaytalūn, à 17,5 km, et la petite tour (?) de Ğabal Abū Zayd, à $20 \mathrm{~km}$ mais également Tall al-Nāṣirīya, les tours (?) de Ğabal Abū Darda, de Ğabal Kafrā‘, de Ğabal Abū Țuwayqiyya et le fortin (?) de Tall Farzān.

Ğabal Abū Tuwayqiyya est une indentation du Ğabal al-'Alā qui domine la vallée de l'Oronte. Sur son côté oriental a pu se trouver une tour, visible sur les images aériennes sous la forme d'une structure circulaire de $20 \mathrm{~m}$ de diamètre. Elle pourrait avoir servi d'intermédiaire entre Ğabal al-Ġuwayhịm et Rubbā et les tours (?) de Ğabal Kāsūn et de Kaytalūn.

\section{La partie sud-ouest du réseau}

Il est possible de trouver une cohérence entre ce que nous avons décrit ci-dessus et des positions stratégiques situées dans un secteur au-delà de la zone prospectée par la mission des Marges arides et dont l'angle sud-ouest serait Qatna (fig. 24). Cette dernière est la plus grande agglomération de la région à l'âge du Bronze moyen et on peut difficilement imaginer, vu son statut et son emplacement en lisière de la steppe aride (Valsecchi 2007), qu'elle ne soit pas impliquée, de près ou de loin, dans ce réseau. Or les possibilités de vision entre cette capitale et les forteresses de la steppe les plus proches sont inexistantes. Des installations intermédiaires auraient-elles été érigées pour assurer les contacts?
Ruğum al-Hुarğ permet de mettre en contact Qatna et la forteresse de Rubbā (à 23,4 km de là) tout en étant en vue de Tall al-Šayh 'Alī. Ce site permet de voir également les potentiels intermédiaires entre ces grands établissements: Ğabal Abū Darda, Ğabal Abū Țuwayqiyya et Tall Harī's Située à la pointe orientale du massif basaltique d'al-Qīna, il s'agit d'une construction en blocs de basalte de $30 \mathrm{~m}$ x $32 \mathrm{~m}$ de côté, évoquant une tour.

Tall Harī' était probablement un fortin, de $45 \mathrm{~m}$ de diamètre, sur un petit tell de $55 \mathrm{~m}$ de diamètre qui semble avoir été entouré d'un fossé (fig. 12). À $11 \mathrm{~km}$ de Qatna, il est situé sur l'axe entre la capitale et Tall al-Šayh 'Alī. Le point haut a été utilisé récemment pour installer une antenne de téléphonie mobile. De là, les tours (?) de Ğabal Abū Darda, de Ruğum al-Ḩarğ, le fortin (?) de Ḍahrat Abū Maqām et la petite tour (?) de Hirbat al-Zarqā' sont également visibles.

Sur l'axe entre Qatna et Tall al-Ṣūr se trouve la butte de Dahrat Abū Maqām (fig. 12). L’image Corona du 4/11/1968 montre, sur ce point culminant, une construction de $45 \mathrm{~m}$ de diamètre qui pourrait être un fortin communiquant également avec Tall al-Šayh 'Alī et le fortin (?) de Tall Harī'.

Ces trois positions, pouvant toutes potentiellement mettre en relation Qatna et Tall al-Šayh 'Alī, souligneraient bien l'importance de cette dernière au sein du réseau. En contact avec elle, sur le bord du Ğabal al-Habla qui domine la ville, la petite tour (?) de Hirbat al-Zarqā' met en contact la place forte de Tall al-Șūr, à $3 \mathrm{~km}$ au sud-est, avec la partie du réseau qui se trouve au nord.

Enfin, au moins une position du réseau pourrait se trouver à l'ouest de l'Oronte, dans son coude le plus oriental au sud de Hama, sur le Ğabal Abū Darda, un massif qui domine le fleuve de $300 \mathrm{~m}$. Le site, visible sur les images satellites, n'a pas été prospecté et nous ne pouvons donc pas connaître sa datation ${ }^{38}$. Il se situe pratiquement à égale distance du fortin de Qal'at Šumaymīs et de Qatna et permet de voir toutes les positions dans l'éventail entre les deux, notamment le fortin (?) de Tall Hुarī' et la tour (?) de Ruğum al-Hुarğ ainsi que, vers le nord, Ğabal al-Ġuwayhịim, la petite tour (?) de Ğabal Kāsūn et la tour (?) de Ğabal Kafrā', à 23,5 km au nord. L'endroit est occupé par des installations militaires modernes.

\section{La partie sud-est du système défensif}

D'après nos observations de terrain, Al-Qasțal al-Šamālī n'est en relation avec le reste du réseau que par la tour de Fahr.

38. Il ne fait pas partie des sites répertoriés par la mission syro-allemande: Bartl and Al-Maqdissi 2014: Fig. 17, 69. 
Cependant, ce fortin devait aussi pouvoir communiquer, au sud-ouest, avec les grands établissements fortifiés de Tall al-Šayh̆ 'Alī et Tall al-Șūr. De fait, il est possible d'envisager le contournement du Ğabal al-Bal'as, dont les reliefs entre Tall al-Šayh 'Alī et Tall al-'Albāwī sont autant d'obstacles à la surveillance visuelle. Il semblerait que les poljés ${ }^{39}$ de Surrāt 'Umm Qabība, Surrāt al-Manqūra et Surrāt al-Hुasān au sud-ouest d'al-Qasțal al-Šamālī puissent s'intégrer dans le système défensif, marquant sa limite sud-est. De fait, ils forment un fossé naturel d'une vingtaine de kilomètres de longueur. La limite sud du réseau, quant à elle, semble être le «couloir» de

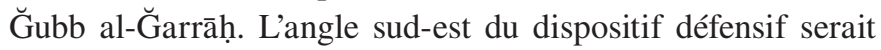
marqué par le point le plus élevé de tout l'ensemble (Qașr alMukarram, à $1060 \mathrm{~m}$ d'altitude), la ligne fortifiée suivant la barrière naturelle et bénéficiant des hauteurs qui bordent les poljés à l'ouest et les dominent de $c a 250 \mathrm{~m}$. Plusieurs points hauts, entre ces défilés et Tall al-Ṣūr permettent de fermer la boucle.

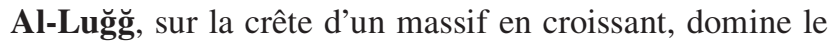
poljé de Surrāt 'Umm Qabība. L'installation la plus visible est une construction rectangulaire, de $76 \times 50 \mathrm{~m}$, avec un massif de brique crue qui a l'aspect des sites d'époque romaine. Il domine un enclos rectangulaire, de 266 x $186 \mathrm{~m}$, en contrebas, à l'est (fig. 17). Celui-ci est construit avec des murs massifs qui diffèrent des constructions romaines et s'apparenteraient plutôt à des installations de l'âge du Bronze. À $c a 400 \mathrm{~m}$ au nordouest, pourrait se trouver une ancienne tour, sous la forme d'une construction de pierre d'une dizaine de mètres de côté. De cet emplacement, il est possible de voir à la fois la tour de Faḩr et le fortin d'al-Qasțal al-Šamālī, au nord, ainsi que Qașr al-Mukarram, au sud.

Qașr al-Mukarram, situé à l'extrémité sud du poljé de Surrāt al-Hुasān, est une construction de $c a 100$ m x 75 m qui a elle aussi une apparence 'romaine'. Elle est dans un enclos polygonal de $c a 375 \mathrm{~m}$ de côté (fig. 17). Au nord, l'enclos comprend ce qui semble être une tour de $25 \mathrm{~m}$ de diamètre. Il pourrait s'agir là à la fois de l'extrémité sud-est du réseau et du point le plus élevé de tout le système, d'où les installations d'al-Luğğ, de Rasm al-Suwayd et de Tulūl al-Hawa sont bien visibles. La proximité de ce site avec le Très Long Mur, qui passe à $500 \mathrm{~m}$ au sud de l'enclos, amène à se poser la question de leur possible contemporanéité. Avec Rağm al-Șawān, il pourrait s'agir des seuls points qui seraient liés à la fois au TLM du Bronze ancien IV et au réseau défensif du Bronze moyen.

Le site de Rasm al-Suwayd, à l'ouest de Qașr al-Mukarram pouvait seconder ce dernier pour la communication avec les

39. Dépression fermée, souvent dotée d'une source et d'un exutoire karstiques. secteurs occidentaux. Il se composerait d'une tour, subsistant sous la forme d'un amas pierreux rectangulaire de $20 \mathrm{~m}$ x $25 \mathrm{~m}$. Depuis cet endroit, Qașr al-Mukarram, al-Luğğ, Tall al-Ṣūr (à $23 \mathrm{~km}$ ) et Tulūl al-Hawa sont clairement visibles. Une autre position au nord-ouest de Rasm al-Suwayd pourrait également servir d'intermédiaire entre al-Luğ $\breve{g}$ et Tulūl al-Hawa.

Tulūl al-Hawa dans la partie nord du Ğabal al-Šawmariyyā, domine le corridor de Ğubb al-Ğarrāḥ et Tall al-Ṣūr, 9 km à l'ouest. Sur le sommet d'une butte se trouve une structure polygonale d'environ $30 \mathrm{~m}$ de diamètre, entourée de terrasses de culture modernes. Elle permet de voir directement Tall al-Šayh 'Alī et Qal'at Šumaymīs et de relayer la transmission de signaux depuis Qașr al-Mukarram et Rasm al-Suwayd.

\section{ÉLÉMENTS DE DATATION: LA CÉRAMIQUE}

La datation de cet ensemble de fortifications repose sur la datation des sites, elle même basée sur l'étude de la céramique. Certes, cette dernière provient de travaux de prospection mais qui se sont déroulés dans une région où les sites sont bien conservés, y compris pour des périodes très anciennes. La variabilité du peuplement d'une période à l'autre, en fonction des critères géopolitiques, économiques, démographiques, éventuellement climatiques et de l'attractivité des différents secteurs a généré des établissements occupés parfois sur une très courte durée, fournissant à l'archéologue des assemblages céramiques avec un nombre réduit de formes, évacuant les problèmes de matériel résiduel, récurrents sur les sites fouillés qui fournissent des datations multipériodes. La répétition d'un même assemblage sur un même type de site renforce la datation et permet de proposer une contemporanéité pour les établissements concernés. C'est le cas des sites fortifiés présentés ci-dessus.

L'ensemble de la céramique a été revu, à partir des dessins, des photographies, et des cahiers d'enregistrement qui mentionnent une description des pâtes et présentent un croquis pour chaque tesson. L'ensemble des tessons collectés est composé en majorité de lèvres ou de bases, ce qui est suffisant pour permettre une datation relativement correcte. Certaines panses ont également été décrites; en effet, les tessons datant de l'âge du Bronze moyen sont pour la plupart non peints et comportent souvent des décorations incisées sous forme des lignes horizontales ou ondulées. La datation préliminaire a ainsi pu être affinée et précisée.

L'assemblage céramique de plusieurs sites fortifiés a déjà été publié, comme celui de Qal'at al-Hawāyis (Calvet 2002), de 
Qal'at al-Rahiyya (Rousset et Duvette 2015) et de Qal'at Šumaymīs (Rousset et Calvet 2016). Pour ce dernier, la céramique date en grande majorité de périodes plus récentes, cependant une dizaine de tessons datables de l'âge du Bronze moyen ont été dessinés. La céramique découverte à Qinnasrīn, notamment sur la montagne qui domine la ville, a été étudiée par C. Kepinski (voir note 29); une partie provient de contextes funéraires. Nous ne présentons pas ici de typologie complète mais dressons un panorama des types identifiés comme les plus caractéristiques de l'âge du Bronze moyen, en précisant leur répartition géographique.

L'étude de la céramique découverte au cours de la prospection des Marges arides a fourni des éléments de datation pour l'ensemble des établissements implantés dans cette zone, grâce aux comparaisons possibles avec les sites de référence situés dans la zone à l'ouest, y compris la moyenne vallée de l'Oronte, ainsi qu'en Syrie du Nord. Elles sont donc essentiellement basées sur les séquences stratigraphiques établies, d'une part, à $E^{4}{ }^{40}$ qui est la plus complète de la Syrie centrale et, d'autre part, à $\mathrm{Hama}^{41}$ et à Qatna (Besana et al. 2008; Morandi Bonacossi 2014).

\section{BOLS CARÉNÉS}

Un des types les plus diffusés dans la région des Marges arides est le bol caréné. Deux des fragments ont été retrouvés à Tall Abū Drīhna (fig. 27, n ${ }^{\circ}$ 00-160-023) et sur la montagne de Qinnasrīn (fig. 27, $\left.\mathrm{n}^{\circ} \mathrm{QP} 70-18\right)^{42}$. La forme de ce bol est très caractéristique des périodes du Bronze moyen IB et II. Ce type a été découvert non seulement sur les villes fortifiées des Marges arides mais aussi sur d'autres établissements de même époque. Il a été retrouvé en abondance à Ebla dans des niveaux de l'âge du Bronze Moyen IB (Nigro 2002a: Pl. XLVIII : 32-37 et LIV : 79-81). À Hama, il est attesté dans des contextes variés, à la fois domestique (silos) et funéraire ${ }^{43}$. À Tall al-Ṭūkān des exemplaires ont également été retrouvés dans un contexte funéraire de la phase 5 (Ascalone 2014: Fig. 42). À Qatna, ce type de bol a été principalement observé dans le sondage $\mathrm{J}$ au

40. La chronologie du Bronze moyen d'Ebla est divisée en deux phases principales avec des sous-phases qui correspondent aux horizons Mardikh IIIA 1-2 (2000-1800 av. J.-C.) et IIIB 1-2 (1800-1600 av. J.-C.). Voir Nigro 2002a: 99.

41. La phase qui correspond au Bronze moyen à Hama est la phase H5-1. Fugmann 1958: 86-116.

42. Voir note 29: Kepinski, à paraître: pl. $1: 11$.

43. Fugmann 1958: Fig. 110, 3K156. La tombe remonte à la période du Bronze moyen II et a été retrouvée dans la ville moderne de Hama, à la périphérie sud-ouest du site. Voir Ibid.: Pl. X, tombe G X, 6A300. sommet de la ville haute (Iamoni and Morandi Bonacossi 2010-2011: Fig. 8, 3).

\section{ASSIETTES}

Le deuxième type distingué dans notre corpus relève de la catégorie des récipients ouverts. Il s'agit d'une assiette avec une lèvre convexe repliée vers l'intérieur ou une lèvre en bourrelet. Ce type a été retrouvé sur plusieurs sites prospectés tels que Tall Abū Drīhna (fig. 27, no 00-160-024, et 00-160-031), Qal'at al-Rahiyya (fig. 27, $\mathrm{n}^{\circ}$ 00-158-39, 00-158-42 et 98-1173), Qal'at al-Hawāyis (fig. 27, $\mathrm{n}^{\circ}$ 99-415-010), Tall Șabha (fig. 27, $n^{\circ}$ 99-020-043) et Qinnasrīn (fig. 27, $n^{\circ}$ QP70-1) ${ }^{44}$. Il est prédominant sur tous les sites de l'âge du Bronze moyen de Syrie intérieure. Les parallèles viennent principalement de Hama où ce type d'assiette n'apparaît qu'à partir de la période H4 (Fugmann 1958: Fig. 117, 2D401) qui correspond à la période du Bronze moyen IB. Il devient l'un des marqueurs du Bronze moyen II et il est toujours présent durant la première partie du Bronze récent I. Cela est également démontré dans la majorité des cités de l'âge du Bronze de la moyenne vallée de l'Oronte, notamment à Qatna (Iamoni and Morandi Bonacossi 2010-2011: Figs. 8, 6-7 et 12) et à Tall Nebi-Mend ${ }^{45}$.

\section{JARRES À COL}

Le troisième type de céramique reconnu dans les Marges arides est un des marqueurs majeurs de la fin de la période du Bronze moyen IB et de toute la période du Bronze moyen II : les jarres à col. Il faut noter que les formes de lèvres sont variées dans notre assemblage. Des fragments diagnostiques du Bronze moyen II ont notamment été retrouvés à Tall Abū Drīha (fig. 28, nº 00-160-035) et à Qal'at Šumaymīs (fig. 28, $\mathrm{n}^{\circ}$ 00-300-74). Ces derniers comportent une lèvre convexe ou une double lèvre superposée et sont comparables à ceux retrouvés à Tall al-Ṭukān (Baffi 2014: Figs. 16, 8 et 18, 18) et à Qatna (Iamoni 2012: Pl. 21, 8-13). Tall Abū Drīha a fourni des fragments de jarres de la même catégorie avec une double lèvre étirée vers l'extérieur (fig. 28, n 00-160-042 et 00-160020). Des parallèles identiques viennent essentiellement d'Ebla, de contextes funéraire et domestique (principalement

44. Voir note 29: Kepinski, à paraître: pl. 2 : 5.

45. À Tall Nebi-Mend, ce type n'apparaît qu'à la fin de la phase G et au tout début de la phase F ce qui correspond à la fin du Bronze moyen II. Voir Bourke 1993: 176 et 186, fig. 13, 1-3. 


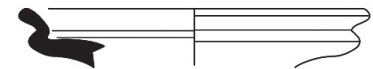

Tall Abū Drīha (00-160-023)

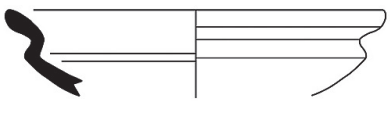

Qinnasrin (QP70-18)

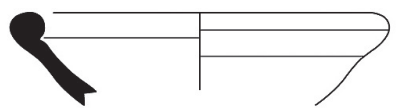

Tall Abū Drīha (00-160-024)

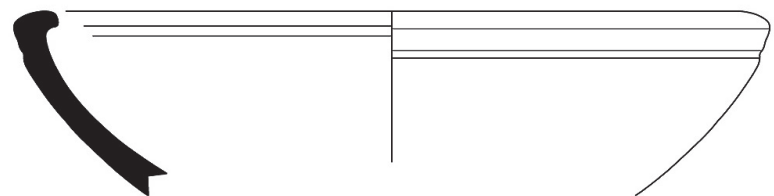

Tall Abū Drīha (00-160-031)

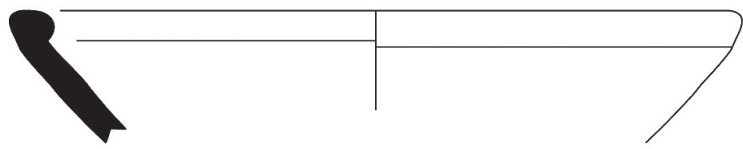

Qal'at al-Rahiyya (00-158-39)

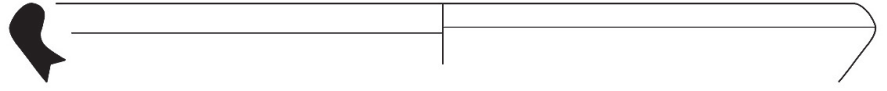

Qal'at al-Rahịyya (00-158-42)

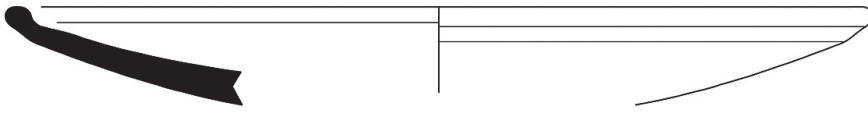

Qal'at al-Rahiyya (98-117-3)

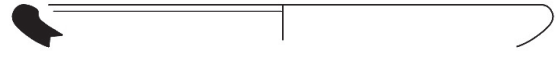

Qal' at al-Hawāyis (99-415-010)

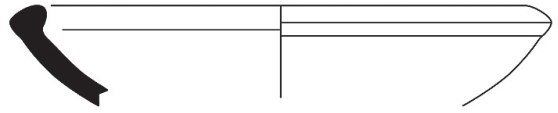

Tall Șabḥa (99-020-043)

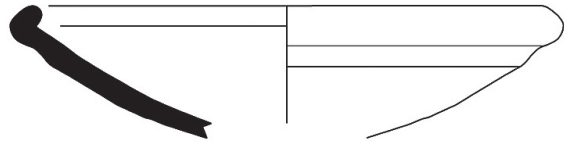

Qinnasrin (QP70-1)

Fig. 27 - Bols carénés et assiettes de l'âge du Bronze moyen. 


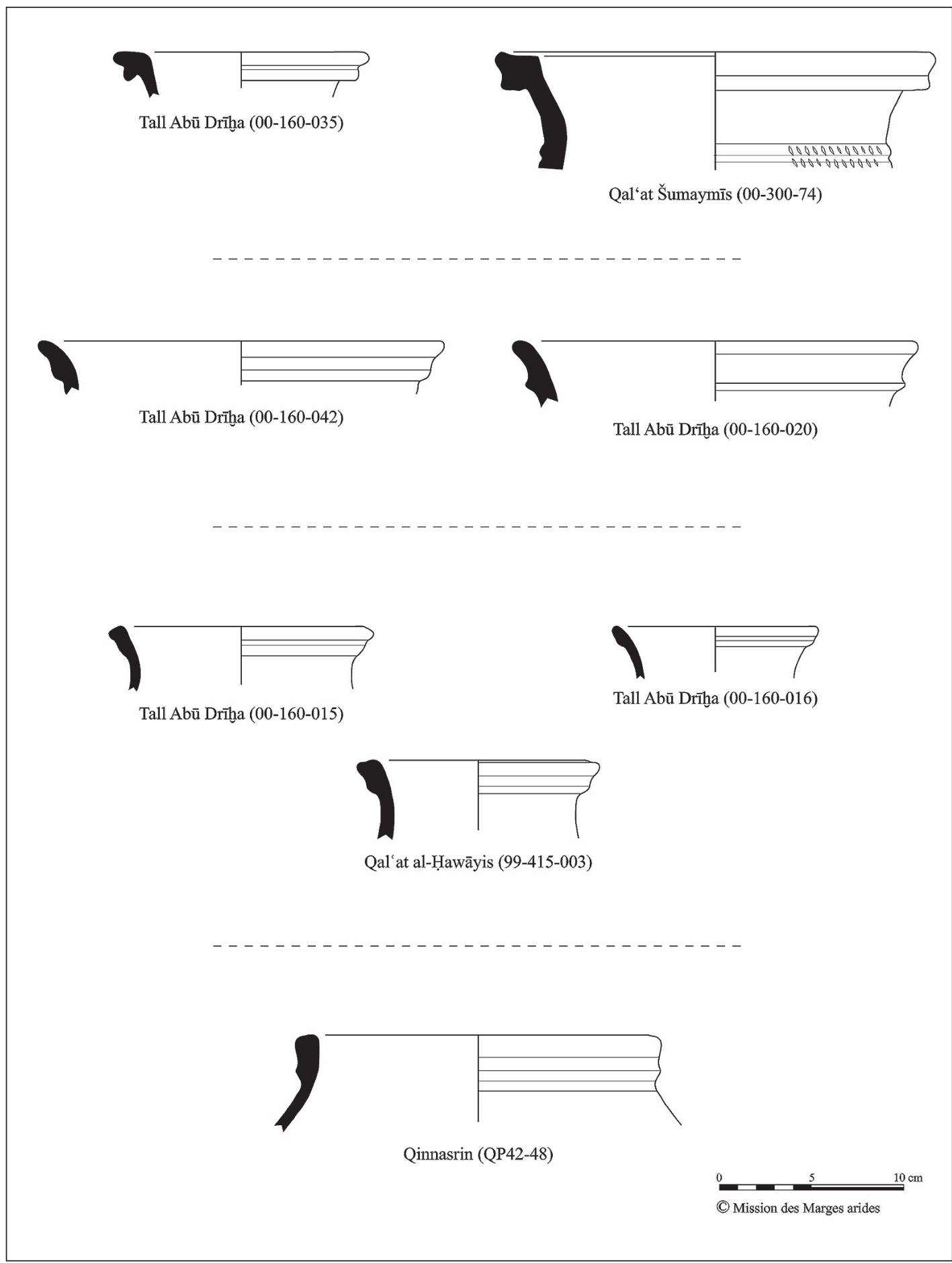

Fig. 28 - Jarres de l'âge du Bronze moyen. 
Nigro 2002b: 305, figs. 7, 18-22 et 9). Deux tessons de partie haute de ce type de jarre ont été retrouvés à Tall Abū Drīha (fig. 28, $\mathrm{n}^{\circ}$ 00-160-015 et 00-160-016) et à Qal'at al-Hawāyis (fig. 28, n 99-415-003) : ils présentent une double lèvre convexe. Ce type de vase est bien attesté à Tall al- Țūkān dès la fin du Bronze moyen I et durant le Bronze moyen $\mathrm{II}^{46}$.

\section{JARRES SANS COL}

Un type de céramique rarement attesté dans l'assemblage collecté au cours de la prospection est celui des jarres sans col. Durant la prospection de Qinnasrīn, un seul tesson avec une double lèvre convexe (fig. 28; $\mathrm{n}^{\circ} \mathrm{QP} 42-48$ : voir note 29, Kepinski à paraître: Pl. 5 : 14) a été retrouvé. Plusieurs exemplaires sont connus dès le Bronze moyen IA, au nord, dans le répertoire d'Ebla ${ }^{47}$. À Qatna ce type de jarre est attesté durant toute la période du Bronze moyen (Iamoni and Morandi Bonacossi 2010-2011: Fig. 6, 10-11).

\section{BOLS PROFONDS}

Une série de bords correspond à des bols profonds (appelés parfois «grandes jarres») dont la panse porte souvent des décorations incisées sous forme de lignes horizontales et/ou ondulées. Le bol comporte une ligne de carénage sur la partie supérieure de la panse. Ce type a été retrouvé sur la plupart des forteresses prospectées. Cependant, une variation au niveau de la lèvre a été notée. Les tessons de Tall Șabḥa (fig. 29, $\mathrm{n}^{\circ}$ 99-020-016) et de Qal'at al-Hawāyis (fig. 29, n 99-415-012) ont une lèvre à extrémité à peine convexe étirée à la fois vers l'intérieur et l'extérieur avec des ondulations sur le sommet de la lèvre. Ceux de Tall Abū Drīha (fig. 29, n 00-160-013 et 00-160-011) ont une lèvre à extrémité à peine convexe étirée vers l'extérieur avec des ondulations sur le sommet de la lèvre. Les fragments de Qal'at al-Rahiyya (fig. 29, $n^{\circ}$ 00-158-30 et 00-158-36) ont une double lèvre à extrémité à peine convexe et peu bombée étirée vers l'extérieur avec des ondulations sur le sommet de la lèvre. L'exemple de Qal'at al-Hawāyis (fig. 29, $\mathrm{n}^{\circ}$ 99-415-005) a une double lèvre étirée vers l'extérieur.

Ce type de bol est bien attesté dans le Levant Nord sur la majorité des sites de l'âge du Bronze moyen. Il a été retrouvé,

46. Pour la période du Bronze moyen I voir Baffi 2014: Fig. 15, 9. Pour la période du Bronze moyen II voir Ibid.: Fig. 18, 19-20.

47. L. Nigro suggère que cet exemple peut être dû à une continuité d'usage depuis le Bronze ancien IV, dans ce cas pour du stockage. Nigro 2002a: 117, pl. XLVII, 24-25. en particulier, sur les sites de la moyenne vallée de l'Oronte, notamment à Hama. D'après E. Fugmann, cette forme est apparue dès le Bronze moyen I et perdure jusqu'à la fin du Bronze moyen $\mathrm{II}^{48}$. De même, à Ebla des exemplaires sont connus dès le début du Bronze moyen (Nigro 2002a: Pl. XLVII: 20-21). À la fin du Bronze moyen I, on observe pour certains de ces objets, comme ceux de Qatna, une transformation de la forme qui s'arrondit (Ibid.: Pl. LIII: 71). Dans ce dernier site, ce type est largement attesté dès la fin du Bronze moyen I et devient prédominant au Bronze moyen II (Iamoni and Morandi Bonacossi 2010-2011: Fig. 7, 3; Morandi Bonacossi 2002: Fig. 120; Kanhoush 2015: Fig. 6, 1). À Tall Nebi-Mend il n'apparaît qu'à la fin du Bronze moyen II dans la phase $\mathrm{G}^{49}$. Ce vase a été retrouvé un peu plus au nord, dans l'assemblage du Bronze moyen de Qinnasrīn ${ }^{50}$.

\section{MARMITES}

Des marmites ont été aussi repérées durant la prospection. Deux exemples avec une lèvre à extrémité convexe repliée vers l'extérieur, ont été retrouvés sur le site de la forteresse de Qal'at al-Hawāyis (fig. 29, n 99-415-018 et 99-415019). D'une manière générale et contrairement aux autres types de vases, la lèvre des marmites n'a pas connu de changement de forme entre la période du Bronze moyen I et celle du Bronze moyen II. Elle a conservé ses caractéristiques tout au long de l'âge du Bronze moyen et c'est plutôt au niveau de la base ou de la panse qu'on observe des modifications morphologiques. Les parallèles viennent essentiellement de la région de la moyenne vallée de l'Oronte, notamment de Hama $^{51}$ et aussi de Qatna (Besana et al. 2008: Figs. 5, 4-5 et $9,1,7$ et 11$)$.

\section{LA CÉRAMIQUE DU BRONZE MOYEN DANS SON CONTEXTE RÉGIONAL}

L'ensemble du matériel collecté sur les différents sites prospectés dans la région des Marges arides a montré une grande homogénéité morphologique. La céramique datant de l'âge du

48. Fugmann 1958: Figs. 109: 3K162 (période H5); 117: 3A858 et 2D218 (période H4) et 127: 2D17 (période H1/fin du Bronze moyen II).

49. Pour S. Bourke, ce type appartient à la catégorie des jarres de stockage. Bourke 1993: 182, fig. 17, 2-5.

50. Voir note 29: Kepinski, à paraître: Pl. $4: 3$ et 7 .

51. Fugmann 1958: Figs. 110,3D581(12); 117, 2B433; 124, R877 MAG./H 10, O785 MAG./H 10 et Y1 MAG./H10; 139, 5A95. 


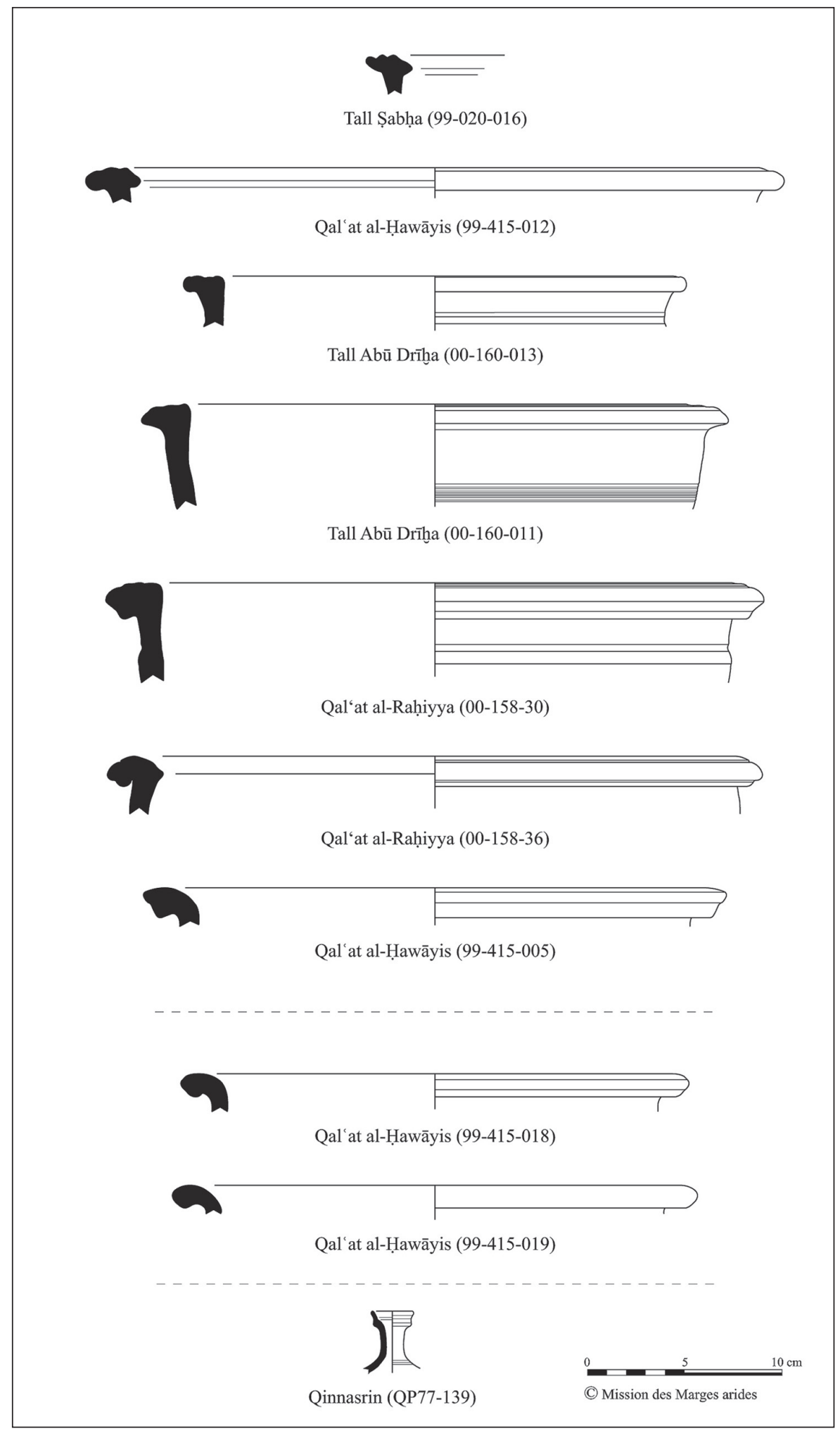

Fig. 29 - Grands bols et marmites de l'âge du Bronze moyen. 
Bronze moyen I est peu représentée par rapport à celle du Bronze moyen II (tabl. 1) $)^{52}$. Cet assemblage est parfaitement comparable, comme nous l'avons vu, avec ceux des différents sites de la Syrie du Nord et de la moyenne vallée de l'Oronte, tels Ebla, Hama et Qatna.

La chronologie de l'âge du Bronze moyen de la Syrie du Nord a été définie grâce aux découvertes d'Ebla. En effet, L. Nigro, par son étude très détaillée de la céramique des niveaux du Bronze moyen, a le premier dessiné l'extension géographique de la diffusion de cette culture matérielle jusqu'à Hama, au sud, ce qui était, avec les connaissances de l'époque, tout à fait raisonnable. Cependant, les travaux récents réalisés à Qatna, notamment les nouvelles fouilles du Sondage $\mathrm{J}$ et du Palais Est, ${ }^{53}$ ont mis au jour des éléments nouveaux qui confirment cette homogénéité et qui permettent d'étendre cette zone de diffusion bien au-delà de Hama, jusqu'à Tall Nebi-Mend, au sud.

Le fait d'avoir une culture matérielle standardisée et homogène, avec une céramique diffusée sur une vaste région géographique qui s'étend d'Alep au nord, jusqu'à Tall Nebi-Mend au sud, semble traduire une forte unité culturelle. Le matériel issu de nombreuses tombes découvertes en Syrie intérieure montre également une tradition commune, bien attestée par le mobilier funéraire. Plusieurs tombes du Bronze moyen découvertes en Syrie intérieure ont fourni un matériel céramique spécifique et identique. Nous pensons en particulier aux vases qu'on appelle Orange Burnished Ware et aux flacons. Les vases de type Orange Burnished Ware ont été trouvés à Ebla dans la tombe Lord of the Goats, à Qatna, à Tall Nebi Mend et dans la Bekaa libanaise à Tall Hizzin ${ }^{54}$. H. Genz et H. Sader (2010-2011: 136), en se fondant sur l'hypothèse formulée par L. Nigro (2002b: 320), mentionnent que ce type de vase est importé de Syrie intérieure. Le deuxième type, - les flacons -, très répandu dans le contexte funéraire en Syrie intérieure et caractéristique du Bronze moyen IB et du Bronze moyen II, peut comporter, ou pas, un revêtement dit Black Burnished. Un exemplaire a été retrouvé à Qinnasrīn, dans les déblais des tombes pillées sur le sommet de la montagne (fig. 29,

52. Ce phénomène a également été observé lors de la prospection de la plaine de Jabbul, au nord de la région des Marges arides. Schwartz 2000: 451.

53. Pour le rapport final sur les différentes phases du sondage J, voir Morandi Bonacossi 2008: 55-127. Concernant le rapport des études de la céramique du sondage J, voir Besana et al. 2008: 129-179; en ce qui concerne le Palais Est, voir Morandi Bonacossi et al. 2009: 61-112.

54. Nigro 2002b: Fig. 23; Matthiae 1979: Fig. O, 2; Al-Maqdissi et al. 2009: Fig. 10; Pfälzner 2014: Fig. 14; Pézard 1931: Pl. XLI; Genz et Sader 2010-2011: Fig. 6. $\mathrm{n}^{\circ}$ QP77-139) ${ }^{55}$. Le site d'Ansari à Alep a fourni plusieurs exemplaires de ce type d'objet (Suleiman 1984: Pl. VI, 62-63). Il est aussi largement attesté à Tall al-Ṭūkān dès le Bronze moyen IB dans la phase 5 (Ascalone 2014: Fig. 40), à Ebla (particulièrement Nigro 2002a: Pl. LVI, 92), à Khan Sheikhoun (Al-Maqdissi 2006: Fig. 10,c et fig. 15,h), à Hama dans la tombe G I (Fugmann 1958: Pl. X, 5B683 et 5B185) et dans la tombe G VI (Ibid:: Pl. X, 5B382), ainsi qu'à Tall al-Tin dans les marais du lac de Qatina au sud de la ville de Homs (Gautier 1895: Fig. 11). À Qatna, un flacon de type Black Burnished Ware a été retrouvé dans la tombe I du chantier T (Al-Maqdissi et al. 2009: Fig. 8), ainsi que dans le tombeau I où plusieurs flacons ont été découverts, certains avec revêtement, d'autres sans (du Mesnil du Buisson 1927: Fig. 48, pl. XII, 1, n 86, $\mathrm{n}^{\circ} 9$ et 64$)$.

De même, les résultats obtenus par la prospection de la région de Qatna (2005-2009) jusqu’à Tall al-Šayh 'Alī et à Tall al-Șūr (Al-Maqdissi 2011 : 43-57), vont dans le même sens. Le croisement de l'ensemble de ces données confirme une continuité dans l'occupation du territoire à l'âge du Bronze moyen et la permanence de la tradition céramique de cette époque dans une grande région. Leétude de la céramique issue de la région des Marges arides permet d'envisager une seule et même aire culturelle, de Qinnasrīn, au nord, jusqu'à Tall al-Ṣūr et ses environs, au sud, partagée par l'ensemble des établissements, qu'ils soient situés dans la région du bassin de l'Oronte à l'ouest ou dans les marges de la steppe à l'est.

Ce travail nous a permis d'identifier une occupation dès la fin de l'âge du Bronze moyen I, principalement sur les sites du réseau défensif. En effet, sur 12 sites avec de la céramique assurée de la fin de cette période, 8 appartiennent au réseau défensif et 4 sont des tells, dont Wādī al-Salīla 2, qui sont des créations nouvelles, à la lisière orientale des implantations sédentaires de cette période (tabl. 1). L'étude de la céramique révèle que les forteresses ont été mises en place à l'âge du Bronze moyen et sans doute dès la fin de l'âge du Bronze moyen I (2000-1800 av. J.-C.) et que ce réseau a été en activité à l'âge du Bronze moyen II (1800-1600/1550 av. J.-C.). Ceci n'exclut pas que certains éléments du réseau, notamment des tours, existaient déjà à l'âge du Bronze ancien et que d'autres positions (principalement des forteresses) aient été réutilisées et intégrées à un système de défense plus tardif, à l'âge du Fer.

55. Note 29: Kepinski, à paraître: Pl. $5: 2$. 


\section{SYNTHÈSE}

\section{SURVEILLANCE ET PROTECTION DES AXES DE CIRCULATION}

La présence de forteresses est souvent interprétée comme nécessaire à la surveillance des routes (Liverani 1965; De Maigret 1978; Del Fabbro 2012; Peyronel 2014: 123). C'est sans doute le rôle - ou l'un des rôles - de certaines des positions fortifiées décrites ci-dessus, comme les grandes villes de Qinnasrīn, Tall Țayyibat al-Ism, Ğabal al-Ġuwayḥim et Tall al-Ṭūkān, les forteresses de Qal'at al-Rahiyya, Tall Abū Drīhna et Tall Șabḥa, les fortins de Dahrat Abū Maqām, Tall Harī‘, Al-Qasțal al-Šamālī, Tall Farzān, Tall Nabārīz et Ğabal al-Mahdiyya ainsi que certaines tours (fig. 24). En effet, leur disposition indique les principales routes connues à l'âge du Bronze moyen (Astour 1995; Joannès 1996; Klengel 2015; Lafont 2016). Ces routes empruntent les itinéraires naturels et passeront par les mêmes vallées à l'époque romaine. Ğabal al-Maḥdiyya, Qinnasrīn et Tall Nabārīz sont régulièrement espacées sur la route de Yamhad (Alep) à Ebla. Tall Țayyibat al-Ism et Ğabal al-Ġuwayḥim sont localisées sur la route d'Alep à Qatna et marquent les intersections avec les routes partant de Tall al-Nāṣirīya vers Emar et vers Abattum (en face de Qal'at Ja‘bar) ou Tuttul (non loin de l'actuelle Raqqa). Les établissements de Tall al-Ṭūkān, Tilāl Ḥmaymāt al-Dāyr et Tall Șabḥa marquent, depuis l'âge du Bronze ancien, la voie d'Ebla à Emar. La route de Tall al-Nāṣirīya à Emar rejoint cet itinéraire à Tall Șabḥa. Elle passe successivement par Tall Țayyibat al-Ism, Rağm al-Farkā, Ğabal Ray` al-Hawā et Tall Abū Drīhna. Pour se rendre à Abattum et Tuttul depuis Tall al-Nāșirīya, la route passe par Ğabal al-Guwayhịim, Al-Ṭūbā et Qal'at al-Rahiyya. Elle rejoint, un peu après Al-Hirbat al-Garbiyya, la branche qui vient de Qatna, passant par Tall Harī' et Tall al-Šayh 'Alī.

Ces vestiges viendraient confirmer la localisation des axes de circulation entre Mari et les royaumes de l'ouest telle qu'indiquée par les textes du XVIII ${ }^{\mathrm{e}} \mathrm{s}$. avant notre ère (Durand 1987; Astour 1995: 1414). Celle que nous venons de décrire correspondrait à la «route haute». La «route basse» suit le même tracé qu'aux époques romaine ou actuelle, par Palmyre et Qaryatayn, mais le trajet de la route intermédiaire n'était pas connu. Les établissements de Ḍahrat Abū Maqām, Tall al-Ṣūr et al-Qasțal al-Šamālī pourraient jalonner cette voie «moyenne» de Qatna à Mari par Halabit (Halabiyya).

En dehors des grandes agglomérations, des forteresses et des fortins, la prospection a fourni d'autres indices sur la localisation de ces routes, en l'occurrence grâce à de très petits sites localisés au-delà des terres des sédentaires, dans la steppe aride (fig. 1). Au nombre de sept, ils comportent certes des cercles de pierres et des petites unités carrées, mais ceux-ci sont caractéristiques des implantations nomades ou semisédentaires des périodes plus tardives. Ils sont répartis en deux lignes dont la plus septentrionale (4 sites) suit le tracé de la route Qatna-Abattum, qui sera la route romaine de Salamya à 'Itriyā. Au-delà de la zone des Marges arides, cette route pouvait rejoindre Abattum (entre Emar et Tuttul), par le Wādī Šatnat al-Salmās, jusqu'à sa confluence avec l'Euphrate. Les trois autres sites (dont l'un daté du Bronze ancien II), au nordest d'al-Qasțal al-Šamālī, longent le piémont du Ğabal Bal'as. Ils se trouvent sur un axe de circulation venant du corridor de Tall al-Ṣū - Ğubb al-Ğarrāḥ puis obliquant vers le nord-est à l'ouest des grands poljés. Ces sites, espacés de 4 à 13,5 km, pourraient marquer des étapes sur ces routes. En effet, la circulation des troupes et des caravanes nécessitait des points de ravitaillement et des haltes, pour abreuver hommes et animaux (Durand 1987: 163-167). Par ailleurs, des tertres de source et des sites avec une occupation de l'âge du Bronze ancien IV (comme 4 des 7 petits sites), correspondant pour certains à des tours, sont situés sur les mêmes alignements et témoigneraient de la pérennité de ces axes de circulation. La présence de ces très petits sites le long des grandes voies de circulation montre qu'il n'y a pas, au-delà de la zone des sédentaires, une défense des itinéraires basée sur des constructions fortifiées qui s'échelonneraient le long des grands axes mais de simples points d'eau. Ces derniers, sous forme de mares aménagées et de kamenitsa étaient connus dans ce secteur depuis le PPNB (Geyer et al. 2014). La route «moyenne» justifierait la présence de la tour de Fahr et du fortin d'al-Qasțal al-Šamālī 2 dans un secteur aussi oriental. Cet itinéraire, contournant le bastion d'Itrriyā par le sud et évitant les zones les plus arides, aurait permis de trouver en chemin des pâturages pour les animaux sur les piémonts du Ğabal Bal'as.

La localisation des très grands établissements sur les routes s'expliquerait donc autant par des raisons économiques que défensives. Mais ce n'est pas forcément le cas de toutes les forteresses de hauteur, comme Rubbā, Qal'at al-Hawāyis et Tall al-'Ūgā, qui sont situées en dehors des grands axes.

\section{DÉFENSE DU TERRITOIRE UTILE}

L'évidence géographique et archéologique permet néanmoins d'envisager une autre hypothèse pour justifier la présence de ces installations fortifiées. Le réseau défensif érigé en position dominante, en lisière de la steppe de Syrie du Nord à 
l'âge du Bronze moyen, est installé en marge du peuplement sédentaire (fig. 23). De fait, à l'est de cette limite, tous les établissements sont très peu étendus, non fortifiés à l'âge du Bronze moyen. On l'a vu plus haut, l'absence de traces d'une occupation nomade dans la zone ne signifie pas forcément l'absence des nomades dans les Marges arides à l'âge du Bronze moyen. Ces derniers pourraient donc ne pas partager la même culture matérielle que les sédentaires. Dans tous les cas, la conception de la défense du territoire assimile de facto cette catégorie de population à l'ennemi. De fait, une des fonctions de ce réseau défensif semble bien avoir été de protéger les terres les plus favorables à la mise en valeur agricole, aux lisières orientales du Croissant fertile.

Ainsi, le croisement de la carte d'attractivités ${ }^{56}$ avec celle du réseau défensif du Bronze moyen (fig. 23) met en évidence le fait que les installations fortifiées devaient permettre de sécuriser les terres les plus favorables au mode de vie sédentaire et à la mise en valeur agricole, puisqu'elles englobent les classes de forte et de très forte attractivité. Seules quelques étroites vallées, potentiellement très attractives mais plus difficiles à sécuriser, y échapperaient au sud. Mais la quasi totalité des mesas basaltiques, aux sols profonds et fertiles, et aux capacités de rétention en eau élevées, ainsi que la plupart des vallées développées à leurs pieds et bénéficiant ainsi d'apports d'altérites basaltiques, auraient été protégées par ce réseau. $\mathrm{Ce}$ sont là les marges du Croissant fertile que l'on aurait voulu intégrer au vaste domaine agricole des plateaux intérieurs de la Syrie, véritable "grenier à céréales» mais aussi, sous réserve de mise en valeur de micro-milieux favorisés, pourvoyeur de productions arboricoles telle l'olive. Certes ces zones de marges étaient, plus que le cœur du Croissant fertile, soumises à l'aléatoire climatique, ici relativement marqué ${ }^{57}$. Mais la qualité des sols, leur fertilité augmentée par la présence des altérites basaltiques, compense en partie cette aridité. Quelle que

56. Le développement du peuplement et de la mise en valeur dépend certes de l'aridité climatique, du fait notamment de la dégradation de la dotation pluviométrique, mais pas uniquement: les états différents de surface (formations superficielles, facteurs édaphiques, composition et densité de la couverture végétale, érosion...), les disponibilités et les occurrences de l'eau, les aménagements hydrauliques et hydroagricoles, l'adaptabilité des populations jouent un rôle important. Prenant simultanément en compte ces différents critères, parmi lesquels l'incidence de l'aridité climatique, l'impact des facteurs édaphiques et la disponibilité de l'eau sont cependant dominants, nous avons identifié un certain nombre d'unités territoriales potentiellement plus ou moins attractives face aux besoins des cultivateurs sédentaires.

57. Le coefficient de variation interannuelle des précipitations (rapport de l'écart-type d'une série à sa moyenne) y est de 40 à $45 \%$, contre seulement 25 à $30 \%$ sur le littoral mais plus de $50 \%$ aux confins des déserts (Traboulsi-Makké 2004). soit la ou les cités à l'origine de ce projet défensif, elles auraient éprouvé le besoin d'étendre leur emprise sur des terres pourtant situées dans des régions déjà arides, et de les sécuriser, marquant ainsi leurs besoins en produits agricoles malgré l'ampleur de l'investissement représenté par un tel réseau.

\section{LES TÉLÉCOMMUNICATIONS PAR SIGNAUX}

Les logiques d'implantation et d'espacement des sites peuvent être interprétés comme la volonté de ménager systématiquement le contact visuel entres les établissements. $\mathrm{Ce}$ système défensif était donc très probablement doublé d'un système de télécommunication par signaux lumineux (ou de fumée), qui n'était pas linéaire mais reliait les différentes positions entre elles (fig. 30). En effet, l'analyse des contacts visuels entre les différentes positions montre que ce critère aurait été prépondérant dans le choix des implantations.

Dans la plupart des cas, les points clés du système de surveillance sont directement visibles les uns des autres par temps clair $^{58}$. Lorsqu'un obstacle empêche la visibilité entre deux fortifications, une tour intermédiaire a été installée. C'est le cas de la tour d'al-Ṭwayhīna 4 entre les forteresses de Tall Draḥam et de Rağm al-Ṣawān et de celle de Fahr entre les fortins d'Al-Qasțal al-Šamālī et de Tall al-'Albāwī. De même, afin de pouvoir communiquer même lorsque la visibilité est réduite, des tours intermédiaires, assurant la bonne transmission du signal, ont été disposées à mi-distance ou à une distance égale des points du premier réseau. La communication visuelle semble donc être un élément essentiel. Excepté aux extrémités des lignes de fortification, chaque position est en vue d'au moins deux autres. Certaines apparaissent comme des pivots du système, à la jonction de deux lignes: la forteresse de Tall Abū Drīhna et le fortin de Tulūl Manatīr al-Hurūṭ. Dans le système de surveillance et de communication, les tours sont plus importantes que les forteresses ou les fortins. Les possibilités de liaisons optiques sont souvent plus nombreuses depuis les

58. Toutes les possibilités de vision d'un édifice à l'autre ont été vérifiées d'abord sur le terrain et sur les cartes topographiques au 1:50000 ou grâce aux profils d'élévation générés par Google Earth. Ces derniers permettent d'observer les obstacles éventuels. Chaque profil a été défini à une altitude de $1,5 \mathrm{~km}$ maximum et le zoom a été plus important sur les secteurs où les visées pouvaient être gênées par le relief; chaque visée douteuse a été écartée. La courbure de la terre a également été prise en considération, sachant que la limite de visibilité sur terrain plat est de 4,7 km. Au-delà, l'observateur doit se situer sur un point élevé, de $5 \mathrm{~m}$ pour voir jusqu'à $8 \mathrm{~km}$; de $10 \mathrm{~m}$ pour $11 \mathrm{~km}$; de $20 \mathrm{~m}$ pour $16 \mathrm{~km}$; de $50 \mathrm{~m}$ pour $20 \mathrm{~km}$; de $100 \mathrm{~m}$ pour $35 \mathrm{~km}$... Nous remercions Damien Laisney (ingénieur topographe) pour cette information. 


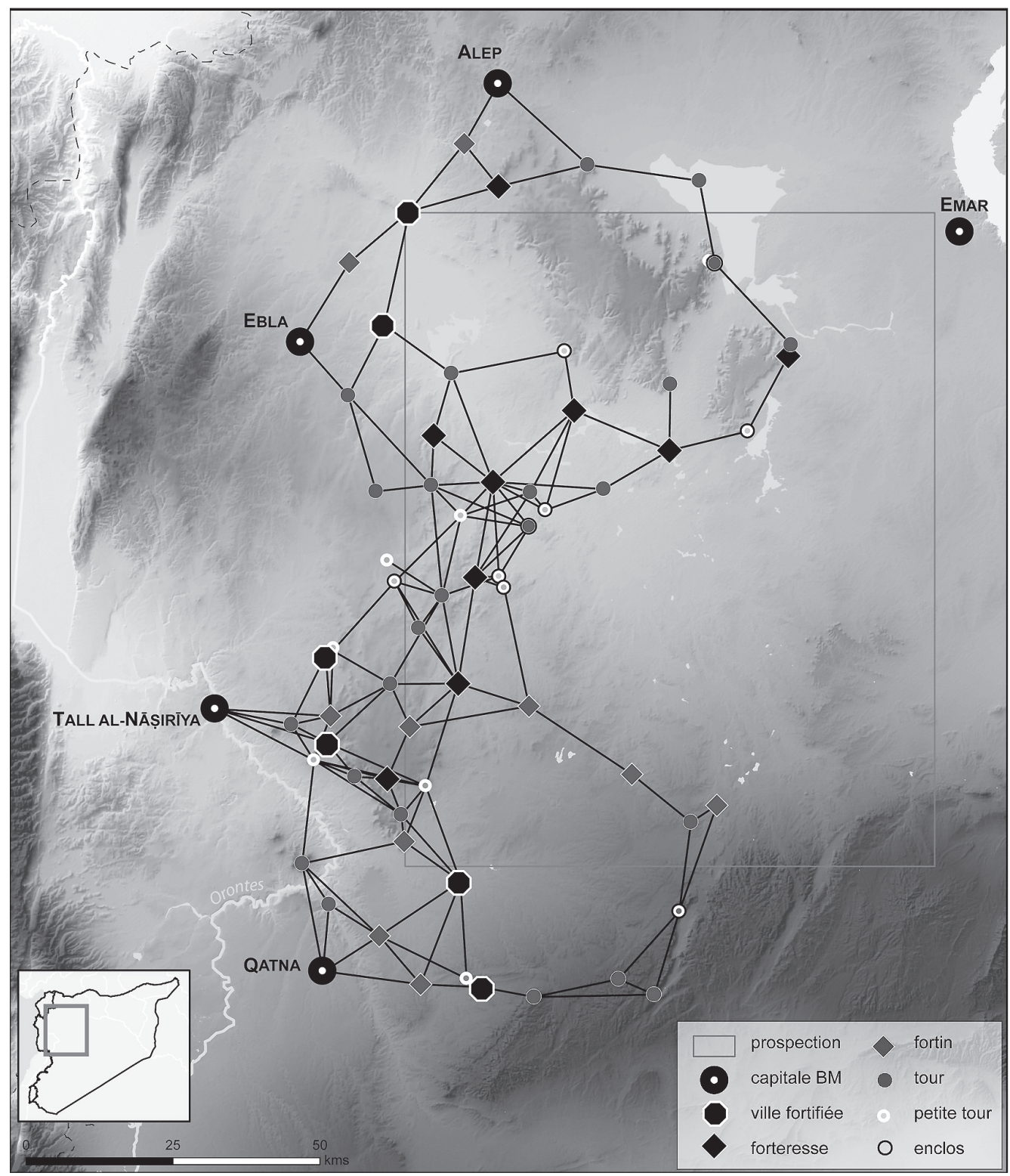

Fig. 30 - Les communications au sein du système défensif. Les traits représentent la vue avérée entre deux établissements séparés au maximum de 21 km (M.-O. Rousset, E. Régagnon).

premières. C'est le cas de Fahrr, en arrière d'al-Qasțal al-Šamālī et sur un point plus élevé. Si le fortin, tourné vers l'est, surveille la steppe qui s'étend à ses pieds, la tour, en arrière, a pour fonction première la transmission des communications entre le fortin et les installations à l'ouest.

L'analyse des distances qui séparent les points du réseau en vue les uns des autres montre qu'une distance maximale de $20,8 \mathrm{~km}$ (mesures prises sur images satellites de centre à centre des établissements), permet de connecter chaque point à au moins deux autres. Même si, pour un certain nombre d'entre eux, la vue est théoriquement possible au-delà de cette distance et peut être effective dans certaines conditions, aucune des liaisons impliquant des visées supérieures à $20,8 \mathrm{~km}$ n'est indispensable à la transmission des communications visuelles d'un bout à l'autre du réseau. Des points intermédiaires (répéteurs) ont été rajoutés, très probablement pour permettre la communication par très mauvais temps. L'espacement maximal de $20,8 \mathrm{~km}$ entre les forteresses et les fortins correspond à la 
limite de visibilité par tous les temps, même si, par temps clair, des signaux de fumée le jour, et des feux la nuit, peuvent être visibles en théorie jusqu'à une quarantaine de kilomètres ${ }^{59}$. Ces transmissions permettaient de communiquer des informations sur la surveillance des territoires orientaux directement aux grands centres de pouvoir (Yamhad, Ebla, Tall al-Nāṣirīya, Qatna). Elles étaient également utilisables pour avertir les populations en cas de danger.

\section{UNE CONCEPTION D'ENSEMBLE FONDÉE SUR UN «SCHÉMA DIRECTEUR»?}

L'édification de ce maillage de surveillance, par la régularité des implantations et des distances entre ses différents éléments, trop systématiques pour n'être que des coïncidences, traduirait une organisation collective, conçue par un pouvoir centralisé (ou une coalition de pouvoirs) ${ }^{60}$. En effet, les mesures de distance entre les différents établissements, prises depuis leur centre, révèlent des constantes. Cela peut, dans la plupart des cas, s'expliquer par la recherche d'une distance optimisée par rapport à la visibilité. On peut cependant souligner certains détails de cet aménagement:

- Le triangle Tall al-Šayh 'Alī - Huirbat al-Zarqā' - Tall Harī' est parfaitement équilatéral, avec un côté de $16,5 \mathrm{~km}$. Celui formé par Ğabal al-Rāyyā, Tall Farzān et Al-Ṭūbā l'est presque, avec des côtés de $11 \mathrm{~km}, 11,6 \mathrm{~km}$ et $11,3 \mathrm{~km}$. Même chose pour celui de Rubbā, Ğabal Abū Zayd et Kaytalūn avec des côtés de 6,75 km, 6,4 km et $6,5 \mathrm{~km}$;

- Plusieurs points fortifiés sont situés à la même distance, soit 20,7 km de Tulūl Manatīr al-Hurūṭ: Al-Dabka 1, Tall al-'Albāwī et Tall Dahab;

- Il semblerait que les grandes villes fortifiées en avant des capitales de royaume soient disposés selon un tracé géométrique, formant des triangles quasiment isocèles (figs. 24 et 30): Tall al-Ṭūkān est disposé pratiquement sur la médiane de l'angle (de $86^{\circ}$ ) qui a pour pointe Ebla et pour extrémités des côtés Qinnasrīn (à $29,2 \mathrm{~km}$ ) et

59. La communication par signaux lumineux est attestée à l'âge du Bronze dans le royaume de Mari, aux environs de 2000 av. J.-C. (Dossin 1938). Elle se fait au moyen de torches et selon un code préétabli. D'après Leibovici (2012: 123), «[...] la visibilité d'une flamme, par nuit noire et ciel clair à une altitude de $100 \mathrm{~m}$, est de plus de $20 \mathrm{~km}$ en l'absence d'obstacles pour une sensibilité normale de l'œil». Par exemple, l'espacement des relais du télégraphe Chappe en France, selon les endroits, est de 7 à 20 km.

60. Rappelons la construction, très probablement au Bronze ancien IV, d'un «Très Long Mur» de près de $220 \mathrm{~km}$ de long (Geyer et al. 2010), dont la mise en œuvre découle du même principe.
Tall al-'Ūgā (à 27,8 km). Dans le cas de Tall al-Nāșirīya, les places fortes sont à 20,8 km (Tall Țayyibat al-Ism) et $19,9 \mathrm{~km}$ (Ğabal al-Ġuwayḥim) et forment un angle de $43^{\circ}$. La forteresse de Qal'at al-Rahiyya est placée à $22,9 \mathrm{~km}$ de Tall Țayyibat al-Ism et à $24,4 \mathrm{~km}$ de Ğabal al-Guwayhim, sur la médiane de cet angle. Pour Qatna, Tall al-Šayh 'Alī, à 28 km et Tall al-Ṣūr, à 27,3 km sont disposées selon un angle de $38,8^{\circ}$;

- Le centre de Ğabal al-Ġuwayhim est exactement au nord du centre de Qatna; la médiane entre le centre de Tall Țayyibat al-Ism et la tour de Ğabal al-Rāyyā est exactement au nord de Ğabal al-Ġuwayhim;

- Un autre fait marquant est l'alignement de certaines positions fortifiées entre elles. Nous n'avons retenu que celles pour lesquelles le décalage était inférieur à $200 \mathrm{~m}$ : Qal'at al-Rahiyya, Qal'at al-Hawāyis et Tall Abū Drīhna sont alignées avec un décalage de $190 \mathrm{~m}$ sur $34,8 \mathrm{~km}$. Ebla, Tall Kursiyan, Ğabal Rağm Șarā‘a, Ğabal Ray al-Hawā présentent un alignement sur $40 \mathrm{~km}$, avec un décalage de $150 \mathrm{~m}$ par rapport à l'axe. Tall al-Nāṣirīya, Ğabal al-Rāyyā (la tour au-dessus de Tall Țayyibat al-Ism) et Ruğum al-Amțal sont alignées sur $43 \mathrm{~km}$ avec un décalage latéral de $100 \mathrm{~m}$ alors qu'il n'y a de connection visuelle qu'entre Tall Țayyibat al-Ism et Ğabal al-Rāyyā. De plus, Tall al-Nāṣirīya et Tall Țayyibat al-Ism sont espacées de 20,8 km, exactement comme Ğabal al-Rāyyā et Ruğum al-Amțal. Qinnasrīn, Ğabal al-Šahīd et Qal'at Sfìrā sont sur une même ligne, avec un espacement de 15,6 km entre chaque point.

L'alignement des fortifications, jusqu'aux limites de la visibilité à l'œil nu, pourrait alors avoir été volontaire, afin de superposer les signaux lumineux et de limiter au maximum les erreurs de lecture ${ }^{61}$. Cependant, l'application rigoureuse d'un plan qui semble prédéfini se serait effectuée en prenant en compte les avantages du relief, comme les buttes isolées qui étaient déjà naturellement défendues et lorsque les contraintes locales de la topographie ne permettaient pas de vision directe entre les établissements, des fortins ou des tours intermédiaires auraient été ajoutés, dans la mesure du possible à égale distance des deux fortifications à relier.

Ces éléments tendraient à prouver l'existence d'un «schéma directeur» pour l'établissement de l'ensemble de cette défense des marges de la steppe. Ceci pourrait expliquer également la croissance des établissements selon des modalités différentes

61. Une tablette de Mari relate une méprise sur la vision de deux feux (signalant une attaque) alors qu'il s'agissait de signaux dans le même alignement: Durand 1998: 494-497, repris par Leibovici 2012: 116. 
d'un site à l'autre (les acropoles de Qatna et Ebla se trouvent à peu près au centre du site, celle de Tall al-Ṭūkān au sud, celle de Tall al-Ṣūr au nord, celle de Tall al-Šayh 'Alī à l'ouest, etc.). En effet, la géométrie du réseau n'apparaît que lorsqu'on mesure les distances à partir du centre des établissements et non à partir du point le plus haut (qui correspond plutôt au centre du noyau ancien). Ceci est particulièrement notable dans le cas des très grands sites qui ont vu leur extension maximale à l'âge du Bronze moyen.

L'édification de ces forteresses ne peut pas être le fruit d'initiatives individuelles de chefs locaux car leur répartition géographique ne répond pas à la défense de petits territoires mais à une seule et même logique régionale. On peut imaginer une coordination de chefs, menée par un pouvoir suffisamment contraignant pour faire appliquer le plan de défense, ou une fédération de plusieurs entités régionales unies face à un ennemi commun susceptible de déferler de l'est par la steppe.

\section{UN PROJET CONCERTÉ?}

Un réseau de défense et de surveillance de cette ampleur ne peut se justifier sans prendre en considération les grands établissements urbains du Croissant fertile, zone de peuplement sédentaire par excellence. Comme nous l'avons vu, il semble avoir été lié aux très grosses agglomérations et donc aux royaumes qui bordent la steppe à cette période : ceux de Qatna (Tall Mišrifa), d'Ebla (Tall Mardih) et de Yamhad (Alep) ${ }^{62}$, auxquels nous proposons d'adjoindre un royaume dont la capitale aurait été située à Tall al-Nāșirīya ${ }^{63}$. En effet, cette vaste ville fortifiée occupée à l'âge du Bronze moyen a des proportions comparables à celles d'Ebla (tabl. 2) et pourrait être l'une des capitales de royaumes de Syrie du Nord encore non identi-

62. Politiquement, la ville d'Alep n'a été importante que durant l'âge du Bronze moyen, comme capitale du royaume de Yamhad. La question de la relation entre Alep et Ebla à cette période n'est pas résolue (Knitter et al. 2014: note 54, 115-116). Alep est implanté en plein cœur du Croissant fertile, bénéficie de sols au moins aussi favorables que ceux d'Ebla, et est situé sur un des rares cours d'eau pérennes de la région (le Qwayq).

63. Le site fait l'objet de travaux archéologiques dirigés par D. Parayre et M. Al-Maqdissi depuis 2006. Il a connu une occupation continue depuis l'âge du Bronze ancien IV jusqu'à l'époque mamelouke. De plan grossièrement carré, il est très vaste $(850 \mathrm{~m}$ de côté, soit 65 ha dans son emprise maximale et 45 ha intra-muros) entouré de grosses levées de terre, jusqu'à $40 \mathrm{~m}$ de hauteur pour $100 \mathrm{~m}$ de largeur, au nord et à l'est. Sur les deux autres côtés, l'Oronte fait office de défense naturelle. L'angle sud est occupé par une acropole rectangulaire de $300 \mathrm{~m}$ x $200 \mathrm{~m}$ (4,5 ha). Petit site ovale à l'âge du Bronze ancien, il serait devenu carré au début du $2^{\mathrm{e}}$ millénaire av. J.-C. (Al-Maqdissi et al. 2010a et b) et aurait atteint son extension maximale à l'âge du Bronze moyen Ib (comm. personnelle D. Parayre). fiée ${ }^{64}$. Ces royaumes seraient tous, et au même titre, concernés par l'édification de cette défense car les forteresses sont régulièrement disposées par rapport à ces capitales.

L'analyse du peuplement des Marges arides de Syrie du Nord à l'âge du Bronze moyen montre une prise en compte systématique de la défense dans la conception des agglomérations. Seuls les petits sites des zones les moins arrosées ne sont pas ou ne semblent pas entourés d'une enceinte mais ils sont dans la plupart des cas installés sur des sites préexistants qui offraient au minimum une position surélevée qui permettait de surveiller les alentours. Dans la zone des sédentaires, un seul site, probablement une ferme (Ğadū'iyyat al-Šamāliyya 1) ne comporte pas de fossé mais une enceinte circulaire avec une porte protégée par des contreforts. Il est cependant situé à un kilomètre seulement d'un fortin et en vue de trois tours et d'une forteresse ! De fait, cette accentuation de la protection et de la défense des populations à l'âge du Bronze moyen a été mise en évidence sur la plupart des sites fouillés et de nombreuses études ont souligné ce fait ${ }^{65}$. Elle correspond à ce que l'on sait du développement de la poliorcétique et des progrès dans les techniques de guerre et de siège et donc de défense, à l'âge du Bronze (Rey 2012; Burke 2008).

Le réseau défensif mis en évidence dans les régions des marges arides complète la protection offerte aux populations par les fortifications urbaines. En effet, ce sont d'abord les tells, installés dans les fonds de vallée et pourvus de remparts et de fossés qui servent, en cas d'incursion ennemie, à abriter la population des alentours en attendant l'arrivée des renforts ${ }^{66}$. Nos travaux de terrain et notre analyse du réseau défensif permettent de mettre en évidence l'empreinte dans le paysage d'une organisation fortement hiérarchisée. Ils confirment la hiérarchie de l'implantation des agglomérations proposée ailleurs par l'archéologie («nested hierarchical model ») ${ }^{67}$.

Ils corroborent également les conclusions sur l'organisation de la défense qui découlent de l'analyse de la documentation écrite (Burke 2008: 122-124). D’après A.A. Burke (2008: 122),

64. Les études de topographie historique à partir de la documentation épigraphique et l'analyse pétrographique et chimique des tablettes d'Amarna, pour une période plus tardive (XIV s. av. J.-C.) permettent de proposer les noms de Tunip, dont l'identification avec Asharneh n'est pas complètement assurée, de Parga ou encore d'Ukulzat, capitale du royaume de Nuhashe au Bronze récent, qui serait située dans la moyenne vallée de l'Oronte, entre Hama et Alep (Richter und Lange 2012; Lafont 2016: 91 ; Bonechi 2016; Finkelstein et al. 2004: 91-92).

65. Pour la région du Maț : Baffi and Peyronel 2014: 14-20; Peyronel 2014.

66. Cette stratégie est fréquemment évoquée dans les textes: voir par exemple Abrahami 1997: chapitre V.

67. Wilkinson 2003. Ces résultats sont surtout très proches de ceux d'Aline Tenu (2008) sur les forteresses assyriennes de la vallée du moyen Euphrate. 
Tableau 2 - Récapitulatif de la typologie des sites.

\begin{tabular}{|c|c|c|c|c|c|c|c|}
\hline \multicolumn{6}{|c|}{ Réseau défensif reconnu dans les Marges arides (datation par la céramique) } & \multicolumn{2}{|c|}{ Sites probables (non datés) } \\
\hline Nom & Dimensions & Surface tot. & Surf. Int. & Surf. VB & Surf. VH & Nom & Dimensions \\
\hline Capitales de royaumes & en $\mathrm{m}$ & en ha & en ha & en ha & en ha & & en $\mathrm{m}$ \\
\hline Qatna & & 160 & 100 & & & & \\
\hline Tall al-Nāșirīya & & 103 & 45 & & 4,5 & & \\
\hline Ebla & & 100 & 46 & & 3,5 & & \\
\hline \multicolumn{8}{|l|}{ Grandes villes fortifiées } \\
\hline Tall al-Șūr & $720 \times 580$ & 37 & 24 & 9,5 & 0,4 & & \\
\hline Tall al-Šayh 'Alī & $580 \times 460$ & 27 & 20 & & 4,5 & & \\
\hline Ǧabal al-Ġuwayḥim & $700 \times 665$ & 53 & 36 & & & & \\
\hline Tall Ṭayyibat al-Ism & $700 \times 600$ & 36 & 28 & 13,5 & 0,6 & & \\
\hline Tall al-Ṭūkān & $650 \times 500$ & 46 & 19 & & 4 & & \\
\hline Qinnasrīn & $700 \times 700$ & 40 & 35 & & 3,3 & & \\
\hline \multicolumn{8}{|l|}{ Forteresses } \\
\hline Rubbā & $230 \times 175$ & & 3,1 & & & Ǧabal al-Šahīd & $190 \times 180$ \\
\hline Qal'at al-Rahiyya & $230 \times 160$ & & 2,8 & & & & \\
\hline Qal'at al-Hawāyis & $115 \times 110$ & & 0,9 & & & & \\
\hline Tall Abū Drīha & $135 \mathrm{~m}$ diam. & & 1,3 & & & & \\
\hline Tall al-'Ūgā & $170 \times 150$ & & 1,9 & & & & \\
\hline Tall Șabḥa & $115 \mathrm{~m}$ diam. & 16,3 & 0,9 & & & & \\
\hline Rağm al-Ṣawān & $370 \times 330$ & 10,5 & 2 & & & & \\
\hline Tall Draham (non daté) & $120 \times 91$ & & 0,5 & & & & \\
\hline \multicolumn{8}{|l|}{ Fortins } \\
\hline Qal'at Šumaymīs & $82 \times 53$ & & 0,3 & & & Tulūl Manatīr al-Hurūț & $60 \mathrm{~m}$ diam. \\
\hline Al-Qasțal al-Šamālī & $60 \mathrm{~m}$ diam. & & 0,4 & & & Ǧabal al-Maḥdiyya & $60 \mathrm{~m}$ diam. \\
\hline Tall al-'Albāwī & $66 \mathrm{~m}$ diam. & & 0,3 & & & Tall Nabārīz & $50 \mathrm{~m}$ diam. \\
\hline \multirow[t]{3}{*}{ Tall Dahab } & $40 \mathrm{~m}$ diam. & & & & & Tall Harī & $45 \mathrm{~m}$ diam. \\
\hline & & & & & & Tall Farzān & $50 \mathrm{~m}$ diam. \\
\hline & & & & & & Ḍahrat Abū Maqām & $45 \mathrm{~m}$ diam. \\
\hline \multicolumn{8}{|l|}{ Tours } \\
\hline Fahr & $37,5 \times 34$ & & 0,07 & & & Qașr al-Mukarram & $25 \mathrm{~m}$ diam. \\
\hline 'Arḍ al-Riğla & $20 \mathrm{~m}$ diam. & & & & & Rasm al-Suwayd & $25 \times 20$ \\
\hline Ruğum al-Amțal & $20 \times 20$ & & & & & Tulūl al-Hawa & $30 \mathrm{~m}$ diam. \\
\hline Ǧabal Fārimha & $25 \mathrm{~m}$ diam. & & & & & Rasm Zabad & $20 \times 15$ \\
\hline Hirbat 'Umm Ruğūm & $35 \mathrm{~m}$ diam. & & & & & Tall Kursiyan & $25 \mathrm{~m}$ diam. \\
\hline Tabārat al-Zbīb 1 & $25 \times 25$ & & & & & Tall al-Baǵl & $30 \mathrm{~m}$ diam. \\
\hline \multirow[t]{11}{*}{ Tilāl Ḥmaymāt al-Dāyr } & $25 \mathrm{~m}$ diam. & & & & & Ruğum al-Harğ & $32 \times 30$ \\
\hline & & & & & & Ǧabal Kafrāa & $30 \mathrm{~m}$ diam. \\
\hline & & & & & & Ǧabal Rağm Șarā‘a & $25 \mathrm{~m}$ diam. \\
\hline & & & & & & Kaytalūn & $20 \times 20$ \\
\hline & & & & & & Ǧabal Abū Țuwayqiyya & $20 \mathrm{~m}$ diam. \\
\hline & & & & & & Al-Ṭūbā & $20 \times 20$ \\
\hline & & & & & & Qurbatiyya & $20 \times 10$ \\
\hline & & & & & & Qal'at Sfírā & \\
\hline & & & & & & Tall Wāsța & \\
\hline & & & & & & Ǧabal Abū Darda & \\
\hline & & & & & & Al-Bāb & \\
\hline \multicolumn{8}{|l|}{ Petites tours } \\
\hline Al-Mințār & $12 \times 11$ & & & & & Al-Luğğ & \\
\hline Al-Dabka 1 & $12 \times 12$ & & & & & Al-Bāb / Al-Burğ & \\
\hline Ruğum al-Harāyiğ & $10 \times 9$ & & & & & Ǧabal Kāsūn & $15 \times 15$ \\
\hline \multirow[t]{7}{*}{ Al-Ṭwayḥina 4} & $9 \times 9$ & & & & & 'Umm ‘Āmūd & $15 \mathrm{~m}$ diam. \\
\hline & & & & & & Ǧabal Abū Zayd & $14 \times 12$ \\
\hline & & & & & & Hirbat al-Zarqā' & $12 \times 12$ \\
\hline & & & & & & Ǧabal al-Rāyyā & $15 \times 12$ \\
\hline & & & & & & Qulay'āt al-Ṭuwaybā & $15 \times 12$ \\
\hline & & & & & & Ǧabal Ray‘ al-Hawā & $15 \times 15$ \\
\hline & & & & & & Rağm al-Farkā & $13 \times 13$ \\
\hline
\end{tabular}


«In order to understand how such defensive networks were formed, the classification of settlement types must rely on a native understanding of different settlement types as described, for example, in Ugaritic, and not simply on criteria such as settlement size and fortification type». Cette démarche lui a permis d'identifier des réseaux défensifs centrés autour de groupes d'agglomérations politiquement affiliées et notamment des districts administratifs et quasi militaires. Six «primary settlement types» ont été identifiés:

- «large fortified towns» (qarītu avec ville basse et ville haute), telles Alep, Ebla et Qatna;

- «secondary fortified towns» (' $r /$ ' $r m$ ), satellites dont la taille n'excède pas celle des capitales royales, situées à une journée des grands centres (ca $30 \mathrm{~km}$ ), comme Tall al-Ṭūkān et Tall al-Ṣūr, ces villes pouvant elles aussi contrôler des agglomérations satellites;

- «unfortified villages» (kaparu) dont la fermeture sur l'extérieur est constituée par la juxtaposition des murs arrière des constructions;

- «fortresses» $(h l)$ entre 0,1 et 1,2 ha le long des routes, avec une excellente vue sur le trafic et en position de relayer les informations;

- «military watchtowers» (magdalu) de taille inférieure à 0,1 ha, mais stratégiquement positionnées sur des crêtes le long des principaux axes de circulation;

- «rural agricultural estates» (gittu), entre 0,1 et 0,5 ha, qui n'étaient pas fortifiés.

Notre analyse confirme donc et complète celle de A.A. Burke. La documentation textuelle qui concerne plus particulièrement la région montre en effet qu'il existait des postes militaires, situés à la lisière de la steppe, chargés de surveiller les voies de communication et les terres cultivées. Les unités mobiles qui y stationnaient avaient un rôle qui pouvait aller, selon la conjoncture, de l'observation à la patrouille et à la résistance effective ${ }^{68}$.

La confrontation de nos résultats avec les textes de la période permettra sans aucun doute d'aller plus loin dans l'interprétation. Mais déjà, la visualisation cartographique de ces résultats permet d'ajouter certains éléments :

- Elle montre que les capitales de royaumes sont espacées de 70 à 44 km et que le site de Tall al-Nāșirīya, dont la surface intra muros est de 45 ha et dont nous pensons

68. Abrahami 1997: 24-26. Par exemple, une lettre (ARM I 20) évoque des forts situés en rase campagne, qui permettaient d'assurer la défense de villes proches (Tuttul et Yabliya), gardés par des soldats venant de Qatna (Abrahami 1997: 43 et 329). qu'il pourrait s'agir d'une capitale de royaume (voir supra, p. 155), s'insérerait parfaitement dans ce premier type d'implantations majeures. En effet, elle se trouve à $48 \mathrm{~km}$ de Qatna et à $64 \mathrm{~km}$ d'Ebla;

- Parmi les grandes villes fortifiées, villes satellites des villes royales, plusieurs peuvent être ajoutées à Tall al-Ṭūkān et à Tall al-Ṣūr, précédemment citées, notamment Tall al-Šayh 'Alī et Tall Țayyibat al-Ism. Toutes ont une taille comprise entre 19 et 28 ha (fig. 24 et tabl. 2) et sont situées en avant des villes royales, côté steppe, à une distance de ces dernières qui varie entre $15 \mathrm{~km}$ (Ebla Tall al-Ṭūkān) et $28 \mathrm{~km}$ (Qatna - Tall al-Šayh 'Alī). Cependant, nous n'avons pas travaillé sur les autres régions et il est probable que ces villes ne constituaient pas les seuls satellites des capitales de royaumes des bordures de la steppe ${ }^{69}$;

- Nous n'avons repéré dans la région qu'un seul exemple qui pourrait être apparenté à un kaparu ou gittu (Ğadū'iyyat al-Šamāliyya $1 ; 0,5$ ha). Dans ce cas, l'absence de fortification serait synonyme d'absence de fossé;

- Aucun des sites prospectés attribués à l'âge du Bronze moyen ne peut indubitablement être qualifié d'établissement nomade. En effet, les seuls sites, non fortifiés, localisés au-delà des terres des sédentaires (ils sont au nombre de sept; supra, p. 151) sont situés sur des routes. Il se pourrait par conséquent que soit les nomades aient été absents de cette région (ce qui paraît peu probable), soit qu'ils relèvent d'une culture matérielle différente dont nous n'aurions pas su interpréter les traces sur le terrain.

Aucune forteresse ne semble avoir été étudiée en tant que telle au Levant Nord avant nos travaux. Celles des Marges arides sont au nombre de neuf. Leur taille varie entre 3,1 ha pour Rubbā et 0,5 ha pour Tall Draḥam (tabl. 2). Elles sont généralement situées sur des hauteurs mais ces dernières sont fonction des reliefs en présence. Certaines, comme Rağm al-Ṣawān sont à une faible altitude mais sur une butte. D'autres, comme Tall Abū Drīhna, ont été installées sur un remblai artificiel. Chaque forteresse est éloignée de la ville satellite la plus proche de 20 à $28 \mathrm{~km}$ et s'insère dans le maillage de ces grandes villes fortifiées. Ensemble, elles forment une ligne de points fortifiés régulièrement espacés: Qinnasrīn -

69. Le cas de 'Umm al-Marā est légèrement différent; elle est de plus petite taille (14 ha) et plus éloignée d'Alep que ne le sont les autres grandes villes par rapport aux capitales. 
Tall al-Ṭūkān, 20 km; Tall al-Ṭūkān - Tall al-'Ūgā, 20,5km; Tall al-'Ūgā - Tall Abū Drīha, 13 km; Tall Abū Drīha - Qal'at al-Hawāyis, 16 km; Qal'at al-Hawāyis - Qal'at al-Rahiyya, 18 km; Qal'at al-Rahiyya - Rubbā, 20 km; Rubbā - Tall al-Šayh 'Alī, 21 km; Tall al-Šayh 'Alī - Tall al-Ṣūr, 18 km.

Une catégorie de sites révélée par le terrain est intermédiaire entre les forteresses et les tours: il s'agit des fortins, en moyenne de 0,3 à 0,4 ha, établis sur des points élevés. Certains d'entre eux sont localisés à mi-chemin entre les capitales de royaumes et les grandes villes fortifiées, par exemple entre Alep, Qinnasrīn et Ebla et entre Tall al-Šayh 'Alī, Qatna et Tall al-Șūr.

Deux types de tours de guet ont été identifiés. Les premières sont similaires à celles (magdalu) répertoriées dans le Levant Sud (Burke 2008: 123, fig. 12.4). Les autres sont d'une taille plus réduite et servaient peut-être uniquement comme répéteur dans la transmission des informations.

Enfin, il semblerait que le dispositif soit complété par des enceintes-refuges, disposées non loin des tours et pouvant accueillir temporairement des populations. Elles sont construites avec des murs larges en appareil polygonal, comme à Ğabal Fārimha 2. Nous en avons recensé une dizaine (fig. 17 et tabl. 3). Aucune céramique n'a été retrouvée sur celles que nous avons prospectées; cependant, le mode de construction, la liaison avec la tour dans le cas d'al-Mințār et la proximité avec les autres tours permettent de supposer une datation de l'âge du Bronze moyen ${ }^{70}$.

La topographie et la géographie sont des composantes essentielles du réseau. On a déjà évoqué la position stratégique des forteresses, fortins et tours et la recherche de points en hauteur pour leur implantation. Il est probable que les éléments défensifs (remparts, tours, portes, plateformes de tir, etc.), outre leur rôle effectif, imprimaient fortement leur marque dans le paysage et notifiaient la puissance de ceux qui les avaient construits; c'était le cas également pour les fortifications urbaines. L'organisation de la défense du territoire prenait aussi en compte la topographie dans l'implantation des grandes agglomérations satellites.

Si les secondary fortified towns ont parfois été interprétées comme des capitales de district, nous pouvons proposer également une autre fonction, à partir de leurs taille, aspect et surtout position dans le paysage. En effet, si l'on considère les implan-

70. De tels sites ont également été identifiés dans la moyenne vallée de l'Euphrate, quoique pour une période un peu plus tardive (fin du $2^{\mathrm{e}}$ - début du $1^{\text {er }}$ millénaires). Ils sont interprétés comme des camps retranchés (Tenu 2008: 168).
Tableau 3 - Récapitulatif des tours associées à des enclos.

\begin{tabular}{|c|c|c|}
\hline \multicolumn{2}{|c|}{ Tours avec enclos } \\
\hline Nom & $\begin{array}{c}\text { Position de la tour } \\
\text { par rapport à l'enclos }\end{array}$ & $\begin{array}{c}\text { Surface enclose } \\
\text { (en ha) }\end{array}$ \\
\hline Al-Mințār & Angle supérieur & 2 \\
\hline Al-Dabka 1 & En lisière supérieure & 2 \\
\hline Ruğum al-Amțal & 545 m au S du centre & 3 \\
\hline Ǧabal Fārimha & 350 m au S du centre & 1 \\
\hline Ruğum al-Harāyiğ & Angle N & $0,6 ?$ \\
\hline Sites non prospectés & & 1,6 \\
\hline Rağm al-Farkā & 250 m au N du centre & 0,4 \\
\hline 'Umm 'Āmūd & À l'intérieur & 9 \\
\hline Qașr al-Mukarram & À l'intérieur & 4,2 \\
\hline Al-Luğğ & 321 m au SE du centre & 4,3 \\
\hline 027, Rigot 2003 & Angle N & \\
\hline
\end{tabular}

tations lourdement fortifiées, de taille proche de 20 ha ou supérieure, mais qui ne sont pas des capitales de royaume, alors subsistent Qinnasrīn (35 ha), Tall al-Ṭūkān (19 ha), Tall Țayyibat al-Ism (28 ha), Ğabal al-Ġuwayhim (36 ha), Tall al-Šayh 'Alī (20 ha) et Tall al-Ṣūr (24 ha). Certaines sont situées de manière à avoir une vue directe sur la totalité du paysage alentour (Qinnasrīn, Ğabal al-Ġuwayḥim, Tall al-Šayh 'Alī), d'autres sont installées dans une plaine et parfois «cachées » derrière un relief (Tall al-Ṭūkān, Tall Țayyibat al-Ism, Tall al-Șūr). Pourrait-on envisager ces établissements, disposés le long des axes majeurs de l'âge du Bronze moyen, comme ayant été des villes de garnison, qui auraient accueilli les soldats chargés d'intervenir auprès des populations civiles retranchées derrière leurs murailles en cas d'attaque? Cette interprétation n'exclut évidemment pas, pour ces grandes agglomérations, d'autres fonctions spécifiques, comme l'organisation de l'exploitation agricole du territoire. De même qu'une capitale de district, elles sont placées au centre d'une région au sens géographique du terme (un bassin endoréique par exemple) ou, pour Qinnasrīn et Ğabal al-Guwayhim, sur la limite entre deux. La distance d'intervention des troupes serait par conséquent optimisée en fonction de la répartition du peuplement et des circulations.

\section{CONCLUSION}

L'approche géo-archéologique, qui s'intéresse à toutes les formes d'anthropisation du paysage sans négliger aucune période ni aucun mode d'occupation, a permis de mettre en évidence un réseau défensif à l'âge du Bronze moyen sur les 
marges arides de la Syrie du Nord. Cette organisation hiérarchisée, fondée sur une répartition spatiale des différentes installations tirant le meilleur parti du relief, prend en compte à la fois la défense, la surveillance et la communication. C'est du moins vers ces conclusions que tend l'analyse des données géographiques et matérielles fournies par la prospection de la région des Marges arides de Syrie du Nord, détachée des considérations historiques, mais qu'on aura voulu rigoureuse.

Cet aspect fondamental des sociétés de l'âge du Bronze moyen avait été jusque-là étudié du point de vue de la défense des agglomérations et du territoire des villes. Nos travaux, fondés sur l'analyse d'un corpus de près d'une centaine de sites, la plupart inédits, répartis sur une distance de $100 \mathrm{~km}$, montrent que, dès la fin de l'âge du Bronze moyen I, se mettraient en place une organisation de la défense à une échelle régionale et la coordination des systèmes défensifs de plusieurs royaumes. Cette structuration s'appuierait sur la création de sites nouveaux, les fortifications de hauteur en lisière des plateaux basaltiques dominant la steppe.

Les découvertes de la mission des Marges arides de Syrie du Nord permettent de réinterpréter les résultats des travaux sur les régions et les sites limitrophes et d'envisager l'ensemble d'un point de vue à la fois plus large et systémique, grâce à une méthodologie de travail mise au point, expérimentée et validée par notre équipe. Cette méthode de prospection et d'analyse, globale, diachronique et pluridisciplinaire a permis cette découverte et l'extension des observations bien au-delà des sites prospectés.
La description de ce réseau n'est qu'une première étape. La confrontation des résultats de l'analyse des éléments matériels avec les informations des sources écrites permettra d'aller plus loin dans l'interprétation, en attendant l'accès au terrain qui seul permettra de confirmer nos interprétations et de compléter les informations sur certains sites. Nous laissons le soin aux historiens et archéologues spécialistes de la période d'approfondir ces pistes de réflexion.

\section{REMERCIEMENTS}

Nous remercions Philippe Abrahami, Frank Braemer et Valérie Matoïan pour leur relecture attentive et leurs orientations bibliographiques.

Marie-Odile ROUSSET

Bernard GEYER

Shadi SHABO

CNRS, UMR 5133 - Archéorient, Maison de l'Orient et de la Méditerranée Université Lumière Lyon 2 7, rue Raulin - 69365 Lyon cedex 07 - FRANCE marie-odile.rousset@mom.fr bernard.geyer@mom.fr shadi.shabo@gmail.com

Nazir AWAD

Direction Générale des Antiquités et des Musées de Syrie Rue Qasr al-Hayr-Damas - RAS nazeerwd@gmail.com

\section{BIBLIOGRAPHIE}

\section{ABRAHAMI P. \\ 1997 L'armée à Mari. Thèse de doctorat non publiée. Université de Paris I.}

AL-MAQDISSI M.

2006 Note d'Archéologie Levantine VII. Matériel archéologique du Bronze moyen à Khan Sheikhoun. Baghdader Mitteillungen 37 : 481-498.

2011 Prospections archéologiques dans la région autour de MishirfehQatna (2005-2009). Chronique archéologique en Syrie V : 43-57 (en arabe).

Al-MaQdissi M., PARAYre D. et SAUVAge M.

2010a La mission conjointe syro-française de l'Oronte: première et deuxième campagnes (2007 et 2008). Chronique archéologique en Syrie IV : 193-198.

2010b Mission archéologique syro-française de l'Oronte. Tell alNasriyah et Tell Massin: les sites quadrangulaires, nouveau regard. Rapport préliminaire sur les opérations des campagnes 2007-2008. Akkadica 131: 165-200.
AL-MaQdissi M., Kanhoush Y., MoRANDI Bonacossi D. et CREMASChi M.

2009 Présentation sommaire des travaux archéologiques de la mission syro-italienne: Les fouilles archéologiques à Mishrifeh-Qatna et la prospection de la Palmyrène occidentale. Studia Orontica I: $5-20$.

\section{AL-MoussLi M.}

$1985 \quad$ Fouilles d'As-Sour. Syria 62: 132.

ASCALONE E.

2014 The Long Life of the Dead. A Middle Bronze IB Necropolis at Tell Tuqan, Syria. In: BAFFI F., Fiorentino R. and PEYRONEL L. (eds.): 189-225.

ASTOUR M.C.

1995 Overland Trade Routes in Ancient Western Asia. In: SASSON J.M. (ed.), Civilizations of the ancient Near East: 1401-1420. New York: Scribner. 
BAFFI F.

2014 The Defences at Tell Tuqan in the 2nd Millennium B.C. In: BAFFI F., FIORENTINO R. and PEYRONEL L. (eds.): 163-188.

BAFFI F. and PEYRONEL L.

2014 Tell Tuqan and the Matkh Basin in a Regional Perspective. Thoughts and Questions Raised by the International Conference. In: BAFFI F., FIORENTINO R. and PEYRONEL L. (eds.): 9-34.

Baffi F., Fiorentino R. and Peyronel L. (eds.)

2014 Tell Tuqan Excavations and Regional Perspectives. Cultural Developments in Inner Syria from the Early Bronze Age to the Persian/Hellenistic Period. Proceedings of the International Conference. Lecce, May 15th-17th 2013. Galatina: Congedo.

BARTL K. and AL-MAQDISSI M.

2014 Archaeological Prospecting on the Middle Orontes River: Survey work between ar-Rastan and Qal'at Šayzar. In: BARTL K. and Al-MAQDISSI M. (eds.), New prospecting in the Orontes Region: first results of archaeological fieldwork: 61-77. Rahden / Westf.: Verlag Marie Leidorf (Orient-Archäologie 30).

BESANA R., DA ROS M. and IAMONI M.

2008 Excavations on the Acropolis of Mishrifeh, Operation J. A New Early Bronze Age III-Iron Age III Sequence for Central Inner Syria. Part 2: The Pottery. Akkadica 129: 79-130.

BESANÇON J. et GEYER B.

2006 Contraintes écogéographiques et modes d'occupation du sol. In: JAUBERT R. et GEYER B. (éd.), Les marges arides du Croissant fertile. Peuplements, exploitation et contrôle des ressources en Syrie du Nord: 11-53. Lyon: Maison de l'Orient (TMO 43, série «Conquête de la steppe» 2).

BONECHI M.

2016 Thorny Geopolitical Problems in the Palace G Archives. The Ebla Southern Horizon, Part One: the Middle Orontes Basin. In: PARAYRE D. (éd.), Le fleuve rebelle. Géographie historique du moyen Oronte d'Ebla à l'époque médiévale: 29-88. Beyrouth: IFPO (Syria, Supplément IV).

\section{BOURKE S.J.}

1993 The transition from the Middle to the Late Bronze Age in Syria: the evidence from Tell Nebi Mend. Levant 25: 113-195.

BRADBURY J. and PHILIP G.

2011 The world beyond the tells: pre-classical activity in the basalt landscape of the Homs region, Syria. In: STEIMER-HERBET T. (éd.), Pierres levées, stèles anthropomorphes et dolmens / Standing stones, anthropomorphic stelae and dolmens: 169-180. Oxford (BAR Int. Ser. 2317)

BURKE A.A

2008 Walled up to Heaven: The Evolution of Middle Bronze Age Fortification Strategies in the Levant. Winona Lake: Eisenbrauns (Studies in the archaeology and history of the Levant 4).

BUTLER H.C

1907-1920 Ancient architecture in Syria. Section B, Northern Syria Publications of the Princeton Archeological Expeditions to Syria in 1904-1905 and 1909 (6 vol.). Leiden: Brill.

BYLINSKI J.

2006 Exploratory Mission to Shumaymis-2002. In: KENNEDY H. (ed.), Muslim Military Architecture in Greater Syria. From the
Coming of Islam to the Ottoman Period: 243-250. Leiden, Boston: Brill (History of Warfare 35).

CALlot O

2010 Les monnaies trouvées dans les «Marges Arides» (Syrie). In: GATIER P.-L., GEYER B. et Rousset M.-O. (éd.), Entre nomades et sédentaires. Prospections en Syrie du Nord et en Jordanie du Sud: 271-287. Lyon: Maison de l'Orient (TMO 55, série «Conquête de la steppe» 3 ).

CAlvet Y

2002 Early Middle Bronze Age Sites in the area of Salamiyah (Syria) In: BIETAK M. (ed.), The Middle Bronze Age in the Levant, Proceedings of an International Conference on MB IIA Ceramic Material, Vienna, 24th-26th of January 2001: 103-112. Wien: Österreichische Akademie der Wissenschaften (Denkschriften der Gesamtakademie, Band 26)

Coqueugniot É.

2011 Apport des industries lithiques à la connaissance de l'occupation des Marges arides (Syrie) du Paléolithique supérieur au Bronze ancien (premières observations). Syria 88: 23-30.

DEL FABBRO R

2012 The Roads from and to Aleppo: Some Historical-geographical Considerations in Light of New Archaeological Data. In: LANFRANCHI G.B., Morandi Bonacossi D., PAPPI C. and PONCHIA S. (eds.), Leggo! Studies Presented to Frederick Mario Fales on the Occasion of His 65th Birthday: 201-222. Wiesbaden: Harrassowitz Verlag.

DE MAIGRET A.

1978 Fluttuazioni territoriali e caratteristiche tipologiche degli insediamenti nella regione del Matah (Siria). Nota preliminare. Orientis Antiqui Collectio 13: 83-94.

Dossin G.

1938 Signaux lumineux au pays de Mari. Revue d'Assyriologie et d'archéologie orientale 35,3-4: 174-186.

DURAND J.-M.

1987 Documents pour l'histoire du royaume de Haute-Mésopotamie I. In: Mari, Annales de recherches interdisciplinaires 5: 155-198. Paris: ERC.

1998 Les Documents épistolaires du palais de Mari, Tome II. Paris Éditions du Cerf (Littératures anciennes du Proche-Orient 17).

FINKELSTEIN I., NA'AMAN N. and GOREN Y.

2004 Inscribed in clay: Provenance study of the Amarna tablets and other ancient near eastern texts. Tel Aviv: Tel Aviv University, Emery and Claire Yass Publications in Archaeology (Sonia and Marco Nadler Institute of Archaeology Monograph series 23).

FUGMANN E. (éd.)

1958 Hama. Fouilles et recherches de la Fondation Carlsberg 19311938, II. L'architecture des périodes pré-hellénistiques. Copenhague: Nationalmuseet.

GAUTIER J.-E.

1895 Note sur les fouilles entreprises dans la Haute vallée de l'Oronte. CRAI 39: 441-464.

GENZ H. and SADER H.

2010-2011 Middle Bronze Age pottery from Tell Hizzin, Lebanon. Berytus 53/54: 133-146. 
GEORGE P.

1993 Dictionnaire de la géographie (5éd.). Paris : PUF.

GEYER B.

2000 Des fermes byzantines aux palais omayyades, ou l'ingénieuse mise en valeur des plaines steppiques de Chalcidique (Syrie). In : NORDiguian L. et SAlles J.-F. (éd.), Aux origines de l'archéologie aérienne. A. Poidebard (1878-1955): 109-122. Beyrouth: Presses de l'Université Saint-Joseph.

2009 Die Syrische Mauer. In: NUNN A. (Hrsg.), Mauern als Grenzen: 38-45. Mainz am Rhein: Verlag Philipp von Zabern.

Geyer B. et Coqueugniot É.

2013 Occupation du sol et conquête territoriale durant le Néolithique dans les Marges arides de Syrie du Nord. Syria 90: 159-176.

Geyer B., Chambrade M.-L. and Coqueugniot É.

2014 Water Quest and Subsistence Strategies during the Neolithic in the Arid Margins of Northern Syria. In: MORANDI BONACOSSI D. (ed.), Settlement Dynamics and Human-Landscape Interaction in the Dry Steppes of Syria: 1-31. Wiesbaden: Harrassowitz Verlag (Studia Chaburensia 4).

Geyer B., AWAd N., AL-Dbiyat M., CAlvet Y. et Rousset M.-O.

2010 Un «Très long Mur dans la steppe syrienne». Paléorient 36,2: $57-72$.

Geyer B., AL-Dbiyat M., AWAD N., BARge O., BESAnÇON J., CALVET Y. and JAUBERT R.

2007 The Arid Margins of Northern Syria: Occupation of the Land and Modes of Exploitation in the Bronze Age. In: MORANDI BonACOSSI D. (ed.), Urban and Natural Landscapes of an Ancient Syrian Capital. Settlement and Environment at Tell Mishrifeh/Qatna and in Central-Western Syria, Proceedings of the International Conference held in Udine, 9-11 December 2004: 269-281. Udine: Forum Editrice (Studi Archeologici su Qatna 1).

Geyer B., Rousset M.-O., AL-Dbiyat M., AWAD N., BARge O.,

BESANÇON J. †, CALVET Y., GATIER P.-L. et JAUbert R.

2004-2005 Les Marges arides de la Syrie du Nord: première synthèse d'une prospection géoarchéologique. Annales Archéologiques Arabes Syriennes 47-48: 17-34.

HAASE C.-P.

1983 Ein archäologischer Survey im Ğabal Šbet und im Ğabal al-'Alā. Damaszener Mitteilungen 1: 69-76.

IAMONI M. (ed.)

2012 The MBA II and the LBA Pottery Horizons at Qatna. Innovation and Conservation in the Ceramic Tradition of a Regional Capital and its Implications for the Second Millennium Syrian Chronology. Udine: Forum Editrice (Studi Archeologici su Qatna 2).

IAMONI M. and MORANDI BONACOSSI D.

2010-2011 The Middle Bronze Age I-III pottery sequence from the Italian excavations at Mishrifeh/Qatna, Syria. Archaeological contexts and ceramic evidence. Berytus 53-54: 181-212.

JOANNÈS F.

1996 Routes et voies de communication dans les archives de Mari. In: DURAND J.-M. (éd.), Amurru I: Mari, Ébla et les Hourrites: dix ans de travaux. Actes du colloque international (Paris, mai 1993): 323-361. Paris: ERC.
KANHOUSH Y.

2015 Rapport préliminaire des résultats des campagnes des fouilles syriennes 2006-2009. Le «Palais Est» du Chantier T sur l'acropole de Mishrifeh-Qatna. In: PFÄLZNER P. and AL-MAQDISSI M. (eds.), Qatna and the Networks of Bronze Age Globalism: 441449. Wiesbaden (Qatna Studien Supplementa 2).

KLENGEL H.

2015 Qatna and Inter-Regional Trade in the Second Millennium BC. In: PFÄLZner P. and AL-MAQDISSI M. (eds.), Qatna and the Networks of Bronze Age Globalism: 65-68. Wiesbaden (Qatna Studien Supplementa 2).

KNitTer D., NAKoinz O., Del Fabbro R., KOHLMeyer K., SChÜtt B. and MEYER M.

2014 The Centrality of Aleppo and its Environs. eTopoi. Journal for Ancient Studies 3: 107-127.

LAFONT B.

2016 Que nous apprennent les textes de Mari sur l'Oronte? In: PARAYRE D. (éd.), Le fleuve rebelle. Géographie historique du moyen Oronte d'Ebla à l'époque médiévale: 89-95. Beyrouth: IFPO (Syria Supplément IV).

LASSUS J.

1935 Inventaire archéologique de la région au nord-est de Hama (2 vol.). Damas: Institut français de Damas (Documents d'études orientales 4$)$.

LEIBOVICI J.

2012 Les télécommunications au premier millénaire av. J.-C. au Proche-Orient ancien. Cahiers d'histoire 31,2: 113-132.

LIVERANI M.

1965 I tell preclassici. In: DAVICO A. et al., Missione archeologica italiana in Siria: rapporto preliminare della Campagna 1964 (Tell Mardikh): 107-133. Roma: Università di Roma, Centro di studi semitici, Istituto di studi del Vicino Oriente.

MANTELLINI S.

2013 Regional Approach and Archaeological Surveys in Northern Syria. An Overview. In: MatThiae P. and MarchetTi N. (eds.), Ebla and its Landscape: Early State Formation in the Ancient Near East: 238-256. Walnut Creek: Left Coast press.

Mantellini S., Micale M.G. and PeYronel L.

2013 Exploiting Diversity. The Archaeological Landscape of the Eblaite Chora. In: MATthiae P. and MARChetTi N. (eds.), Ebla and its Landscape: Early State Formation in the Ancient Near East: 163-194. Walnut Creek (CA): Left Coast press.

MATTHERS J.

1981 The river Qoueiq Northern Syria and its Catchment. Oxford (BAR Int. Ser. 98).

MATThiae P.

1979 Scavi a Tell Mardikh-Ebla 1978. Rapporto sommaria. Studi Eblaiti 1: 129-184.

MAXWEll-Hyslop R., DU Plat Taylor J., SETON Williams M.V. and D'ARCY WAECHTER J.

1942 An archaeological survey of the plain of Jabbul, 1939. Palestine Exploration Quarterly 74: 8-40.

MESNIL DU BUISSON R. (DU)

1927 Les ruines d'el-Mishrifé au Nord-Est de Homs (Émèse) ( $2^{\mathrm{e}}$ article). Syria $8: 13-33$. 
MORANDI BONACOSSI D.

2002 Operation J. In: AL-MAQDISSi M., MORANDI BONACOSSI D., PFÄlZnER P., LUCIANI M. and NOVÁK M. (eds.), Excavating Qatna I: Preliminary Report on the 1999 and 2000 Campaigns of the Joint Syrian-Italian-German Archaeological Research Project at Tell Mishrifeh: 123-144. Damascus: Salhani.

2008 Excavations on the Acropolis of Mishrifeh, Operation J. A New Early Bronze Age III-Iron Age III Sequence for Central Inner Syria. Part 1: Stratigraphy, Chronology and Architecture. Akkadica 129: 5-77.

2014 Some Considerations on the Urban Layout of Second Millennium BC Qatna. In: BAFFI F., FIORENTINO R. and PEYRONEL L. (eds.): 275-296.

MORANDI BONACOSSI D., DA Ros M., GARnA G., IAMONI M. and MERLINO M.

2009 The 'Eastern Palace' and the Residential Architecture of Area T at Mishrifeh/Qatna. Preliminary Report on the 2006-2008 Excavation Campaigns of the Italian Component of the SyroItalian Archaeological Project. Mesopotamia 44: 61-112.

MOUAMAR G.

2014 Tell Al-Ṣūr/Al-Sankarī: une nouvelle agglomération circulaire du Bronze ancien IV à la lisière de la steppe syrienne. In: BAFFI F., FIORENTINO R. and PEYRONEL L. (eds.): 95-114.

MOUTERde R. et POIDEBARD A.

1945 Le Limes de Chalcis. Organisation de la steppe en haute Syrie romaine. Paris: Geuthner (BAH 38).

MUSIL A.

1928 Palmyrena, a topographical Itinerary. New York: American Geographical Society.

NIGRO L.

2002a The Middle Bronze Age Pottery Horizon of Northern Inner Syria on the Basis of the Stratified Assemblages of Ebla and Hama. In: Al-MAQdissi M., MATOÏAN V. et NiCOLle C. (éd.), Céramique de l’Âge du Bronze en Syrie, I. La Syrie du Sud et la vallée de l'Oronte: 97-128. Beyrouth: IFPO (BAH 161).

2002b The MB Pottery of Tell Mardikh/Ancient Ebla in a Chronological Perspective. In: BIETAK M. (ed.), The Middle Bronze Age in the Levant, Proceedings of an International Conference on MB IIA Ceramic Material. Contributions to the Chronology of the Eastern Mediterranean III: 297-328. Vienna: Verlag der Österreichischen Akademie der Wissenschaften.

\section{PEYRONEL L.}

2014 Living Near the Lake. The Matkh Region (Syria) during the Early and Middle Bronze Ages. In: BAFFi F., Fiorentino R. and PEYRONEL L. (eds.): 117-161.

PÉZARD M. (éd.)

1931 Qadesh. Mission archéologique à Tell Nebi Mend 1921-1922. Paris: Geuthner (BAH 15).

\section{PFÄLZNER P}

2014 Royal Funerary Practices and Inter-Regional Contacts in the Middle Bronze Age Levant: New Evidence from Qața. In: PFÄlZnER P., NIEHR H., PERNiCKA E., LANGE S. and KÖSTER T. (eds.), Contextualising Grave Inventories in the Ancient Near East. Proceedings of a Workshop at the London 7th ICAANE in April 2010 and an International Symposium in Tübingen in November 2010, both Organised by the Tübingen
Post-Graduate School "Symbols of the Dead": 141-156. Wiesbaden: Harrassowitz Verlag (Qatna Studien Supplementa 3).

PHILIP G. and BRADBURY J.

2010 Pre-Classical Activity in the Basalt Landscape of the Homs Region, Syria: Implications for the Development of "SubOptimal" Zones in the Levant During the Chalcolithic-Early Bronze Age. Levant 42: 136-169.

REY S.

2012 Poliorcétique au Proche-Orient à l'âge du Bronze: fortifications urbaines, procédés de siège et systèmes défensifs. Beyrouth: IFPO (BAH 197).

RICHTER T. und LANGE S.

2012 Das Archiv des Idadda: die Keilschrifttexte aus den deutschsyrischen Ausgrabungen 2001-2003 im Königspalast von Qatna. Wiesbaden: Harrassowitz Verlag (Qatna Studien 3).

Rigot J.-B.

2003 Environnement et occupation du sol dans la région du lac Jabboul (Syrie) à l'Holocène. Thèse de doctorat non publiée. Université Lumière - Lyon 2.

ROUSSET M.-O.

$2011 \quad$ Le peuplement de la steppe de Syrie du Nord entre le II $^{\mathrm{e}}$ s. av. et le IV s. apr. J.-C. Syria 88: 123-139.

2013a De Chalcis à Qinnasrin. In: CHARPENTIER G. et PUECH V. (éd.), Villes et campagnes aux rives de la Méditerranée ancienne. Hommages à Georges Tate: 311-340. Lyon: Maison de l'Orient et de la Méditerranée (Topoi Suppl. 12).

2013b Traces of the Banu Salih in the Syrian steppe? The Fortresses of Qinnasrin and Abu al-Khanadiq. Levant 45: 69-95.

ROUSSET M.-O. et CALVET Y.

2016 Céramiques du château de Salamya: de l'installation de l'âge du Bronze à la citadelle mamelouke de Šumaymīs. In: Rousset M.-O., Geyer B., GATIER P.-L. et AWAD N. (éd.) : 89-103.

Rousset M.-O. et DuvetTe C.

2015 Un village médiéval dans une forteresse de l'âge du Bronze: Qal' at al-Rahiyya.In: GEYER B., MATOÏAN V. et AL-MAQDISSI M. (éd.), De l'île d'Aphrodite au Paradis perdu, itinéraire d'un gentilhomme lyonnais. En hommage à Yves Calvet: 245-274. Louvain: Peeters (Ras Shamra-Ougarit XXII).

Rousset M.-O., GEYER B., AWAD N. et CALVET Y.

Sous presse Un «limes» de l'âge du Bronze moyen dans les Marges arides de Syrie du Nord. Annales Archéologiques Arabes Syriennes.

Rousset M.-O., Geyer B., GATIER P.-L. et AWAD N. (éd.)

2016 Habitat et environnement. Prospections dans les Marges arides de la Syrie du Nord. Lyon: Maison de l'Orient (TMO 71, série «Conquête de la steppe»4).

SACHAU E.

1883 Reise in Syrien und Mesopotamien. Leipzig: Brockhaus.

SCHWARTZ G.

2000 Excavation and Survey in the Jabbul Plain, Western Syria: The Umm el-Marra Project 1996-1997. American Journal of Archaeology 104: 419-462.

SULEIMAN A.

1984 Excavation at Ansari-Aleppo for the Seasons 1973-1980: Early and Middle Bronze Ages. Akkadica 40: 1-24. 
TALLON M.

1956 Une nouvelle enceinte antique en Emésène. Annales Archéologiques Arabes Syriennes 6: 51-62.

1957 Le camp retranché de As-Sour. Mélanges de l'Université SaintJoseph 34: 241-245.

TENU A.

2008 Les forteresses assyriennes de la vallée du moyen Euphrate. In: ABRAHAMi P. et BATTINi L. (éd.), Les armées du Proche-Orient ancien (III ${ }^{e} \mathrm{I}^{\text {er }}$ mill. av. J.-C.), Actes du colloque international organisé à Lyon les $1^{\text {er }}$ et 2 décembre 2006: 151-176. Lyon: Maison de l'Orient et de la Méditerranée; Oxford (BAR Int. Ser. 1855).

TRABOULSI-MAKKÉ M.

2004 Les précipitations au Proche-Orient: variabilité spatio-temporelle et relations avec la dynamique de l'atmosphère (1960-
61/1989-90). Thèse de doctorat non publiée. Dijon (Diffusion ANRT).

\section{VALSECCHI V.}

2007 Vegetation and Environmental Changes during the Middle-Late Holocene at Mishrifeh/Qatna: Climate Versus Land-Use. In: MORANDI BONACOSSI D. (ed.), Urban and Natural Landscapes of an Ancient Syrian Capital. Settlement and Environment at Tell Mishrifeh/Qatna and in Central-Western Syria, Proceedings of the International Conference held in Udine, 9-11 December 2004: 105-114. Udine: Forum Editrice (Studi Archeologici su Qatna 1).

WILKINSON T.J.

2003 Archaeological landscapes of the Near East. Tucson: University of Arizona Press. 